\title{
Feuerprobe, Portraits in Stein. Mittelalterliche Propaganda für Venedigs Reliquien aus Konstantinopel und die Frage nach ihrem Erfolg*
}

\section{Karin Krause}

Bis heute ist der Tesoro von San Marco reich an prachtvollen Artefakten aus Byzanz und stellt damit weltweit eine der größten sowie qualitativ bedeutendsten Sammlungen byzantinischer Kunst dar. ${ }^{1}$ In Ermangelung plausibler Alternativen sieht die Forschung es als wahrscheinlich an, dass die Mehrzahl dieser Artefakte - liturgische Gefäße, Ikonen und dergleichen - als Beutestücke der Venezianer aus der Zeit der Lateinerherrschaft in Konstantinopel (1204-1261) in die Dogenkirche gelangt sind. ${ }^{2}$ Gemessen an der großen Menge von Kunsterzeugnissen aus Byzanz in San Marco nimmt sich die Zahl der Reliquien gleicher Herkunft bescheiden aus: Nur für eine kleine Handvoll von nicht mehr als fünf Reliquien deklarieren die mittelalterlichen Quellen ausdrücklich eine Herkunft aus Konstantinopel als Teil der venezianischen Beute aus dem Jahre 1204. Diese Reliquien aus Byzanz und die frühe Geschichte ihrer Verehrung im venezianischen Spätmittelalter stehen im Mittelpunkt des folgenden Beitrags. ${ }^{3}$

Es mutet angesichts der Fülle an Fachliteratur zu San Marco einerseits und der vergleichsweise günstigen mittelalterlichen Quellenlage andererseits beinahe merkwürdig an, dass das Heiltum aus Konstantinopel bislang nur selten im Mittelpunkt von For-

* Die folgende Studie ging aus den laufenden Forschungen für meine Habilitationsschrift hervor, in der viele Aspekte, die im Rahmen eines Aufsatzes lediglich skizziert werden können, ausführlicher behandelt werden. Ich danke den Veranstaltern des Workshops ,Aspekte interkulturellen Zusammenlebens im Mittelmeerraum des Spätmittelalters' sehr herzlich für die Gelegenheit, meine Forschungen dort sowie im vorliegenden Beitrag zur Diskussion stellen zu dürfen.

1 Das wichtigste Referenzwerk ist nach wie vor die monumentale Publikation von Hans R. Hahnloser (Hrsg.), Il tesoro di San Marco. Bd. 2: Il tesoro e il museo. Florenz 1971 (nachfolgend zitiert als Il tesoro di San Marco). Damit keinesfalls entbehrlich geworden ist der älteste umfassende Katalog von Antonio Pasini, Il tesoro di San Marco. Venedig 1886. Zur Geschichte des Schatzes grundlegend Rodolfo Gallo, Il tesoro di S. Marco e la sua storia. Venedig/Rom 1967.

2 Vgl. z. B. Pasini, Il tesoro (wie Anm. 1), 9; Émile Molinier, Le trésor de la Basilique de Saint Marc à Venise. Venedig 1888, 10, 21, 25, 26, etc.; Il tesoro di San Marco (wie Anm. 1), XIII, 3, 15, etc.

3 Auf die Problematik, dass die Dogenkirche nach dem Zeugnis der frühesten Inventare in den Jahrzehnten um 1300 faktisch über mehr Reliquien und Reliquiare byzantinischen Ursprungs verfügte, sei an dieser Stelle lediglich hingewiesen. 
schungen gestanden hat. Als die wichtigsten Studien sind zwei ältere Aufsätze von Anatole Frolow (1964/65) und Debra Pincus (1984) zu nennen. ${ }^{4}$ Frolow behandelte eine Vielzahl von im Laufe der Jahrhunderte im Schatz von San Marco nachweisbaren Reliquien und Reliquiaren aus Byzanz und thematisierte überhaupt erstmals grundsätzliche Probleme, die deren Provenienz, Datierung und Rezeption betreffen. ${ }^{5}$ Wie auch der vorliegende Beitrag widmete sich Pincus' Studie konkret denjenigen Reliquien, von denen man bereits im mittelalterlichen Venedig behauptete, sie seien unmittelbar nach der Eroberung Konstantinopels durch die Kreuzfahrer vom Dogen Enrico Dandolo in die Lagunenstadt gesandt worden. Dabei fragte Pincus speziell nach der Signifikanz dieser Reliquien für die politische Propaganda der Dogen nach dem Verlust der venezianischen Vormachtstellung im östlichen Mittelmeerraum 1261. ${ }^{6}$ Während Pincus sich folglich vor allem dafür interessierte, inwieweit man im mittelalterlichen Venedig mit dem Heiltum Propaganda betrieb, schlägt der vorliegende Beitrag eine andere Richtung ein: Gefragt wird vor allem nach der Propaganda für diese Reliquien. Man sollte nämlich nicht aus dem Blick verlieren, dass es sich bei ihnen - im Vergleich zu den im 13. Jahrhundert schon längst etablierten und weit über Venedig hinaus bekannten Markusreliquien in der Dogenkirche - um Neuankömmlinge handelte. Es wird daher zu rekonstruieren sein, mit welchen Mitteln man sich im spätmittelalterlichen Venedig von offizieller Seite um die Kulte des neu erworbenen Heiltums bemüht zeigte. Dabei ist gleichfalls zu fragen, wie effizient diese Bemühungen waren, was sich folglich auf der Basis der zeitgenössischen Quellen über Wahrnehmung, Akzeptanz und Stellenwert dieser neuen Reliquien und ihrer Kulte sagen lässt. Den zeitlichen Rahmen der Untersuchung bildet das 13. bis 14. Jahrhundert, wobei auch gelegentliche Ausblicke in die frühe Neuzeit sinnvoll sind. Es werden sowohl die der Forschung schon länger bekann-

4 Anatole Frolow, Notes sur les reliques et les reliquaires byzantins de Saint-Marc de Venise, in: Deltion tes christianikes archaiologikes hetaireias, ser. 4, 4, 1964/65, 205-226; Debra Pincus, Christian Relics and the Body Politic. A Thirteenth-century Relief Plaque in the Church of San Marco, in: David Rosand (Hrsg.), Interpretazioni veneziane. Studi di Storia dell'Arte in onore di Michelangelo Muraro. Venedig 1984, 39-57. An neueren Studien, die zumindest einige dieser Reliquien behandeln, seien erwähnt: Michele Donega, I reliquiari del sangue di Cristo del tesoro di San Marco, in: Arte documento 11, 1997, 64-71, mit gewissen Ungenauigkeiten bzw. Verwechslungen; Renato Polacco, I reliquiari del sangue di Cristo nel tesoro di San Marco, in: Tiziana Franco/Giovanna Valenzano (Hrsg.), De lapidibus Sententiae. Scritti di Storia dell'Arte per Giovanni Lorenzoni. Padua 2002, 307-319. Jüngst waren die venezianischen Reliquien aus der Beute von 1204 Teil einer Studie von Holger A. Klein (Die Heiltümer von Venedig - Die ,byzantinischen' Reliquien der Stadt, in: Gherardo Ortalli, Giorgio Ravegnani, Peter Schreiner (Hrsg.), Quarta Crociata, Venezia - Bisanzio - Impero Latino. Venedig 2006, II 798-802). Dieser Beitrag bewegt sich jedoch hinter den Forschungsstand zurück, denn dem Verfasser war offenbar weder der Brief des Dogen Ranieri Zen aus dem Jahre 1265 als die früheste und wichtigste Quelle, noch der maßgebliche Aufsatz von Debra Pincus bekannt. Zudem wird das Reliquienrelief von San Marco falsch verortet („noch heute über dem Eingang zur Schatzkammer“, ebd., 799).

5 Frolow, Notes (wie Anm. 4), passim.

6 Pincus, Christian Relics (wie Anm. 4), passim, bes. 39, 44, 46 u. 48. 
ten Dokumente erneut gelesen und befragt als auch bislang unberücksichtigt gebliebene Quellen ausgewertet. Die wichtigste Ausgangsbasis für jegliche Beschäftigung mit Reliquienkulten sollte freilich das Heiltum selbst sein. Daher gilt es nachzuvollziehen, um welche Reliquien es sich eigentlich genau bei denjenigen handelte, deren Provenienz aus Konstantinopel man im spätmittelalterlichen Venedig proklamierte, und in welcher Gestalt sie sich zu jener Zeit präsentierten.

\section{Reliquienwerbung im Jahre 1265: Feuerprobe}

Am 30. Mai des Jahres 1265 schrieb der venezianische Doge Ranieri Zen an seine Botschafter in Rom mit dem Anliegen, Papst Clemens IV. über ein Reliquienwunder in Kenntnis setzen zu lassen. Dieses soll sich fünfunddreißig Jahre zuvor, am Tag nach Epiphanias des Jahres 1230 (nach heute gültigem Kalender 12317), in der Schatzkammer von San Marco ereignet haben. ${ }^{8}$ Das Wunder, von dem Ranieri dem Papst ausführlich berichtet, lässt sich knapp zusammenfassen: Bei dem verheerenden Brand sei der gesamte Schatz von San Marco praktisch restlos vernichtet worden - mit Ausnahme dreier Reliquien, die wunderbarer Weise von den Flammen verschont geblieben seien: eine Kreuzreliquie, eine Ampulle mit dem Heiligen Blut Christi und der Schädel Johannes des Täufers. Wie weiter unten ausgeführt wird, zeigen sich die Schilderungen des Dogen vom mittelalterlichen Brauch der Feuerprobe an Reliquien inspiriert und vor allem von verbreiteten Berichten über solche, die eine ,Feuerprobe“ in Gestalt eines Brandes überstanden hatten.

Es war dem Dogen ein Anliegen, dem Papst gegenüber sowohl die zeit- als auch die heilsgeschichtliche Relevanz der drei wunderbaren Reliquien zu betonen: Nachdem sie zuerst von Helena aus Jerusalem nach Konstantinopel gesandt worden seien, habe später, unmittelbar nach der lateinischen Eroberung (1203/04), Christus selbst ihren Transfer von Konstantinopel nach Venedig veranlasst, und zwar, weil er sie dort mit den Reliquien seines Evangelisten Markus habe vereinen wollen. ${ }^{9}$

Die bislang ausführlichste Beschäftigung mit dem Dokument stellt die bereits erwähnte Studie von Debra Pincus dar, in der das Schreiben Ranieris im Licht machtpolitischer Propaganda interpretiert wird. Venedig habe sich, so die ansprechende Theorie von Pincus, vermittels der Reliquien aus Byzanz der Außenwelt als legitime Nachfolgerin Konstantinopels und damit als von Gott erwählte Erbin der von Konstantin be-

7 Es handelt sich um die Jahresangabe 1230 ,more veneto ‘ mit dem 1. März als Jahresbeginn.

8 Der Brief wurde kritisch ediert in Andreae Danduli ducis Venetiarum Chronica per extensum descripta aa. 46-1280 d. C. Ed. Ester Pastorello. Bologna 1938-1958, Documenti, 393f. Alle folgenden Zitate aus dem Brief sind dieser Edition entnommen. Verschiedene spätere Editionen sind aufgeführt bei Polacco, I reliquiari (wie Anm. 4), Anm. 32.

9 (...) dictae sanctae reliquiae de Jerusalem, per operam Sanctae Helenae, in Constantinopolim fuerant deportatae; et qualiter Dominus noster Jesus Christus ipsas jn civitate Venetiae, cum corpore beati Marci, Euangelistae sui uoluit collocari (...); Andreae Danduli Chronica (wie Anm. 8), 393, 30-33. 
gründeten christlichen Herrschaft präsentieren wollen. ${ }^{10}$ Die vom Dogen skizzierte Geschichte des Reliquientranfers lässt eine solche Deutung durchaus plausibel erscheinen, jedoch muss man sich die Frage stellen, weshalb Ranieri erst 1265, immerhin rund vier Jahre nach dem Verlust von Venedigs lukrativer Stellung in Konstantinopel, eine solche Aussage trifft, und weshalb gerade beim Papst. ${ }^{11}$ Bevor man mögliche implizite Botschaften des Schreibens diskutiert, sollte das Dokument insgesamt in seinem Wortlaut genauer analysiert werden, um anderen, ausdrücklich formulierten Zielen des Dogen auf die Spur zu kommen. Dies wird nachfolgend versucht.

Der Wert des Textes aus dem Jahre 1265 ist kaum zu unterschätzen, handelt es sich doch bei ihm um den frühesten, der sich auf Reliquien aus Konstantinopel bezieht, noch dazu vergleichsweise ausführlich. So enthält das Schreiben wichtige Informationen zum Aussehen und zur zeitgenössischen Präsentation des Heiltums. Diese Angaben werden durch zwei weitere Quellen ergänzt, welche von der Forschung unerklärlicherweise weitgehend ignoriert worden sind, nämlich die beiden ersten Schatzinventare von San Marco, verfasst in den Jahren 1283 und 1325.12

Doch welche drei Reliquien hatte Ranieri eigentlich bei seinem Wunderbericht konkret im Sinn? Gleich zu Beginn des Briefes werden „,die heiligen Reliquien, nämlich das Holz des heiligen Kreuzes, eine Ampulle mit dem wahren Blut Christi und der Schädel des seligen Johannes Baptist" 13 aufgezählt. Weiter unten im Text, nach dem ausführlichen Bericht über die verheerenden Auswirkungen des Feuers und die unerwartete Wiederentdeckung der Reliquien, finden sich dann recht genaue Angaben zu deren physischer Gestalt. Zuerst heißt es zu der Kreuzreliquie und dem Heiligen Blut:

„(...) sie fanden das hochheilige Kreuz vom Holz des Herrn mit geringem Schmuck, gänzlich vom Feuer verschont und, [mit der Suche] fortfahrend, die kristallene Ampulle, in der [ein Teil] vom wahren Blut des Herrn war, mit einem am Hals befestigten Kärtchen, auf dem geschrieben stand ,Blut des Herrn`(... ${ }^{‘ c} .{ }^{14}$

10 Pincus, Christian Relics (wie Anm. 4), bes. 46. Vgl. auch Thomas E. A. Dale, Inventing a Sacred Past: Pictorial Narratives of St. Mark the Evangelist in Aquileia and Venice, ca. 1000-1300, in: DOP 48, 1994, bes. 87; Maria Georgopoulou, Late Medieval Crete and Venice: an Appropriation of Byzantine Heritage, in: The Art Bulletin 77, 1995, bes. 479.

11 Eine Interpretation des Schreibens vor der Folie der politisch-wirtschaftlichen Situation nach 1261, wie Pincus sie vorgenommen hat, ist durchaus angebracht. Jedoch sollte man dabei die konkrete Lage Venedigs zur Zeit der Korrespondenz im Auge haben. Dies kann aus Gründen des Umfangs hier nicht weiterverfolgt werden.

12 Alle erhaltenen Schatzinventare, beginnend mit dem frühesten des Jahres 1283, hat Rodolfo Gallo gesammelt und ediert; Gallo, Il tesoro (wie Anm. 1), 273-402. Die folgenden Zitate aus den Inventaren folgen dieser Edition.

13 (...) sacrae reliquiae, videlicet Lignum Sanctae Crucis, ampulla de uero Sanguine Christi et vertex beati Joannis Baptistae; Andreae Danduli, Chronica (wie Anm. 8), Documenti, 393, $28 \mathrm{f}$.

14 (...) jnuenerunt Crucem sanctissimam de Ligno Domini cum paruo ornamento jllesam penitus ab igne: et procedentes, ampullam crystallinam, ubi erat de uero Sanguine Domini, cum cartulina ligata in collo ubi scriptum erat „,Sanguis Christi“ (...); ebd., 394, 16-19. 
Zur dritten Reliquie, dem Täuferschädel, führt der Text besonders detailliert aus:

„(...) in der Asche fanden sie darüber hinaus eine hölzerne Kiste, in der [ein Stück] vom Schädel des heiligen Johannes Baptist war. Diese Kiste war beinahe ganz verbrannt, nur dort nicht, wo der Schädel sie berührte. Ein griechisches Seidentuch, mit dem sie oben bedeckt war, kam [noch] vollständig zum Vorschein. " 15

Der Bericht betont unmissverständlich, dass ansonsten alles komplett ,in Asche verwandelt" 16 worden sei. Im Kontrast dazu erscheint der Grad der Erhaltung des Heiltums bemerkenswert, wobei die detaillierten Ausführungen des Dogen freilich dazu dienen sollten, das Wunder gegenüber dem Papst noch zu unterstreichen. Für die kunsthistorische Forschung bergen die Beschreibungen wertvolle Informationen zum Aussehen und damit für eine Identifikation der gemeinten Reliquien:

Bei dem Reliquiar mit dem Heiligen Blut Christi, das nach dem Bericht des Ranieri Zen das Feuer von 1230 ohne Schaden überstanden hatte, handelte es sich um eine kleine Flasche aus Bergkristall (ampullam crystallinam). Sogar ein an ihrem Hals befestigtes Stückchen Papier bzw. Pergament (cartulina ligata in collo) mit der Aufschrift Sanguis Christi soll den Brand heil überdauert haben. Dieses Detail ist ein Zeugnis dafür, dass im Mittelalter auch so genannte Authentiken von Reliquien, Kärtchen, auf denen ihr Name bzw. ihre Art schriftlich beglaubigt war, selbst als

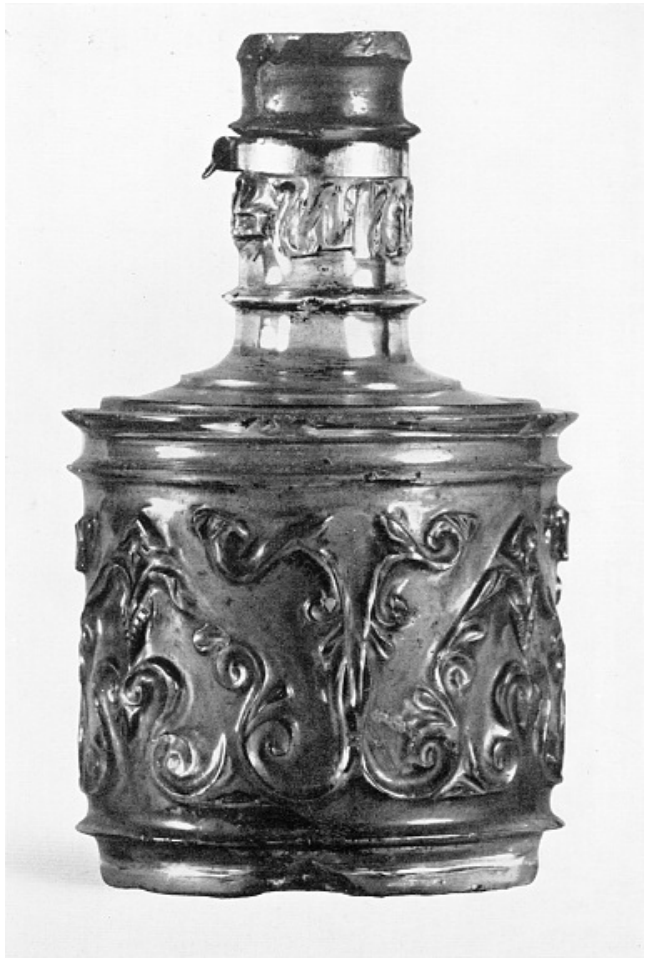

Abb. 1: Ampulle aus Bergkristall im Schatz von S. Marco, Venedig (Fondazione Giorgio Cini, Venedig) Reliquien aufgefasst wurden. ${ }^{17}$ Die Hinweise auf die Form des Behälters, eine kleine Flasche mit Hals, sind von zentraler Be-

15 (...) jnter ipsos carbones jnuenerunt jnsuper capsam ligneam, jn qua erat de uertice beati Joannis Baptistae, quae capsa combusta erat quasi per totum, excepto in tantum quantum uertex ille tangebatur, cendato graeco, cum quo cohoperta erat desuper, jntegro existente; ebd., 394, 20-23.

16 (...) quanquam plures aliae ampullae et alia plura crystallina jbidem jnvenissent jn cineres fore conuersas; ebd. 394, $19 \mathrm{f}$.

$17 \mathrm{Zu}$ Authentiken vgl. z. B. Anton Legner, Reliquien in Kunst und Kult. Zwischen Antike und Aufklärung. Darmstadt 1995, 53. 
deutung, um die von Ranieri Zen gemeinte Ampulle von einem anderen Behälter aus Bergkristall in San Marco (Santuario 68) zu unterscheiden, der von zylindrischer Form ist und gemäß seiner griechischen Aufschrift ebenfalls Blut Christi enthält. ${ }^{18}$ Wegen der detaillierten Hinweise des Dogen auf das Aussehen des von ihm gemeinten Artefakts

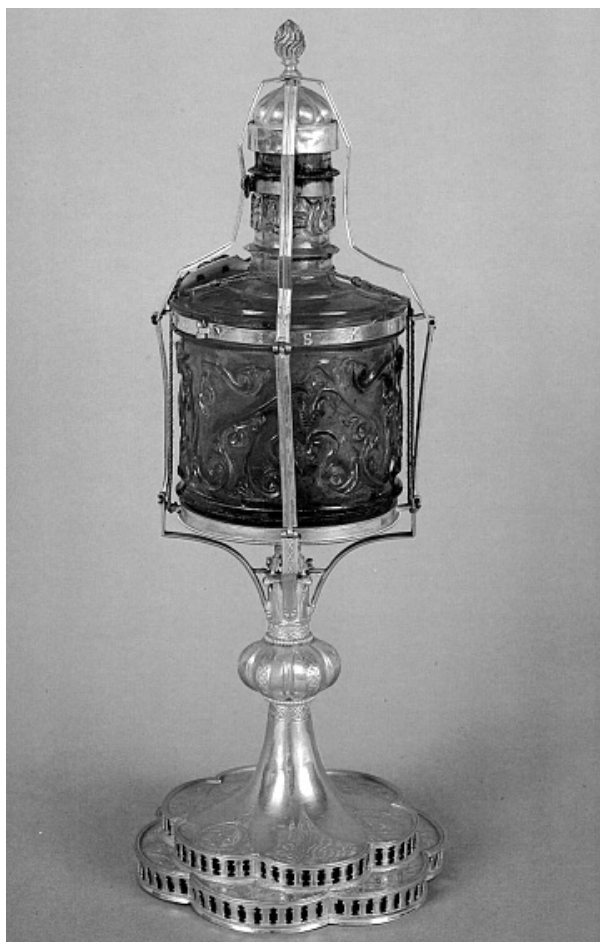

Abb. 2: Ostensorium des heiligen Blutes Christi im Schatz von S. Marco, Venedig (Gauthier, Strassen [wie Anm. 38], 117)

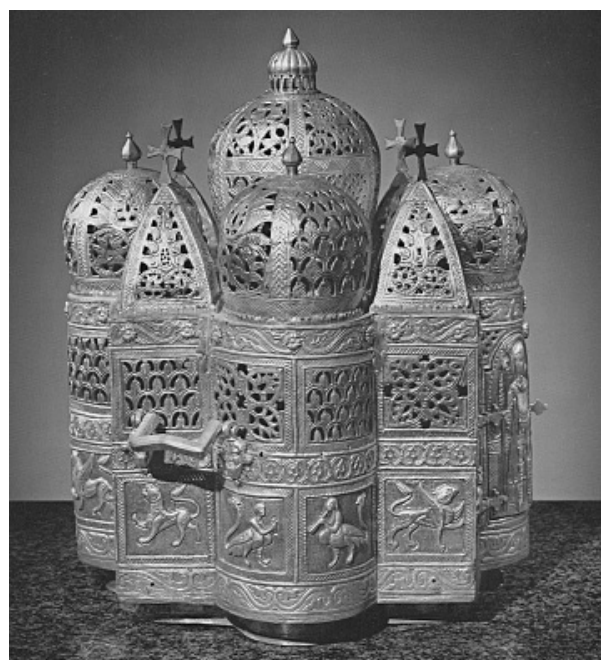

Abb. 3: Sog. ecclesialecclesiola im Schatz von S. Marco, Venedig (Hellenkemper (Hrsg.), Schatz von San Marco [wie Anm. 23], 246)

steht jedoch außer Frage, dass er an die im Tesoro noch vorhandene Bergkristallampulle mit der Inventarnummer Santuario 63 dachte (Abb. 1). ${ }^{19}$

Beide frühen Inventare verzeichnen die von Ranieri Zen beschriebene Ampulle, und zwar an erster Stelle. Dies ist bemerkenswert, hatte der Doge die Reliquien im Wunderbericht, sogar zweimal, in der Reihenfolge Kreuzreliquie - Heiliges Blut - Täuferschädel aufgeführt. ${ }^{20}$ Zwischen 1265 und 1283 hatte sich in Venedig folglich ein Wandel in der Rangfolge von Heiligem Blut und Reliquienkreuz vollzogen. Im gleichen

18 Il tesoro di San Marco (wie Anm. 1), Nr. 172.

19 Ebd., Nr. 128.

20 Andreae Danduli Chronica (wie Anm. 8), Documenti, 393, 28f. u. 394, 16-22. 
Zeitraum geschah, wie der Eintrag im ersten Schatzinventar nahe legt, eine materielle und ästhetische Aufwertung der Blutreliquie, die beschrieben wird als „eine Ampulle aus Kristall, in der das Blut unseres Erlösers Jesus Christus ist, verziert mit Gold und zuoberst mit einer Perle; und sie ist in jener Kirche aus Silber". ${ }^{21}$ Im zweiten Inventar (1325) heißt es entsprechend, wenngleich mit größerer Detailgenauigkeit: „Eine Ampulle aus Kristall, mit goldenem Standfuß, rundum verziert mit Gold und mit einer Perle als Bekrönung, in der [etwas] vom Blut unseres Erlösers ist; und sie ist in jenem Kirchlein aus Silber, gefertigt mit Gitterwerk [?]".22 Die Ampulle aus Bergkristall besaß also spätestens 1283 ihre heutige Fassung, bestehend aus einem goldenen Fuß, weiterem goldenem, um das Gefäß herum geführtem Dekor und einer bekrönenden Perle (Abb. 2, Tafel II 2). Mit dieser Goldfassung war die Ampulle, den beiden Inventaren zufolge, schon in den Jahrzehnten um 1300 in dem einer Kuppel-Kirche nachempfundenen, rund $36 \mathrm{~cm}$ hohen Artefakt (ecclesia; ecclesiola) untergebracht, welches ebenfalls heute noch in der Schatzkammer zu sehen ist (Tesoro 142) (Abb. 3). ${ }^{23}$ Die zentrale Kuppel der ecclesiola ist abnehmbar, so dass die Ampulle samt Fassung leicht von oben hineingestellt und zur Verehrung herausgenommen werden konnte. ${ }^{24}$

Doch zurück zum Heilig-Blut-Reliquiar selbst: Der eigentliche Behälter, die nur zehn Zentimeter hohe Flasche aus Bergkristall, ist fatimidischer, wohl ägyptischer Herkunft und wird in die Zeit um 1000 datiert. ${ }^{25}$ Die kleine Flasche hat auf ihrem zylindrischen Corpus einen geschnittenen Dekor aus stilisierten Ranken. ${ }^{26}$ Mittig auf der flach ansteigenden, leicht profilierten Schulter sitzt mit deutlich kleinerem Durchmesser der Hals auf, der mit einer Segensformel in arabischer Schrift versehen ist. ${ }^{27}$ Gefäße aus Bergkristall, islamischen oder anderen Ursprungs, fanden im mittelalterlichen Eu-

21 (...) ampulla una de christallo in qua est sanguis Salvatoris Nostri Jesu Christi, ornata auro et una perla desuper, et est in quadam ecclesia argenti; Gallo, Il tesoro (wie Anm. 1), 273.

22 Ampulam unam de cristallo, cum pede auri, ornatam circumcirca aurum et cum una perla in capite, in qua est de sanguine Salvatoris nostri; et est in quadam Ecclesiola argenti facta cum clatis [clatris?]; ebd., 276 (Ergänzungen in eckigen Klammern: K. K.).

23 Il tesoro di San Marco (wie Anm. 1), Nr. 109, 86-88; Hansgerd Hellenkemper (Hrsg.), Der Schatz von San Marco in Venedig. Köln 1984, Nr. 32.

24 Pasini, Il tesoro (wie Anm. 1), 26.

25 Il tesoro di San Marco (wie Anm. 1), 116 u. 117; Avinoam Shalem, Islam Christianized. Islamic Portable Objects in the Medieval Church Treasuries of the Latin West. Frankfurt a. M. u. a. 1996, Nr. 47. Grundlegend zu solchen Artefakten Kurt Erdmann, Islamische Bergkristallarbeiten, in: Jahrbuch der preussischen Kunstsammlungen 61, 1940, 125-146 und Kurt Erdmann, Neue islamische Bergkristalle, in: Ars Orientalis. The Arts of Islam and the East 3, 1959, 200-205, jeweils passim.

26 Vgl. auch die Zeichnung (Abwicklung) des Dekors in Il tesoro di San Marco (wie Anm. 1), 117.

27 Der genaue Wortlaut des Segens ist umstritten. Vgl. zu den Deutungen Pasini, Il tesoro (wie Anm. 1), 25; Il tesoro di San Marco (wie Anm. 1), 117; Shalem, Islam Christianized (wie Anm. 25), 206; vgl. auch Avinoam Shalem, The Oliphant. Islamic Objects in Historical Context. Leiden/Boston 2004, 226. 
ropa eine weite Verbreitung und unterschiedliche Verwendung. ${ }^{28}$ Seit dem frühen Mittelalter, häufiger dann ab der Zeit um 1200 ist ihre Nutzung als Reliquiare bezeugt. ${ }^{29}$ Zum einen lag dies sicher in der Kostbarkeit des Materials begründet, welches zudem oft mit kunstvollen Steinschnittarbeiten versehen wurde, zum anderen dürfte diese Art der Verwendung mit der Transparenz des Steins zu tun gehabt haben, durch den die Reliquien sichtbar blieben.

Sicher um das vergleichsweise kleine venezianische Gefäß mit dem Heiligen Blut optisch hervorzuheben, fertigte man einen Standfuß, der ungefähr die gleiche Höhe hat wie die Ampulle selbst. Dieser Sockel ist unten zweifach gestuft, wobei die Stufen wellenförmig gegeneinander versetzt sind und durchbrochene Kanten haben. Entlang der Kanten wurde jeweils Dekor aus vegetabilen und ornithomorphen Formen eingraviert. ${ }^{30}$ Die obere der beiden Stufen ist mittig bis zu einer perlenartigen, aus mehreren Segmenten bestehenden Verdickung emporgeführt. Auf ihr wiederum sitzt die eigentliche Tragekonstruktion der Flasche auf. Aus einer Art vegetabilem Kelch scheinen die vier schmalen Goldleisten zu sprießen, die vertikal am Behälter entlanggeführt wurden. In eleganter Weise formen diese Leisten in geringem Abstand von dem Gefäß jeweils dessen Kontur nach. Sie sind oberhalb des Halses über einer Kappe zusammengeführt und werden von einem gedrehten Zapfen bekrönt. Die Ampulle scheint in dieser filigranen Konstruktion zu schweben und wird lediglich von einem um ihren Fuß herumgeführten Band am Platz gehalten, das seinerseits durch Scharniere mit den vertikalen Leisten verbunden ist. Analog dazu verläuft oben, rund um den oberen Rand des Flaschen-Körpers, ein weiteres Band, diesmal mit einer in Majuskelbuchstaben eingravierten Authentik: HIC EST SANGUIS XPI [Christi]. ${ }^{31}$ Es ist bemerkenswert, mit welcher Zurückhaltung diese elegante Goldfassung entworfen wurde, die durch ihre filigrane Leichtigkeit besticht. Eindeutig beabsichtigte man, den Blick auf die Flasche und damit auf ihren wertvollen Inhalt so wenig wie möglich zu beeinträchtigen. Durch die Aufschrift der Goldfassung - „Dies ist das Blut Christi““ - wurde die erwähnte cartulina mit der Aufschrift „Blut Christi“ obsolet, die offenbar noch vorhanden war, als Ranieri Zen 1265 seinen Brief nach Rom schickte. Es ist angesichts der ansonsten vergleichsweise detaillierten Angaben zum Aussehen der drei Wunderreliquien bezeichnend, dass

$28 \mathrm{Zu}$ Imitiationen islamischer Gefäße und zu Problemen hinsichtlich ihrer Datierung und Lokalisierung vgl. im Überblick Rudolf Distelberger, Die Gefäße aus Bergkristall, in: Wilfried Seipel (Hrsg.), Nobiles Officinae. Die königlichen Hofwerkstätten zu Palermo zur Zeit der Normannen und Staufer im 12. und 13. Jahrhundert. Wien 2004, 109-113, mit Lit..

29 Joseph Braun, Die Reliquiare des christlichen Kults und ihre Entwicklung. Freiburg 1940, 100 109, mit Zitaten aus diversen Quellen (ebd., 101-104), die sich allerdings auf unterschiedlich geformte Behältnisse aus Bergkristall beziehen. Speziell zu fatimidischen Fläschchen ebd., 105f. $\mathrm{Zu}$ Bergkristallgefäßen in Verwendung als Reliquiare, besonders für das Heilige Blut, und den mittelalterlichen Assoziationen des Materials vgl. Shalem, Islam Christianized (wie Anm. 25), 147-151, bes. $149-151$.

30 Vgl. Il tesoro di San Marco (wie Anm. 1), Taf. CXXXVI, unten.

$31 \mathrm{Zu}$ der Inschrift ebd., 117. 
Ranieri das mit der Ampulle eine Einheit bildende goldene Ostensorium nicht erwähnt. Folglich ist wahrscheinlich, dass die bisher nicht genauer datierte goldene Fassung der Blut-Ampulle erst nach 1265 entstand und vor 1283, als sie in dem ersten Schatzinventar beschrieben wird. ${ }^{32}$

Die venezianische Blutampulle mit ihrer Goldfassung gehört im Typus zu den Ostensorien mit einem transparenten Behälter als Schaugefäß, die um 1200 oder im frühen 13. Jahrhundert aufkamen und bis weit in die Neuzeit hinein populär blieben. ${ }^{33}$ Der flaschenförmige und zudem mit Reliefdekor verzierte Reliquienbehälter lässt das venezianische Exemplar allerdings um ein Vielfaches extravaganter erscheinen als prinzipiell vergleichbare Ostensorien, auf deren Fuß in der Regel ein glatter Behälter von zylindrischer Form steht. ${ }^{34}$

Extravagant ist die durch beide frühen Inventare bezeugte Aufbewahrung des HeiligBlut-Ostensoriums in der ecclesiola, solange es nicht gerade in Verwendung war. Das kirchenförmige, aus silbernem, teils vergoldetem Gitterwerk gefertigte Behältnis wurde folglich im Venedig des 13. Jahrhunderts zum Reliquiar und behielt diese Funktion bis mindestens ins ausgehende 19. Jahrhundert hinein..$^{35}$ Ursprünglich handelte es sich bei dem Artefakt, das aufgrund seines Dekors wahrscheinlich profaner Bestimmung war, vielleicht um eine Lampe oder ein Räuchergefäß.36 Interessanterweise erwähnt das zweite Inventar im Eintrag Nr. 2 unmittelbar nach der goldgefassten Ampulle ein kleines silbernes Behältnis, in dem die Heilig-Blut-Ampulle zuvor (!) aufbewahrt worden sei (Item capsiculam unam parvam argenti, in qua consueverat stare dictus sanguis ${ }^{37}$ ).

Die frühesten Textquellen zum Heiligen Blut legen folglich nahe, dass man höchst wahrscheinlich erst nach 1265 und sicher vor 1283 mit der elaborierten Goldfassung samt Standfuß ein Ostensorium schuf, wodurch die kleine Bergkristall-Flasche und damit vor allem ihr Inhalt besser zur Geltung kamen. Mit der Goldfassung wurde der

32 Im entsprechenden Katalogeintrag ebd., Nr. 128, liest man widersprüchliche Datierungen der Goldfassung in die Mitte des 13. Jahrhunderts (ebd., 116) sowie ,poco prima di quell'anno [1283]“" (ebd., 118).

33 Braun, Reliquiare (wie Anm. 29), 302-306, zum Aufkommen ebd., 302f. Brauns Klassifizierung betrifft allerdings Denkmäler, die - bei generellen formalen Übereinstimmungen - gleichzeitig mehr oder weniger große individuelle Unterschiede aufweisen. Zu frühen Ostensorien in jüngerer Zeit bes. Christof L. Diedrichs, Vom Glauben zum Sehen. Die Sichtbarkeit der Reliquie im Reliquiar. Ein Beitrag zur Geschichte des Sehens. Berlin 2001, 119-125.

34 Beispiele bei Braun, Reliquiare (wie Anm. 29), Abb. 291-308, vgl. für das venezianische Exemplar ebd., bes. 294-296 u. 308.

35 „Il (...) reliquiario (...) dal principio del secolo decimoquarto, e forse alla fine dell'antecedente, è rinchiuso dentro una ricca e curiosa custodia in forma di chiesa"; Pasini, Il tesoro (wie Anm. 1), 25; vgl. auch Molinier, Le trésor (wie Anm. 2), 61.

36 Die aufklappbare Flügeltür wird von den griechisch beschrifteten Personifikationen des Mutes und der Vernunft geziert. Zu möglichen Funktionen der ecclesiola s. Il tesoro di San Marco (wie Anm. 1), bes. 87; Hellenkemper (Hrsg.), Schatz von San Marco (wie Anm. 23), Nr. 32, bes. 251.

37 Gallo, Il tesoro (wie Anm. 1), 276. Das erste Inventar verzeichnet dieses Behältnis nicht. 


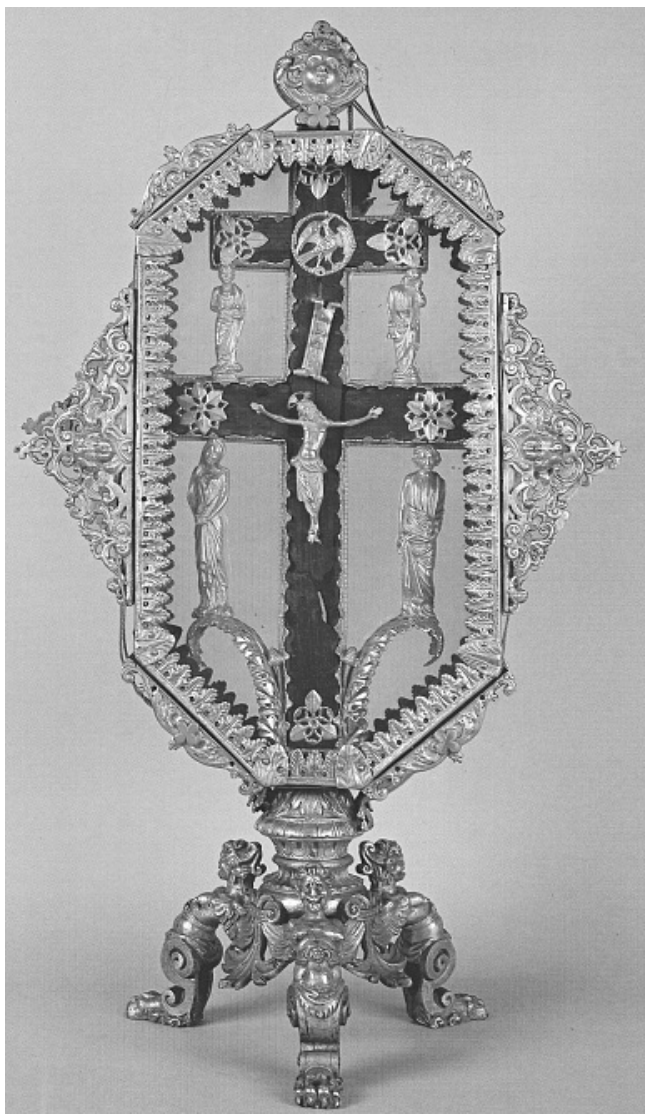

Abb. 4a: Reliquienkreuz Heinrichs von Flandern im Schatz von S. Marco, Venedig; Vorderseite (Gauthier, Strassen [wie Anm. 38], 77)
Silberbehälter überflüssig, der die Ampulle zuvor beherbergt hatte und der bis mindestens 1325 weiter aufbewahrt wurde. Gleichfalls zwischen 1265 und 1283 brachte man das neue Blut-Ostensorium in der ecclesiola unter. Die gestalterische und materielle Aufwertung der Heilig-Blut-Ampulle sowie die neue Art ihrer Aufbewahrung sind klare Indizien dafür, dass man sich in diesem Zeitraum von knapp zwanzig Jahren um eine Förderung des Heilig-Blut-Kultes in San Marco bemühte. Dass die Verehrung des Blutes im Verlauf von rund zwei Jahrzehnten an Bedeutung zunahm, signalisiert auch die Tatsache, dass die Blut-Ampulle in beiden Inventaren an erster Stelle erscheint, während Ranieri zuerst die Kreuzreliquie genannt hatte.

Letztere wird im Bericht des Ranieri Zen lediglich erwähnt, doch erfahren wir immerhin, dass sie die Form eines Kreuzes besa $\beta$ und „mit wenig Schmuck" (cum paruo ornamento) versehen war. Debra Pincus hielt dieses Kreuz für das noch heute im Schatz von San Marco vorhandene Reliquienkreuz Heinrichs von Flandern (Santuario 55), der zwischen 1206 und 1216 zweiter

Lateinerkaiser in Konstantinopel war und auf den sich eine lange Inschrift auf der Rückseite bezieht (Abb. 4 a-b) ${ }^{38}$ Es ist nicht bekannt, wann und unter welchen Umständen das Artefakt nach Venedig gelangte. Das 33,5 cm hohe hölzerne Kreuz mit doppeltem Querbalken erhielt seine Inschrift sowie seine goldenen Zierden, wie die

38 Vgl. für diese Identifikation bes. Pincus, Christian Relics (wie Anm. 4), 42, mit Anm. 25. Ausführlich zum Kreuz Heinrichs Il tesoro di San Marco (wie Anm. 1), Nr. 140; Hellenkemper (Hrsg.), Schatz von San Marco (wie Anm. 23), Nr. 33; Marie-Madeleine Gauthier, Strassen des Glaubens. Reliquien und Reliquiare des Abendlandes. Fribourg 1983, Nr. 40, 76; zuvor auch Pasini, Il tesoro (wie Anm. 1), $29 f$. 
Forschung vermutet, zur Regierungszeit Heinrichs, folglich noch in Konstantinopel..$^{39}$ Die Inschrift, gemäß derer das Reliquienkreuz dazu gedacht war, Heinrich auf seinen Feldzügen zu begleiten ${ }^{40}$ rahmt die Rückseite des Kreuzes, dessen Schmalseiten von einem Fries aus goldenen, stilisierten Blättern eingefasst sind. Den auffälligsten Dekor stellen die vier goldenen Figuren an den Seiten dar: Unten stehen, jeweils auf einer Ranke, die Figuren Mariens und des Johannesjüngers, darüber, zwischen den beiden Querbalken, wurden die etwas kleineren Personifikationen der Ecclesia und der Synagoge platziert. Das Kreuz besitzt zudem vorne und hinten verschiedene goldene Applikationen, die jedoch nur teilweise mittelalterlichen Ursprungs sind. ${ }^{41}$

Schon der Aufwand und der materielle Wert all dieser Zierden lassen sich schwer-

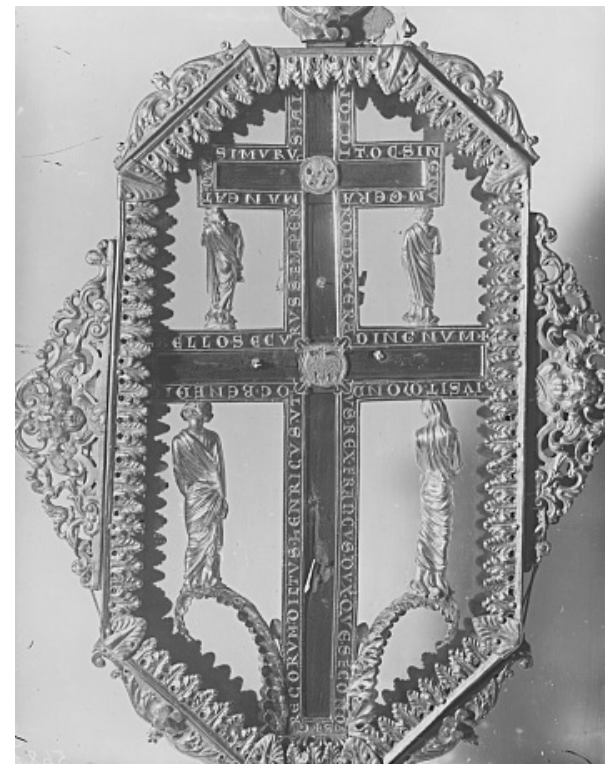

Abb. 4b: Reliquienkreuz Heinrichs von Flandern im Schatz von S. Marco, Venedig; Rückseite (Osvaldo Böhm, Venedig) lich mit Ranieris Erwähnung von ,wenig Schmuck“ an dem Reliquienkreuz aus dem Schatzbrandwunder vereinbaren. In der Tat wurde das Kreuz des Lateinerherrschers, entgegen Pincus' Meinung, im Mittelalter mit Sicherheit nicht mit demjenigen aus dem Schatzbrand identifiziert. Dies ist anhand der beiden frühen Inventare zweifelsfrei belegbar: Das Kreuz Heinrichs mit seinen vier flankierenden Figuren ist dasjenige, das erstmals im Inventar von 1325, an dritter Stelle, aufgeführt ist als Kreuz „mit Gold und Silber verziert“ und mit „,vier Bildnissen [Figuren] zu seinen Seiten“42 Das Kreuz aus dem Schatzbrandwunder ist hingegen in beiden Inventaren, auch schon in dem von 1283, unter Nr. 2 aufgeführt als

39 Die genauen Maße des Kreuzes sind: 33,5 cm Höhe, $24 \mathrm{~cm}$ Breite; Il tesoro di San Marco (wie Anm. 1), 139. Heute befindet sich das Kreuz in einem Ostensorium des frühen 17. Jahrhunderts. Dass Inschrift und übriger Dekor des Kreuzes, besonders die flankierenden Figuren, gleichzeitig entstanden sind, erscheint zwar möglich, allerdings nicht zwingend.

40 Transkription und italienische Übersetzung der Inschrift in Il tesoro di San Marco (wie Anm. 1), 139.

41 Detailliert zum Goldschmuck des Kreuzes ebd., Nr. 140; Hellenkemper (Hrsg.), Schatz von San Marco (wie Anm. 23), Nr. 33, bes. 252.

42 Item Crucem unam Christi, de ligno Domini, auro et argento ornatam, quae crux habet quatuor imagines ad ipsius latera positas (...); Gallo, Il tesoro (wie Anm. 1), 276. Unzutreffend ist die Angabe von Danielle Gaborit-Chopin, das Kreuz sei erstmals in einem Inventar aus dem Jahre 1402 verzeichnet; Hellenkemper (Hrsg.), Schatz von San Marco (wie Anm. 23 ), 252. 
„Kreuz Christi, das im Feuer war [sic!], in einem Reliquiar [ycona] mit Deckel, bedeckt mit vergoldetem Silber, auf dem sich die Bildnisse des hl. Konstantin und der heiligen Helena befinden". 43

Der Wortlaut im zweiten Inventar, wo das Reliquiar allerdings erst an fünfter Stelle erscheint, ist beinahe wortgleich, wobei hier jedoch kein Deckel erwähnt ist. ${ }^{44}$

Während beide Dokumente keinerlei Verzierungen am Kreuz, „das im Feuer war", erwähnen, gehen sie immerhin auf das Behältnis ein, in dem das Kreuz lag: Es handelte sich um eine Staurothek, die mit den Figuren Konstantins und Helenas dekoriert und, zumindest ursprünglich, mit einem Deckel verschließbar war. Dieses heute verlorene Reliquiar war, wie ich andernorts demonstriert habe, im 11. oder 12. Jahrhundert in Konstantinopel im Auftrag einer Kaiserin namens Maria angefertigt worden..$^{45}$ Mit ursprünglich drei Vertiefungen für Reliquienkreuze handelte es sich bei diesem Reliquiar um eine besonders prominente Stiftung. 1517 ersetzte man den heute nicht mehr erhaltenen originalen Behälter durch eine Replik, die noch im Schatz von San Marco vorhanden ist (Abb. 5). ${ }^{46}$ Auf der Rückseite des Renaissance-Artefakts erinnert eine lateinische Inschrift an das Reliquienwunder beim Schatzbrand

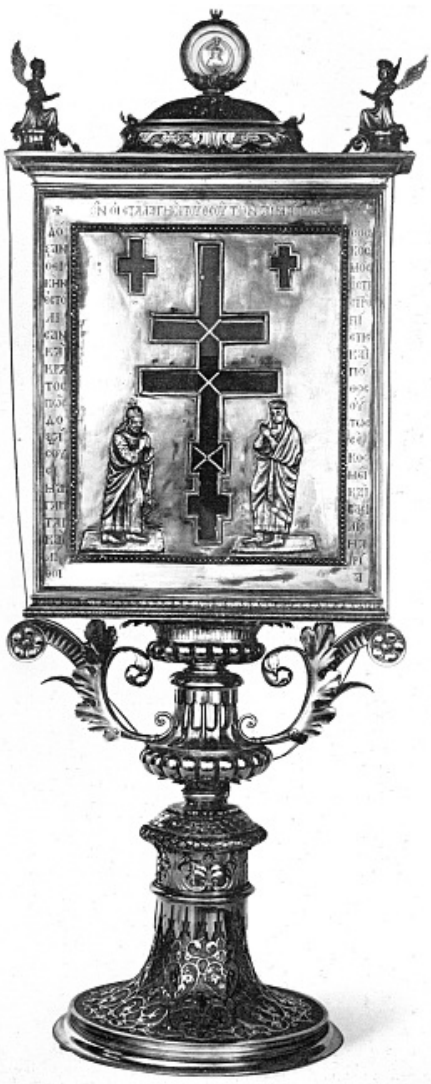

Abb. 5: Sog. Staurothek der Basilis Maria (1517) im Schatz von S. Marco, Venedig (Fondazione Giorgio Cini, Venedig)

43 Item Crux Christi quae fuit in igne in una ycona cum coperclo coperta argento deaurato, in qua est imago Vgl. Costantini et Sanctae Helena; Gallo, Il tesoro (wie Anm. 1), S. 273. Für icona (ycona) als gängige Bezeichnung für ein Reliquiar vgl. Braun, Reliquiare (wie Anm. 29), 46; Hans Belting, Die Reaktion des 13. Jahrhunderts auf den Import von Reliquien und Ikonen, in: Anton Legner (Hrsg.), Ornamenta Ecclesiae. Kunst und Künstler der Romanik. Köln 1985, Bd. 3, 177f.

44 Crucem unam Christi de ligno Domini, quae fuit in igne, et est in una icona cohoperta argento deaurato, in qua sunt imagines S. ${ }^{i}$ Costantini et S. te Helenae; Gallo, Il tesoro (wie Anm. 1), 276. Vielleicht war der Deckel 1325 schon nicht mehr vorhanden, oder der Eintrag ist unpräzise.

45 Ausführlich hierzu Karin Krause, The Staurotheke of the Empress Maria in Venice: a Renaissance Replica of a Lost Byzantine Cross Reliquary in the Treasury of St. Mark's, in: Wolfram Hörandner/Andreas Rhoby (Hrsg.), Die kulturhistorische Bedeutung byzantinischer Epigramme. Akten des Internationalen Workshops (Wien, 1.-2. Dezember 2006). Wien 2008, 37-53.

$46 \mathrm{Zu}$ dieser Replik zuvor vor allem Il tesoro di San Marco (wie Anm. 1), Nr. 192. 
von 1230.47 Was nun das einst in der byzantinischen Staurothek verwahrte Kreuz, „das im Feuer war", angeht, so handelte es sich mit an Sicherheit grenzender Wahrscheinlichkeit um das heute noch in der Schatzkammer erhaltene Kreuz der Kaiserin Irene Dukaina (Santuario 57) (Abb. 6 a-b). Das etwa 31,5 cm hohe Kreuz, das wegen seines zurückhaltenden Dekors vergleichsweise unspektakulär wirkt, befindet sich heute in einem Ostensorium des frühen 16. Jahrhunderts. ${ }^{48}$ Dass es sich um ein Kreuz byzantinischer Herkunft handelt, ist durch seine lange griechische Vers-Inschrift gesichert, die die Kaiserin Irene, Gattin des Kaisers Alexios I. Komnenos, als Stifterin nennt. Das Epigramm ermöglicht eine auf wenige Jahre genaue Datierung zumindest der Fassung der Reliquie in die Zeit zwischen 1118 und 1123.49 Das aus niellierten Buchstaben bestehende Epigramm wurde auf Kappen aus vergoldetem Silber aufgebracht, welche alle vier Enden der Kreuzbalken zieren. Diese Seite des Kreuzes ist ansonsten holzansichtig und schmucklos, bis auf ein Metallkreuz, das diagonal über seine Vierung gelegt ist (Abb. 6a). ${ }^{50}$ Die Gegenseite des Kreuzes wurde vollständig mit vergoldetem Silberblech verkleidet, welches gleichfalls um die Schmalseiten der Balken gefaltet wurde (Abb. 6b). Die Metallkappen der Balkenenden sind in zurückhaltender Weise mit einem emaillierten Dekor versehen, bestehend aus einfachen, geometrisch gestalteten Ranken. Zu dem Kreuz der Irene passt folglich Ranieris Beschreibung gut, das Kreuz habe den Brand cum paruo ornamento überstanden. ${ }^{51}$ Wie weiter unten ausgeführt

47 Es heißt dort: Servatis ex media flamma divinitus cum salut.[is] ann.[o] MCCXXX reliqua conflagrassent et in augustiorem postea formam restitutis monimentum ann. [o] MDXVII; vgl. auch E.A. Cicogna, Corpus delle iscrizioni di Venezia e delle isole della laguna veneta. Opera compilata da P. Pazzi con il contributo di S. Bergamasco. Venedig 2001, Bd. 2, 1237, Nr. 41; Il tesoro di San Marco (wie Anm. 1), 192; Krause, Staurotheke (wie Anm. 45), 37.

48 Il tesoro di San Marco (wie Anm. 1), Nr. 25; zur Datierung des Ostensoriums ebd., 35 u. 37. Die dortigen Maßangaben für das Reliquienkreuz (ebd., 35) sind von Pasini übernommen worden, bezogen sich dort allerdings allein auf die Holzteile ohne die beschrifteten bzw. dekorierten Kappen; vgl. Pasini, Il tesoro (wie Anm. 1), 28: „La Reliquia, la quale presenta la forma di una croce latina, consta di due pezzi del Sacro Legno, grossi e larghi un quattro centimetri; il più lungo di essi misura centimetri ventuno, e quattordici l'altro“. Zu dem Reliquienkreuz auch Anatole Frolow, La relique de la Vraie Croix. Recherches sur le développement d'un culte. Paris 1961, no. 308, ebenfalls mit den Maßangaben von Pasini. Das Irenenkreuz ist nur um knapp $2 \mathrm{~cm}$ kleiner als das 33,5 cm hohe Kreuz Heinrichs von Flandern.

49 Zur Datierung vgl. Il tesoro di San Marco (wie Anm. 1), 35 u. 37; vgl. für die korrekten Daten ODB 2, 1991, 1009. Zu dem Epigramm und seinem Wortlaut vgl. André Guillou, Recueil des inscriptions grecques médiévales d'Italie. Rom 1996, Nr. 90; E. Voordeckers/L. Milis, La croix byzantine d'Eine, in: Byzantion 39, 1969, 461-463.

50 Zum Sinn dieser Metallkreuze an byzantinischen Reliquienkreuzen vgl. Jannic Durand, La relique impériale de la vraie croix d'après le typicon de Sainte-Sophie et la relique de la vraie croix du trésor de Notre-Dame de Paris, in: Jannic Durand/Bernard Flusin (Hrsg.), Byzance et les reliques du Christ. Paris 2004, bes. 91f. Zu dem Metallkreuz am Irenenkreuz bemerkt Durand (ebd., 98), es sei „sans doute moderne“, was m. E. jedoch nicht zwingend erscheint.

51 S. oben Anm. 14. 


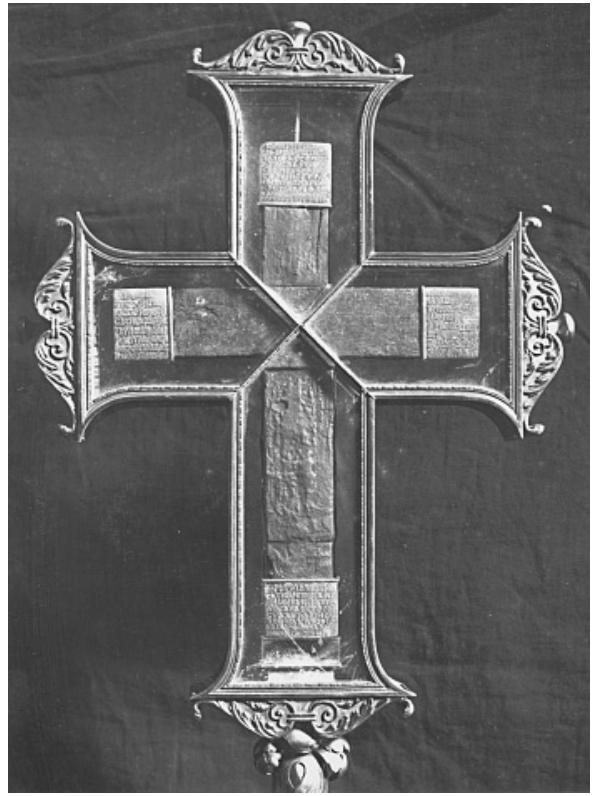

Abb. 6a: Reliquienkreuz der byzantinischen Kaiserin Irene Dukaina im Schatz von S. Marco, Venedig; Holzsichtige Seite (Osvaldo Böhm, Venedig)

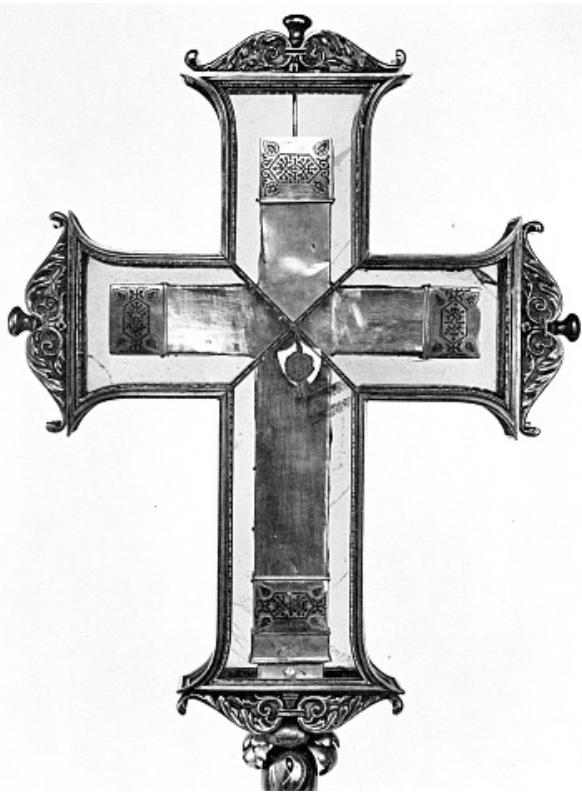

Abb. 6b: Reliquienkreuz der byzantinischen Kaiserin Irene Dukaina im Schatz von S. Marco, Venedig; Metallverkleidete Seite (Fondazione Giorgio Cini, Venedig)

wird, muss das zerstörerische Ausma $\beta$ des Feuers nach den Schilderungen des Dogen Ranieri mindestens als grobe Übertreibung angesehen werden. Daher ist wahrscheinlich, dass die Formulierung „mit geringem Schmuck“ sich nicht etwa auf das bezieht, was an Dekor nach dem Feuer noch übrig war, sondern auf die seit dem 12. Jahrhundert und bis heute am Kreuz vorhandenen, eher unauffälligen Goldschmiedearbeiten.

Der sparsame Dekor des Irenenkreuzes hat wohl dazu geführt, dass ihm bislang kaum Aufmerksamkeit zuteil wurde. Als 1984 viele prominente Stücke des Schatzes von San Marco in einer über Paris, Köln und New York führenden Wanderausstellung einer breiten Öffentlichkeit präsentiert wurden, war das Kreuz der Kaiserin Irene nicht darunter. ${ }^{52}$ Für das vergleichsweise geringe Interesse der Forschung an diesem Reliquienkreuz spricht nicht zuletzt auch die Tatsache, dass noch nie der Versuch unternommen worden ist, es mit einem der Artefakte zu identifizieren, die die frühen Inventare auflisten. Die Tradition, dass es das Irenenkreuz war, welches als das wundertätige Kreuz aus dem Schatzbrand von 1230 einst in der byzantinischen Staurothek mit den Figuren Konstantins und Helenas lag, war in Venedig jedoch offenbar noch bis ins

52 Vgl. z. B. den Kölner Katalog: Hellenkemper (Hrsg.), Schatz von San Marco (wie Anm. 23). 
18. Jahrhundert hinein lebendig: Eine aquarellierte Zeichnung ihrer Replik fertigte 1755 Jan Grevembroch an, versehen mit der Bildunterschrift „Croce alta due palmi ornata d'Argento, et Lettere Greche fù dell'Imperatrice Irene (sic!), or in San Marco" (Abb. 7).53

Die von Ranieri Zen erwähnte Reliquie des Täuferschädels bereitet die größten Schwierigkeiten hinsichtlich einer Identifikation, zum einen weil die Reliquie heute zwar - vielleicht - noch vorhanden, jedoch nicht mehr sichtbar ist, und zum anderen weil sich schon die frühen Schatzinventare nicht eindeutig zu ihrem $\mathrm{Zu}-$ stand und Verbleib äußern. Obwohl der Doge auf die Schädelreliquie am ausführlichsten eingeht, ist in seinen Schilderungen zweideutig, ob es sich um einen vollständigen Schädel handelte oder lediglich um ein Fragment, wie Formulierungen in den späteren Inventaren nahe legen. ${ }^{54}$ Der Beschreibung Ranieris nach war die Reliquie mit einem byzantinischen Seiden-

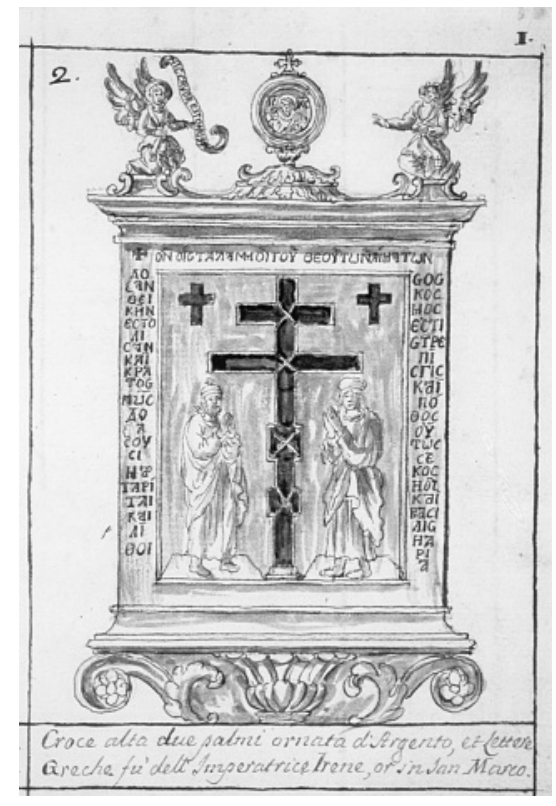

Abb. 7: Jan Grevembroch, aquarellierte Zeichnung (1755) der sog. Staurothek der Basilis Maria. Venedig, Museo Civico Correr, ,Varie venete curiosità sacre $\mathrm{e}$ profane', Ms. Gradenigo Dolfin 219 I / Coll. 65, Taf. I, 2 (Museo Civico Correr, Venedig)

53 Das Bild ist Teil einer dreibändigen Kompilation von Aquarellen, die zwischen 1755 und 1764 im Auftrag des Senators Pietro Gradenigo entstanden und den Titel Varie venete curiosità sacre e profane tragen; Venedig, Museo Civico Correr, Ms. Gradenigo Dolfin 219 I - III / Collocamento 65), Taf. I, 2. Grevembroch dachte bei seiner Bildunterschrift offenbar an das große Kreuz in der Mitte. Dieses zeigt (auch beim realen Artefakt) signifikante und schwer erklärbare Abweichungen sowohl vom Irenenkreuz, wie von byzantinischen Kreuzen insgesamt. Hierzu ausführlich Krause, Staurotheke (wie Anm. 45). Das zwischen 1118 und 1123 verzierte Irenenkreuz war eines von insgesamt drei Kreuzen in der byzantinischen Staurothek, die von einer Kaiserin namens Maria gestiftet worden war. Verschiedene Zusammenhänge sind denkbar: Entweder wurde das ältere Irenenkreuz zwischen 1161 und 1182/3 in die zu dieser Zeit von Maria von Antiochien gestiftete oder verschönerte Staurothek aufgenommen. Alternativ war die Staurothek eine Stiftung der Maria Alania (ca. 1071-1103). Demnach wäre das Irenenkreuz entweder in einer schon existenten Staurothek untergebracht worden, oder aber eines von deren Reliquienkreuzen wurde nachträglich in Irenes Auftrag verziert.

$54 \mathrm{Zu}$ Beginn des Briefes ist entweder ein vollständiger Schädel gemeint (... et vertex beati Joannis Baptistae; Andreae Danduli Chronica, wie Anm. 8, Documenti, 393, 29), oder aber Ranieri fasste ein Schädelfragment im Sinne des ,pars pro toto' auf. Bei der Beschreibung der Wiederauffindung der Reliquien nach dem Brand ist jedoch explizit die Rede von de (sic!) uertice beati Joannis Baptistae; ebd., 394, 21-22. Zu den Beschreibungen der Inventare s. weiter unten in diesem Abschnitt. 
tuch (cendato graeco ${ }^{55}$ ) bedeckt, vielleicht in dieses eingehüllt.56 Zusammen mit diesem Stoff wurde der Schädel offenbar in einer Holzkiste aufbewahrt, von der allerdings nur diejenigen Teile den Brand überlebten, die in direktem Kontakt mit der Reliquie gestanden hatten. Diese detaillierten Beschreibungen des Dogen illustrieren eindrücklich die seit der Spätantike verbreitete Idee einer Multiplikation der Heiligkeit von Reliquien durch deren Berührungskontakt mit anderen Gegenständen (brandea). ${ }^{57}$

Das Inventar von 1283 beschreibt zwar keine Schädelreliquie des Täufers, nimmt aber indirekt auf deren Existenz Bezug. Genannt wird dort an achter Stelle

„(...) ein zerbrochenes Kästchen mit Stückchen von Silber, in dem, wie wir glauben, das Haupt des heiligen Johannes Baptist lag, das im Feuer war". ${ }^{58}$

Die Formulierung erlaubt verschiedene Schlüsse, nämlich, dass entweder im Jahre 1283 der Schädel bereits verloren war oder dass man ihn bis dahin anderweitig untergebracht hatte.

Bis 1325 war die Schädelreliquie des Täufers oder - vorsichtiger formuliert - etwas, das man dafür hielt, offenbar in einem neuen Behältnis aus vergoldetem Silber untergebracht worden, denn an sechster Stelle des Inventars erscheint

„(...)[ein Teil] vom Haupt des heiligen Johannes Baptist, in jenem Kästchen [capsicula] aus vergoldetem Silber, von Schrift in Niello umgeben und mit Figuren auf dem Deckel.“ 59

Die Bezeichnung capsicula gehört zu den ältesten und geläufigsten Benennungen für einen Reliquienbehälter überhaupt und bezeichnete seit dem Hochmittelalter vor allem kasten- und schreinförmige Behälter.$^{60}$ Das im Inventar vergleichsweise detailliert beschriebene Kästchen ist unter den erhaltenen Reliquiaren im Schatz von San Marco nicht identifizierbar und hat sich vielleicht nicht erhalten. Hingegen befindet sich dort ein kleines, nur $14 \mathrm{~cm}$ messendes, rechteckiges Behältnis aus vergoldetem Silber (San-

55 Vgl. Art. zendado, in: Nicolò Tommaseo/Bernardo Bellini (Hrsg.), Dizionario della lingua italiana. Pisa u. a. 1865-1879, Bd. 4/2; Art. zendado, in: Manlio Cortelazzo/Michele A. Cortelazzo (Hrsg.), Il nuovo etimologico (DELI). Bologna 1999; Art. cendà, in: Giuseppe Boerio, Dizionario del dialetto venziano. Seconda edizione aumentata e corretta. Venedig 1856.

56 Dass Reliquien im Mittelalter in wertvolle Stoffe eingewickelt wurden, ist vielfach bezeugt; z. B. Regula Schorta, Reliquienhüllen und textile Reliquien im Welfenschatz, in: Joachim Ehlers/Dietrich Kötzsche (Hrsg.), Der Welfenschatz und sein Umkreis. Mainz 1998, 139-176; zu Textilien als Schädelhüllen ebd., 151-153 und Anhang, Nr. 30, 42.

57 Zu Berührungsreliquien z. B. Legner, Reliquien (wie Anm. 17), 11-12, 203.

58 Item capseleta una fracta cum pezoletis de argento in qua credimus fuisse caput Sancti Jo. Baptistae cum fuit in igne; Gallo, Il tesoro (wie Anm. 1), 274.

59 Item de capite Sancti Johannis Baptistae, in quadam capsicula argenti deaurata, cum literis de nielo circundata et cum figuris in cohopertura; ebd., 276.

60 Es handelt sich, wie auch im Falle des Terminus capseleta aus dem Inventar von 1283 (vgl. Anm. 58), um einen Diminutiv von capsa (bzw. capsella, capsula). Zu den Quellen und Bedeutungen dieser Termini vgl. Braun, Reliquiare (wie Anm. 29), 40-42; zur Bezeichnung besonders der Kasten- bzw. Schreinform ebd., 41. 
tuario 105). ${ }^{61}$ Dieses Reliquiar besitzt auf seinem Deckel allerdings nur eine Figur - die des stehenden Täufers - und hat zudem keinerlei den Behälter umlaufende Inschriften. Sein Inhalt ist nicht näher identifizierbar, ${ }^{62}$ folglich ist das Kästchen allein aufgrund der Abbildung des Täufers mit diesem assoziiert.

Auch die frühneuzeitlichen Schatzinventare erwähnen die Schädelreliquie. So bestätigt dasjenige aus dem frühen 15. Jahrhundert, dass sie in einem Kästchen aufbewahrt wurde (Una cassella che ha del capo di S. Gio. Battista ${ }^{63}$ ). Rund hundert Jahre später, im Inventar aus dem Jahre 1507, wird die Reliquie nur noch lapidar unter der Nr. 25 als Un pezo de la testa de ms. San Zuane Baptista ${ }^{64}$ aufgelistet, ohne Erwähnung eines Behälters. Interessant ist jedoch, dass bis 1580 die Schädelreliquie des Täufers offenbar wieder eine Aufwertung erfahren hatte. In dem in diesem Jahr angefertigten Inventar liest man die folgende Beschreibung:

Una parte della Creppa di S. Z. Battista, involta in zendato cremesin, la quale è dentro in un Calice copperta. ${ }^{65}$

Bemerkenswert ist, dass man sich bis zum späten 16. Jahrhundert offenbar wieder auf die mittelalterliche Aufbewahrung der Reliquie, verhüllt mit einem Tuch, besonnen hatte. ${ }^{66}$ Demgegenüber neu ist ihre Unterbringung in einem Kelch mit Deckel. Die Beherbergung von Reliquien in verschiedenen Arten von Trinkgefäßen ist seit dem Mittelalter im Westen mehrfach bezeugt. ${ }^{67}$ In San Marco drängt sich eine solche Unterbringung beinahe auf, denn der Tesoro birgt bis heute rund drei Dutzend Exemplare wertvoller Kelche mittelalterlichen, überwiegend byzantinischen Ursprungs. ${ }^{68}$ Tatsächlich ist das 1580 beschriebene Kelchreliquiar noch im Schatz von San Marco erhalten (Santuario 26) (Abb. 8). ${ }^{69}$ Es handelt sich bei dem Behältnis um die kuriose Kombination eines byzantinischen Kelches und einer ebenfalls aus Byzanz stammenden Patene, die beide im 10. Jahrhundert aus Jaspis gefertigt wurden. Bei der Herstellung dieses Reliquiars im 16. Jahrhundert vergrößerte man den Durchmesser der Patene vermittels

61 Il tesoro di San Marco (wie Anm. 1), Nr. 34, Taf. XXXI. Das Kästchen wird dort für eine im spätmittelalterlichen Westen entstandene Arbeit byzantinischen Stils gehalten. Zweifel an einem byzantinischen Ursprung des Reliquiars hegte auch schon Pasini (Il tesoro, wie Anm. 1, 43).

62 Im späten 19. Jahrhundert beschrieb Pasini (ebd.) den Inhalt des Kästchens mit den folgenden Worten: „Oggidì vi si conservano carboni e ceneri provenienti dalle Reliquie che in quell'incendio rimasero preda delle fiamme.“

63 Gallo, Il tesoro (wie Anm. 1), 287.

64 Ebd., 290.

65 Ebd., 302.

66 Es ist hingegen wenig wahrscheinlich, dass es sich bei dem 1580 erwähnten zendato etwa noch um denselben handelte, den Ranieri Zen 1265 erwähnt hatte; vgl. Anm. 15.

67 Zahlreiche Beispiele bei Braun, Reliquiare (wie Anm. 29), 255-262.

68 Vgl. Il tesoro di San Marco (wie Anm. 1), Nr. 40-66. Dies ist die mit Abstand größte Sammlung mittelalterlicher (byzantinischer) Kelche an einem Ort.

69 Ebd., Nr. 66. 
eines flachen Ringes aus Silber. ${ }^{70}$ Umgedreht wurde die Patene zu einer Art schwebendem Deckel über der Kelchöffnung, wobei drei kleine Markuslöwen als Abstandhalter zwischen Kelchrand und Patenendeckel dienen. Pasini und Hahnloser gaben an, der Kelch beherberge ein Stück vom Täuferschädel, ${ }^{71}$ ohne allerdings die höchst merkwürdige Art dieser Präsentation zu kommentieren. Die Kelchöffnung ist mit nach oben gewölbten Lamellen bzw. Segmenten aus Metall offenbar fest geschlossen, wobei ein in der Mitte herausragender Zipfel aus Stoff (?) eventuell dazu gedacht ist, einen Berührungskontakt mit der Reliquie im Innern herzustellen.72 Auffällig ist, dass man zwar suggerierte, die Reliquie sei durch den Schlitz zwischen Patenen-Deckel und Kelchrand berührbar, zumindest sichtbar, sie in Wirklichkeit aber den Blicken entzog.

Auf der Grundlage der Quellen ist zunächst festzuhalten, dass zwei der drei im Jahre 1265 von Ranieri Zen erwähnten Reliquien aus Konstantinopel, die Heilig-Blut-Ampulle und das Reliquienkreuz (dasjenige der byzantinischen Kaiserin Irene Dukaina), auch noch in den Jahrzehnten um 1300 eine prominente Stellung unter den Heiltümern von San Marco einnahmen. Dies legen die beiden frühesten Schatzinventare aus den Jahren 1283 und 1325 nahe, wo sie gleich unter den ersten Artefakten erscheinen. Während das Reliquienkreuz, „,as im Feuer war“, in beiden Inventaren unter den ersten fünf Objekten aufgeführt ist, nimmt die Blut-Ampulle jeweils sogar den ersten Rang ein. Das erste Schatzinventar bezeugt, dass der Kult um das Heilige Blut in San Marco in den zwei Jahrzehnten, die auf Ranieris Wunderbericht folgten, an Prominenz zugenommen hatte. Zum einen schuf man für das Blut in der Ampulle als Ersatz für deren Silberreliquiar ein wertvolles Ostensorium aus Gold, zu dessen "Schrein' man den extravaganten Kuppelbau aus Gitterwerk erkor. Dubios erscheinen, zumindest auf der Grundlage der ältesten Textquellen sowie der einschlägigen Artefakte im Schatz von San Marco, Art und Verbleib der Schädelreliquie des Täufers.

Außer dem langen Schreiben Ranieris vom 30. Mai 1265 sind aus den beiden folgenden Monaten vier weitere, bislang von der Forschung nicht beachtete diplomatische Briefe des Dogen überliefert, in denen verschiedene geistliche und politische Würden-

70 Pasini gibt die Maße wie folgt an: Die Gesamthöhe des ,Reliquiars` betrage $26 \mathrm{~cm}$; der Durchmesser der Patene betrage $13 \mathrm{~cm}$, mit dem sie umgebenden Silberring $20 \mathrm{~cm}$; Pasini, Il tesoro (wie Anm. 1), 42. Zur Datierung vgl. Il tesoro di San Marco (wie Anm. 1), Nr. 66, wobei allerdings die Evidenz der Schatzinventare von 1507 und 1580 außer Acht gelassen wurde. Zu den beiden byzantinischen Artefakten und ihren Inschriften vgl. Guillou, Recueil (wie Anm. 49), Nr. 74 u. 75.

71 Pasini, Il tesoro (wie Anm. 1), Nr. 50; Il tesoro di San Marco (wie Anm. 1), Nr. 66.

72 Die Beschreibung des Kelchverschlusses verdanke ich einem Touristen in der Schatzkammer, der dank seiner Körpergröße im Gegensatz zu mir in der Lage war, durch das Vitrinenglas in den Kelch hinein zu blicken. Auf der Abbildung im Katalog ist der Bereich unterhalb der Patene verschattet; Il tesoro di San Marco (wie Anm. 1), Taf. LVII, links. Erkennbar sind dort jedoch der gewölbte Metallverschluss sowie eine Erhebung in der Mitte. 
träger ersucht werden, Ranieris Anliegen beim Papst zu unterstützen.73 Bereits die Ausführlichkeit, in der der Doge dem Papst den zerstörerischen Brand und die unerwartete Entdeckung dreier davon völlig unversehrt gebliebener Reliquien schilderte, legt nahe, dass es nicht etwa darum ging, an ein Wunder zu erinnern, das im Vatikan längst, aktenkundig' war. Hingegen ist davon auszugehen, dass es sich hier um die erste offizielle Verkündung des Ereignisses in Rom handelte, und die Anzahl der Dokumente signalisiert deutlich den Stellenwert dieser Korrespondenz. Doch welche Belange waren es, die dem Dogen so sehr am Herzen lagen?

Je zerstörerischer das Feuer, desto bemerkenswerter die Tatsache, dass drei Reliquien es unbeschadet überdauern konnten. Dem Papst dies glaubhaft zu machen, darum ging es Ranieri, und als Begründung verwies er auf die ehrwürdige und antike Provenienz der Reliquien aus dem Besitz des ersten christlichen Kaisers sowie auf das besondere Interesse Gottes an ihnen: Die zweifelsfreie Authentizität der Reliquien, die genau wegen ihrer Echtheit das Gefallen Gottes fanden, ermög-

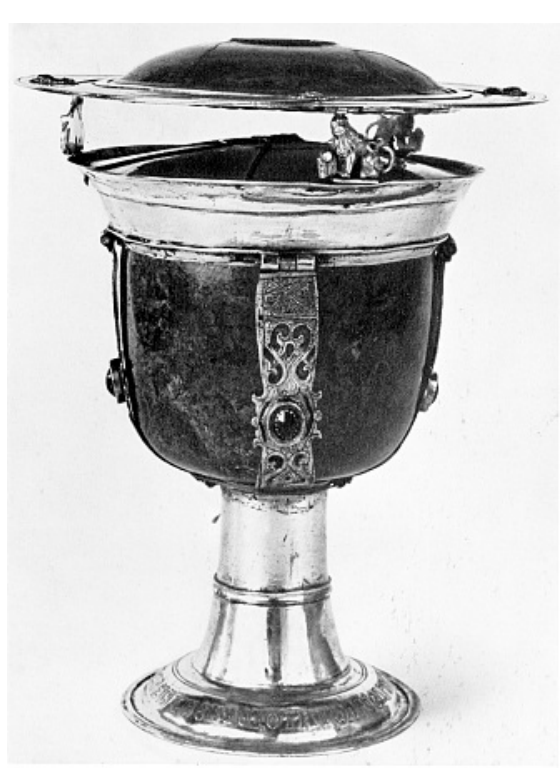

Abb. 8: Kelch-Patenen-Reliquiar für den Schädel des Täufers im Schatz von S. Marco, Venedig (Fondazione Giorgio Cini, Venedig) lichte erst das Wunder beim Schatzbrand. Gleichzeitig lieferte, umgekehrt, das Wunder den Beweis für die Echtheit der Reliquien, so die Botschaft des Dogen an Clemens.

Es sei an dieser Stelle zumindest angedeutet, dass Venedig durch die lateinische Eroberung von Konstantinopel keinesfalls in den Besitz der ranghöchsten Reliquien gelangt war, nämlich derjenigen aus dem Besitz der byzantinischen Kaiser. Diese verblieben noch jahrzehntelang in Konstantinopel, bis sie an König Ludwig IX. von Frankreich veräußert wurden. Der in den Jahren 1239 bis 1247 erfolgte, sukzessive Verkauf von über zwanzig Reliquien aus der kaiserlichen Pharos-Kapelle nach Paris stellt den mit Abstand bedeutendsten Reliquientransfer der Lateinerzeit dar, zumal sich darunter die Dornenkrone Christi und das vielleicht größte Reliquienkreuz der christlichen Welt befanden. ${ }^{74}$ Demgegenüber nimmt sich die Handvoll Reliquien, deren

73 Diese weiteren Briefe wurden zwischen dem 13. Juni und dem 7. Juli 1265 verfasst; vgl. die Edition dieser Texte in Andreae Danduli Chronica (wie Anm. 8), Documenti, 394, 39-396, 3.

74 Ausführlich zu den historischen Zusammenhängen und den Artefakten der neuere Ausstellungskatalog von Jannic Durand/Maire-Pierre Laffitte (Hrsg.), Le trésor de la Sainte-Chapelle. Paris 2001. 
Herkunft aus Konstantinopel man im spätmittelalterlichen Venedig proklamierte, bescheiden aus. Die Lagunenstadt befand sich damit in Konkurrenz zu zahllosen Orten im Westen, an die durch die Plünderung Konstantinopels, meist durch Zufall gesteuert, eine oder mehrere Reliquien gelangt waren, darunter vielfach Kreuzreliquien und andere Herrenreliquien. ${ }^{75}$ Zudem werden mindestens zwei der von Ranieri Zen beworbenen Reliquien manch einem Zeitgenossen dubios erschienen sein: Das Blut der Passion war (wie prinzipiell alle Körperreliquien Christi) im 13. Jahrhundert Gegenstand erhitzter theologischer Debatten, die um die Problematik kreisten, inwiefern nach der Himmelfahrt des Herrn etwas von dessen Körper auf Erden verblieben sein könne. ${ }^{76}$ Vom Schädel des Täufers kursierten offenbar schon seit der Spätantike mehrere vollständige Exemplare im östlichen Mittelmeerraum, ${ }^{77}$ und so hat es fast eine gewisse Logik, dass man dieses heilige Haupt im Mittelalter mitnichten nur in Venedig verehrte: Im Jahre 1206 war der (komplette) Schädel aus dem Manganenkloster in Konstantinopel von Walon de Sarton nach Amiens gebracht worden, wo er noch heute erhalten ist. ${ }^{78}$ Auch in dem erwähnten, kurz vor der Mitte des 13. Jahrhunderts aus Konstantinopel nach Paris gelangten Reliquienkonvolut befand sich nach zeitgenössischen Quellen die obere Schädelpartie des Täufers. ${ }^{79}$ Jacobus von Voragine verbreitete mit seiner im späten 13. Jahrhundert bereits enorm populären ,Legenda aurea' gar, dass das Haupt des Johannes schon in karolingischer Zeit aus Konstantinopel nach Poitiers gebracht worden sei. ${ }^{80}$ Nicht zuletzt vor diesen Hintergründen erscheint es durchaus verständlich, dass Ranieri Zen sich darum bemühte, seine Reliquien byzantinischer Herkunft mit der Aura des Wunderbaren zu versehen, um damit ihre zweifelsfreie Authentizität plausibel zu machen.

Ganz eindeutig fußt der Wunderbericht des Dogen auf dem Brauch der Feuerprobe an Reliquien, der mindestens bis zum späten 12. Jahrhundert, dann wieder in der frü-

75 Vgl. Paul E. D. Riant, Des dépouilles religieuses, enlevées à Constantinople au XIIIe siècle, et des documents historiques nés de leur transport en Occident, in: Mémoires de la Société nationale des antiquaires de France, 4 ser., Bd. 6, Paris 1875, 3-85 u. 176-213.

76 Vgl. für die Entwicklung der Debatte und ihre Protagonisten Nicholas Vincent, The Holy Blood. King Henry III and the Westminster Blood Relic. Cambridge 2001, 82-136.

77 John Wortley, Relics of the ,Friends of Jesus' at Constantinople, in: Jannic Durand/Bernard Flusin (Hrsg.), Byzance et les reliques du Christ. Paris 2004, bes. 145-149.

78 Vgl. Leslie C. Brook, La translation de la relique de saint Jean-Baptiste à la cathédrale d'Amiens: récits latin et français, in: Neuphilologische Mitteilungen 91, 1990, 93-106; Musée du Louvre (Hrsg.), Byzance. L'art byzantin dans les collections publiques françaises. Paris 1992, Nr. 240.

79 Durand/Laffitte (Hrsg.), Le trésor (wie Anm. 74), bes. 79-81.

80 Iacopo da Varazze, Legenda aurea. Ed. Giovanni Paolo Maggioni. 2 Bde. Florenz 21998, Bd. 2, 883 (146); zur Entstehung und Verbreitung des Textes im 13. Jh. ebd., Bd. 1, XIII-XV. 
hen Neuzeit, vielerorts nachgewiesen ist. ${ }^{81}$ Abgeleitet aus der ursprünglich juristischen Praxis, die Glaubwürdigkeit von Angeklagten und Zeugen durch die Feuerprobe zu testen, diente das offizielle, durch den Ordo ad probandas reliquias geregelte kirchliche Ritual bei Reliquien dazu, deren Echtheit zu beweisen. ${ }^{82}$ Während man solche Feuerproben mit offiziell geregeltem Procedere gezielt herbeiführte, existieren aus dem Mittelalter gleichfalls viele Berichte zufälliger Feuerproben, nämlich über Reliquien, die wunderbarerweise bei Brandkatastrophen unbeschadet geblieben seien. ${ }^{83}$ Schon die Tatsache, dass Ranieri Zens Schilderungen ganz offensichtlich von solchen Geschichten inspiriert sind, erhärtet den Verdacht, dass der Doge zumindest die Schwere des Brandes stark übertrieben dargestellt haben wird: Nur wenn das Feuer so verheerend war, dass praktisch alles zerstört wurde, kann plausibel als Wunder deklariert werden, dass drei Reliquien dabei vollkommen unversehrt blieben. Vorsichtshalber bezog sich Ranieri auf ein Ereignis, dessen genaue Umstände nach immerhin rund 35 Jahren, rund zwei Generationen später, kaum noch jemandem in Erinnerung gewesen sein können, erst recht nicht dem Papst im fernen Rom. Um Clemens von der Wahrheit der Schilderungen zu überzeugen, führt der Doge eine Liste honoriger Zeugen an, die sofort nach dem Wunder zu dessen Verifizierung (ad jnquisitionem de tanto miracolo ${ }^{84}$ ) herbei gerufen worden seien, darunter der venezianische Bischof von Castello, der Patriarch von Grado sowie viele Ordensleute und andere Kleriker. ${ }^{85}$ Doch was genau bezweckte der Doge mit seiner Korrespondenz im Frühjahr 1265?

Das Anliegen des Dogen ist in dem Brief klar zum Ausdruck gebracht: Dem Papst und der römisch-katholischen Kirche sollte das ,große und ruhmvolle Wunder“ mitgeteilt werden, damit „die Wahrheit bekannt und über alle Teile der Erde feierlich und mit seiner [des Papstes] Erlaubnis verbreitet“ und „vielen Seelen Erbauung und Ablass

81 Thomas Head, Saints, Heretics, and Fire: Finding Meaning through the Ordeal, in: Sharon Farmer/Barbara H. Rosenwein (Hrsg.), Monks \& Nuns, Saints \& Outcasts. Religion in Medieval Society. Essays in Honor of Lester K. Little. Ithaca/London 2000, 220-238, mit einer Auflistung von insgesamt 20 durch Texte bezeugten Feuerproben an Reliquien ebd., 236-238; G. J. C. Snoek, Medieval Piety from Relics to the Eucharist. Leiden u. a. 1995, 329-331. In Venedig wurde im Jahre 1528 eine kurz zuvor der Kirche San Marco gestiftete Kreuzpartikel auf ihre Echtheit geprüft, indem man sie Feuer aussetzte; Gallo, Il tesoro (wie Anm. 1), 109f., bes. 110. Allgemein zu Feuerproben an Reliquien in der Frühen Neuzeit Head, Saints (wie Anm. 81), 224.

82 Ebd., 224, mit Anm. 10.

83 Für Beispiele vgl. ebd., 230; Snoek, Medieval Piety (wie Anm. 81), 331f.; Vincent, Holy Blood (wie Anm. 76), 70-71 u. 209-210; Ilene H. Forsyth, The Throne of Wisdom. Wood Sculptures of the Madonna in Romanesque France. Princeton 1972, $32 \mathrm{f}$.

84 Andreae Danduli Chronica (wie Anm. 8), Documenti, 393, 43.

85 Ebd., 393, 41-394, 1. 
zuteil" werde. ${ }^{86}$ Bestimmte Formulierungen zu Beginn des Wunderberichts legen nahe, dass es in der Dogenkirche schon seit einer gewissen Zeit üblich war, die drei Reliquien aus der Feuerprobe am Himmelfahrtstag öffentlich zu zeigen. ${ }^{87}$ Wenn sich der Doge nun mit dem ausdrücklichen Anliegen einer offiziellen Anerkennung des Reliquienwunders an den Papst wandte und gleichzeitig eine Institutionalisierung von Ablässen anregte, so signalisiert dies, dass für die Reliquien aus Konstantinopel bis in die 1260er Jahre hinein kein päpstlich approbierter und mit entsprechenden Ablässen verknüpfter Kult existierte. Folglich beabsichtigte der Doge mit seinem Schreiben eine Aufwertung und effiziente Propaganda bestehender, jedoch offenbar noch wenig bekannter Reliquienkulte durch päpstliche Förderung.

Abgesehen von einem allgemeinen Prestigegewinn Venedigs nach einer günstigen Reaktion des Papstes, erhoffte man sich wohl, dass der Kult um die Reliquien mit den vom Papst erteilten Ablässen mehr Pilger nach San Marco locken und dem Dogen zu zusätzlichen finanziellen Mitteln verhelfen würde. Man muss dabei bedenken, dass große Teile der Markuskirche erst im fortgeschrittenen 13. Jahrhundert in Angriff genommen bzw. fertig gestellt worden sind. Vor allem sind hier der Bau und die Mosaizierung des gesamten Atriums sowie die aufwändige Gestaltung der Fassaden zu nennen. ${ }^{88}$ All dies war während der Amtszeit Ranieris noch in vollem Gange, und es ist klar, dass man für die Fertigstellung der Dogenkirche eine Menge Geld benötigte - dies eben auch noch nach 1261, als Venedig erhebliche Einbußen im Mittelmeerhandel zu verzeichnen hatte.

Dass der Papst geneigt sein würde, für die Verehrung von Reliquien, die aus Konstantinopel stammten, einen Ablass zu gewähren, konnte sich Ranieri mit Blick auf die Pariser Sainte-Chapelle erhoffen: Für den Besuch der königlichen Palastkapelle und die Verehrung der bereits erwähnten, um 1240 aus Byzanz dorthin gelangten ranghohen Reliquien waren immer wieder großzügige päpstliche Ablässe erteilt worden, erstmals bereits unter Innozenz IV. (1243-54) ${ }^{89}$ Gerade Clemens' unmittelbarer Amtsvorgänger, Urban IV. (1261-64), wie Clemens selbst ein gebürtiger Franzose, hatte im ersten Jahr

86 (...) quod hoc tam grande et tam gloriosum miraculum, quod ad tantam roborationem fidei noscebatur, Summo Pontifici, et ecclesiae Romanae minime reuelabant, ad hoc, ueritate cognita, et per mundi partes solenniter et de sua licentia diuulgata, jn multam animarum edificationem jndulgentia praeberetur; ebd, 393, 36-39.

87 (...) dum noviter jn festo beate Ascensionis Domini, sacrae reliquiae, videlicet Lignum Sanctae Crucis, ampulla de uero Sanguine Christi et vertex beati Joannis Baptistae more solito populo fuissent ostensae (...); ebd., 27-29. Die Formulierungen noviter und more solito zeigen an, dass der Brauch schon länger bestand.

88 Grundlegend zu den Mosaiken des 13. Jahrhunderts Otto Demus, The Mosaics of San Marco in Venice. Chicago/London 1984, Bde. 2/1 und 2/2 (The Thirteenth Century); zur Fassadenverkleidung Otto Demus, Der skulpturale Fassadenschmuck des 13. Jahrhunderts, in: Die Skulpturen von San Marco in Venedig. Die figürlichen Skulpturen der Aussenfassaden bis zum 14. Jahrhundert. Berlin 1979, 1-15.

89 Nikolaus Paulus, Geschichte des Ablasses im Mittelalter. Vom Ursprunge bis zur Mitte des 
seines Pontifikats mehrfach Ablässe für diejenigen ausgesprochen, die in der Pariser Palastkapelle am Gottesdienst teilnahmen. Denjenigen, die die Kapelle am Jahrestag von deren Weihe oder an den acht darauf folgenden Tagen aufsuchten, hatte Urban am 21. November 1261 gar den für damalige Verhältnisse gigantischen Ablass von drei Jahren und hundertzwanzig Tagen zugestanden. ${ }^{90}$

Die Vermutung liegt nicht allzu fern, dass sich Ranieri für seine Reliquien gleicher Provenienz vergleichbare Aufmerksamkeiten seitens des kurz zuvor, am 5. Februar 1265, neu ins Amt gewählten Clemens erhoffte. Die Zusatzqualifikation der venezianischen Reliquien durch eine erfolgreich bestandene Feuerprobe sollte wohl ihren Teil dazu beitragen, päpstliches Wohlwollen zu erlangen. Seinen Amtsvorgängern folgend gewährte Clemens noch im ersten Jahr seines Pontifikats gleichfalls einen Ablass für den Besuch der Pariser Reliquien. ${ }^{11}$ Ob Ranieris Wunderbericht überhaupt bis zum Papst vorgedrungen ist, ist unbekannt. Jedenfalls findet sich an keiner Stelle in den Registern Clemens' ein Eintrag, der mit Reliquien in Venedig zu tun hätte. Nun könnte man einwenden, dass aus dem Mittelalter längst nicht alle Ablassbewilligungen, die schriftlich fixiert wurden, erhalten sind. ${ }^{92}$ Dass es im Jahre 1265 eine päpstliche Anerkennung des Wunders und damit verbundene Ablässe gegeben hat, die nur nicht mehr dokumentiert sind, kann wohl dennoch mit Sicherheit ausgeschlossen werden: Die venezianischen Chronisten des 13. Jahrhunderts schweigen hierzu, vor allem aber über

14. Jahrhunderts (2 Bde.). Mit einer Einleitung und einer Bibliographie von Thomas Lentes. Darmstadt 22000, Bd. 2, 9. Ich danke einem Leser, der es vorzieht, anonym zu bleiben, für den Hinweis auf die von verschiedenen Päpsten gewährten, umfangreichen Ablässe anlässlich der Verehrung der Reliquien in der Ste-Chapelle.

90 Les registres d'Urbain IV (1261-1264). Recueil des bulles de ce pape. Publiées ou analysées d'après les manuscrits originaux du Vatican. Par M. Jean Guiraud. (Bibliothèque des Écoles francaises d'Athènes et de Rome, Bd. 2,13.) 4 Teil-Bde. Paris 1901-1906, Bd. 4, Paris 1906, Nr. 2874; für die anderen auf die Ste-Chapelle bezogenen Ablässe ebd., Bd. 2, Paris 1901, Nr. 23, 24. Allgemein üblich waren Ablässe von wenigen, maximal 40 Tagen, wobei allerdings Päpste teilweise mehr gewährten; Vincent, Holy Blood (wie Anm. 76), 158. Zu den Bemühungen Urbans um das französische Königshaus vgl. auch Ivan Gobry, Deux papes champenois: Urbain II, Urbain IV. Troyes 1994, 159.

91 Les registres de Clément IV (1265-1268). Recueil des bulles de ce pape. Publiées ou analysées d'après les manuscrits originaux du Vatican. Par Edouard Jordan. (Bibliothèque des Écoles francaises d'Athènes et de Rome, Bd. 2,11.) Paris 1895-1945, Nr. 1847 (25. Oktober 1265). Die Höhe des Ablasses fiel jedoch mit einem Jahr und vierzig Tagen deutlich geringer aus als bei seinem Amtsvorgänger. Allerdings ist der Ablass für die Verehrung des Pariser Heiltums einer von nur wenigen, die Clemens überhaupt für die Verehrung von Reliquien gewährte, und ansonsten erteilte der Papst Ablässe von normalerweise erheblich küzerer Dauer. Vgl. ebd., Index analyticus notabilium rerum, 52, sub voce „Indulgentiarum concessio“. Unter den dort aufgeführten 46 Ablässen während des Pontifikats Clemens' beziehen sich nur sechs mehr oder weniger explizit auf die Verehrung von Heiligen bzw. deren Reliquien; ebd., Nr. 468, 1445, 1644, 1811, 1847/48, u. 1894. Eine Übersicht der von Clemens gewährten Ablässe bei Paulus, Geschichte des Ablasses (wie Anm. 89), Bd. 2, 8f.; vgl. auch ebd., 176.

92 Ebd., Bd. 1, 131; Vincent, Holy Blood (wie Anm. 76), 161. 
das von Ranieri detailreich geschilderte Schatzbrandwunder vollständig. Hierauf wird weiter unten zurückzukommen sein.

\section{Portraits in Stein - die Reliquientafel von San Marco}

Unabhängig von möglichen Gründen für Ranieris Bemühungen um die Reliquien aus Konstantinopel und von der Frage, wie erfolgreich der Doge damit war, bezeugt die Korrespondenz des Jahres 1265, dass man von offizieller Seite die vergleichsweise jungen Kulte um das Heiltum aus Konstantinopel in der Dogenkirche zu fördern suchte. Als ein seltenes Bilddokument, das ebenfalls im Kontext dieser Reliquienwerbung zu betrachten ist, hat ein marmornes Relief in San Marco zu gelten (Abb. 9 a-c, Tafel II 1). Auf ihm sind insgesamt fünf Reliquien abgebildet, und gleichzeitig wird visuell an deren Präsenz in der Lagunenstadt aufgrund göttlicher Vorsehung erinnert. Letztere ist im Relief mit der Hand Gottes oben rechts angedeutet sowie durch die Anwesenheit von insgesamt drei Engeln, von denen derjenige oben im linken Zwickel ebenfalls die Reliquien segnet.

Das Relief befindet sich in einer Passage, die vom Hof des Dogenpalastes, außen an der Ostwand der Schatzkammer entlang, in den Südarm von San Marco führt und die in der modernen Forschungsliteratur überwiegend als Andito Foscari bezeichnet wird (s. Abb. 14-15). ${ }^{93}$ Es handelt sich dabei um einen schmalen, nur wenig mehr als zwei Meter breiten, und fast sechs Meter langen Korridor mit einem hohen Tonnengewölbe. ${ }^{94}$ Die Tafel befindet sich an der Westwand dieser Passage, also zur Reliquienkammer des Schatzes, dem so genannten Santuario hin orientiert.

Die bislang ausführlichste Beschäftigung mit der Tafel und den auf ihr abgebildeten Gegenständen stellt die bereits erwähnte Studie von Debra Pincus dar. Pincus siedelte darin die Entstehung des Reliefs in demselben zeitlichen und ideologischen Kontext wie Ranieri Zens Wunderbericht an. ${ }^{95}$ Andere Autoren, wie Staale Sinding-Larsen und Renato Polacco, haben vor allem zu rekonstruieren versucht, auf welche Weisen die

93 Diese Bezeichnung leitet sich von dem rechwinklig zu diesem Korridor, zwischen Porta della Carta und der Scala dei Giganti verlaufenden, so genannten Porticato Foscari ab. Mit diesem, in den 1440er Jahren unter dem Dogen Francesco Foscari errichteten Porticato ist der Andito durch sein südliches Portal verbunden. Zum Porticato Foscari vgl. Umberto Franzoi, Il Palazzo Ducale. Architettura, in: Umberto Franzoi u. a., Il Palazzo Ducale di Venezia, Treviso 1990, 57-63, bes. 57f.; zuvor auch Umberto Franzoi, Storia e leggenda del Palazzo Ducale di Venezia. Prefazione di Terisio Pignatti. Venedig 1982, 57-64; Debra Pincus, The Arco Foscari: The Building of a Triumphal Gateway in Fifteenth Century Venice. New York/London 1976, 58-64 u. 69-75.

94 Die genauen Maße der Passage sind: 2,12 m Breite (Wand zum Südarm der Kirche) bzw. 2,33 m Breite (Wand zum Andito Foscari) / 5,70 m Länge / 5,70 m Höhe (Gewölbescheitel).

95 Pincus, Christian Relics (wie Anm. 4), passim, bes. 39f., 46 u. 48; im Anschluss daran auch Dale, Pictorial Narratives (wie Anm. 10), 87. 


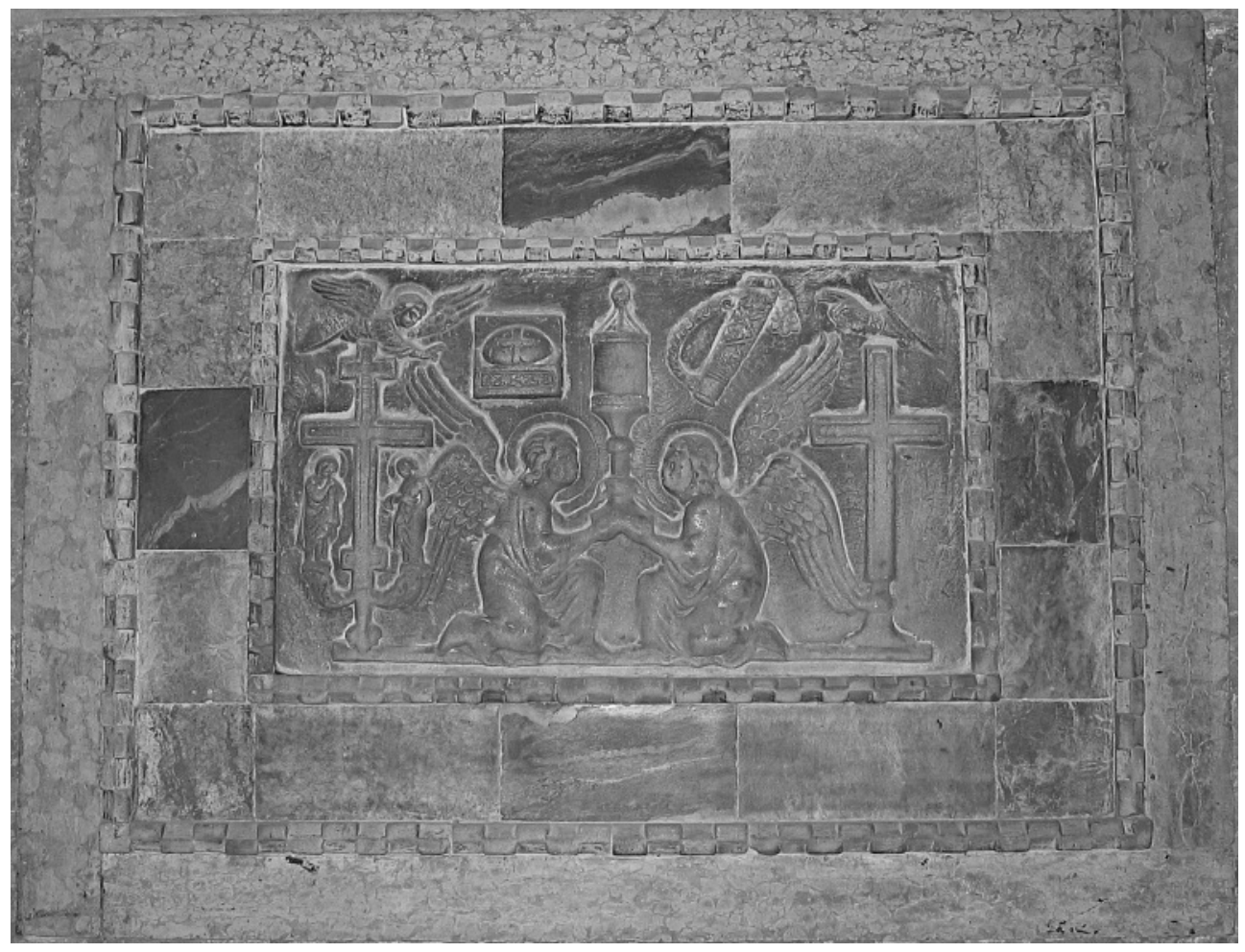

Abb. 9a: Reliquientafel im sog. Andito Foscari, S. Marco, Venedig (Foto: K. Krause)

Tafel in das religiöse Zeremoniell von San Marco eingebunden war. ${ }^{96}$ Das Monument selbst ist trotz aller Erklärungsversuche noch wenig bekannt, zumal es in den einschlägigen Publikationen speziell zur Skulptur der Markuskirche meist vollständig übergangen oder bestenfalls gestreift wurde. ${ }^{97}$

Für die Tafel hat die Forschung verschiedene Entstehungszeiten vorgeschlagen, die von der Mitte des 13. Jahrhunderts bis ins 14. Jahrhundert reichen. Sofern die bisherigen Datierungen überhaupt begründet wurden, geschah dies vor allem auf stilistischer

96 Renato Polacco, Proposte per una chiarificazione sul significato e sulla funzione del „,bassorilievo" delle reliquie dell'Andito Foscari in San Marco a Venezia, in: Hadriatica. Scritti in onore di Wladimiro Dorigo. Padua 2003, 133-137; Staale Sinding-Larsen, Christ in the Council Hall. Studies in the Religious Iconography of the Venetian Republic. Rom 1974 (Institutum Romanum Norvegiae. Acta ad Archaeologiam et Artium Historiam Pertinentia, Bd. 5.), 199, 211f., bes. 212, mit Anm. 4, jedoch mit weitgehend unzutreffender Identifikation der dargestellten Gegenstände.

97 Ohne Bezugnahmen auf das Relief: Wolfgang Wolters, La scultura veneziana gotica (13001460). Venedig 1979; Wolfgang Wolters (Hrsg.), Die Skulpturen von San Marco in Venedig. Die figürlichen Skulpturen der Außenfassaden bis zum 14. Jahrhundert. Berlin 1979; Otto Demus/Lorenzo Lazzarini/Mario Piana/Guido Tigler, Le sculture esterne di San Marco. Mailand 1995; 
Basis. ${ }^{98}$ Würde man mit Debra Pincus eine frühe Entstehung erwägen, also schon in den $1250 \mathrm{er}$ bis $60 \mathrm{er}$ Jahren ${ }^{99}$ so wäre allerdings verwunderlich, dass das Relief fünf Reliquien abbildet, wo doch praktisch gleichzeitig Ranieri Zen nur drei zu fördern suchte, die zudem angeblich einzige Überlebende eines verheerenden Schatzbrandes waren.

Standen bisher Fragen der politischen und zeremoniellen Signifikanz der Tafel im Mittelpunkt des Forschungsinteresses, so wurde das physische Erscheinungsbild der abgebildeten Reliquien weder umfassend beschrieben noch gedeutet. Antonio Pasini äußerte in seiner monumentalen Publikation des Schatzes von San Marco die Meinung, dass das Relief lediglich eine grobe Vorstellung vom Aussehen der Reliquien vermittle, die der Bildhauer sicher nicht mit eigenen Augen gesehen habe. ${ }^{100}$ Diesem Urteil möchte ich mit Nachdruck widersprechen. Die Reliefs sind, im Gegenteil, für ihre Entstehungszeit bemerkenswert genaue Portraits der realen Artefakte. Genau deshalb ist die Tafel ein einzigartiges Dokument für Gestalt und Präsentation der Reliquien aus Byzanz in der Markuskirche vor rund siebenhundert Jahren.

Das $82 \mathrm{~cm}$ breite und $50 \mathrm{~cm}$ hohe Reliquienrelief wird von einem Rahmen umgeben, der aus sechzehn Rechtecken bzw. Quadraten aus verschieden farbigem Marmor zusammengesetzt und seinerseits von zwei schmalen Friesleisten eingefasst ist. ${ }^{101}$ Auf diesen Leisten sind zudem im Streiflicht Spuren einer einstigen Vergoldung zu erkennen, und möglicherweise waren auch Teile der Reliefdarstellung, die heute stark abgegriffen ist, ursprünglich golden gefasst. Der polychrome Rahmen aus Marmor ist von

Ruth Papadopoulos, Die Skulpturen des 13. Jahrhunderts an San Marco in Venedig. Würzburg 2002 (knappe Erwähnung des Reliefs in Anm. 85, mit Verweis auf die Studie von Pincus).

98 Pasini, Il tesoro (wie Anm. 1), 3, hielt die Tafel für ein Werk ,probabilmente“ des 13. Jahrhunderts; Molinier, Le trésor (wie Anm. 2), 77, datierte sie ohne Begründung ins 13. oder 14. Jahrhundert; Hahnloser legte sich nicht fest und meinte, das Relief sei „di epoca medievale“; Il tesoro di San Marco (wie Anm. 1), 140; im Katalog der Wanderausstellung von Artefakten aus San Marco im Jahre 1984 findet sich eine nicht begründete Datierung erst ins 14. Jahrhundert; Hellenkemper (Hrsg.), Schatz von San Marco (wie Anm. 23), 257. Pincus, Christian Relics (wie Anm. 4), 40, datierte die Tafel ca. 1240-75, am ehesten in die 1250er oder 1260 er Jahre. Die wenigen angeführten Stilvergleiche (ebd.) vermögen jedoch nicht zu überzeugen.

99 S. die vorhergehende Fußnote. Im Anschluss daran auch Dale, Pictorial Narratives (wie Anm. 10), 87.

100, ,...) è più che probabile, che allo scultore, quanto alla forma, se ne darà data all'ingrosso un'idea, e ch'ei non le avrà vedute: a quei tempi così gelosamente si custodivano le Reliquie“; Pasini, Il tesoro (wie Anm. 1), 3. Ein Stich des Reliefs (ohne den Rahmen) ziert die Titelseite sowohl des Text- als auch des Tafelbandes von Pasinis monumentaler Publikation.

101 Die Maßangaben (89 x $56 \mathrm{~cm}$ ) bei Pincus, Christian Relics (wie Anm. 4), 39, wiederholt bei Polacco, Proposte, (wie Anm. 96), 133, sind falsch. Der Rahmen ist, einschließlich der beiden Friesleisten, $21 \mathrm{~cm}$ breit. Die farbigen Marmorstücke sind symmetrisch angeordnet: vier terracottafarben gemaserte Quadrate aus verschiedenen Steinsorten bilden die Eckkompartimente, 
einem weiteren umgeben, bestehend aus vier schmalen Leisten aus Rosso di Verona, der dem Relief wahrscheinlich erst in späterer Zeit zugefügt wurde. ${ }^{102}$

Zwei kniend abgebildete Engel vorn in der Mitte halten, einander zugewandt, ein Ostensorium empor, dessen Identifikation unproblematisch ist. Eindeutig handelt es sich bei ihm um die Heilig-Blut-Ampulle aus Bergkristall samt ihrer goldenen Fassung (Vgl. Abb. 1). ${ }^{103}$ Was die Wiedergabe angeht, so ist das Relief von bemerkenswert großer Exaktheit: Das Größenverhältnis von Standfuß und Ampulle entspricht der Realität. Auch wurde das Profil des Fußes vom Bildhauer weitgehend genau nachvollzogen. Entsprechend dem Original erscheinen die beiden horizontalen Bänder der Fassung, und deren vertikal verlaufende Leisten fanden zumindest in der spitz zulaufenden Bekrönung eine Abbildung. Der heutige Zapfen oben auf der Goldfassung ist barockzeitlich, ${ }^{104}$ ersetzte jedoch, wie sich aus der Reliefabbildung schließen lässt, eine ganz ähnliche Bekrönung des 13. Jahrhunderts. Es ist sicher vor allem auf die vergleichsweise geringe Größe der Darstellung zurückzuführen, dass das Relief nicht die Flaschenform zeigt, sondern das eigentliche Schaugefäß zylindrisch abgebildet wurde. Oben war argumentiert worden, dass die Bergkristallampulle ihre goldene Fassung höchst wahrscheinlich erst erhielt, nachdem der Doge Ranieri Zen im Jahre 1265 seinen Brief nach Rom geschickt hatte, womit wir gleichzeitig auch einen terminus post quem für die Anfertigung der steinernen Reliquientafel hätten.

Die privilegierte Platzierung der Blut-Ampulle im Zentrum des Reliefs, zudem von Engeln präsentiert, entspricht ihrer Nennung an erster Stelle in beiden Schatzinventaren. Dem prominenten Rang des Ostensoriums angemessen wurde es zudem als einziges der fünf Artefakte auf der Tafel größer als in der Realität abgebildet. ${ }^{105}$

Zwei Reliquienkreuze flankieren auf dem Relief das Ostensorium. Während das früheste Inventar von 1283 nur ein Reliquienkreuz anführt, nämlich dasjenige, „das im Feuer war", beschreibt das Inventar von 1325 sogar insgesamt vier Reliquien vom ,wahren' Kreuz ausdrücklich als kreuzförmig. Jedoch erscheinen nur zwei davon im vorderen Teil der Liste, nämlich das Kreuz Heinrichs von Flandern (Nr. 3) sowie dasjenige aus dem Schatzbrand (Nr. 5), sehr wahrscheinlich identisch mit dem Kreuz der

während die Längs- und Schmalseiten jeweils mit drei rechteckigen Stücken gefüllt sind. Von diesen bestehen die jeweils mittleren aus einem mehrfarbig gemaserten, hauptsächlich dunkelroten Marmor. Die jeweils flankierenden Rechtecke bestehen aus hellgrauem Marmor.

102 S. hierzu unten Anm. 146.

103 Diese Identifikation auch schon bei Pasini, Il tesoro (wie Anm. 1), 3; Il tesoro di San Marco (wie Anm. 1), 140; Pincus, Christian Relics (wie Anm. 4), 42; Polacco, Proposte (wie Anm. 96), 133.

104 Vgl. Il tesoro di San Marco (wie Anm. 1), 117.

105 Das reliefierte Reliquiar ist 30,5 cm hoch, während die reale Höhe nur 24,5 cm beträgt. 
byzantinischen Kaiserin Irene Dukaina. ${ }^{106}$ Die Abbildung von zwei Reliquienkreuzen auf der Marmortafel legt die Annahme nahe, dass es sich bei beiden um besonders prominente Exemplare in der Dogenkirche handelte, folglich am ehesten um die beiden in den Inventaren zuvorderst genannten.

Das Kreuz auf der linken Seite kann mit an Sicherheit grenzender Wahrscheinlichkeit als dasjenige Heinrichs von Flandern identifiziert werden (Vgl. Abb. 4 a) ${ }^{107}$ Auch in diesem Fall sind die Proportionen des Kreuzes, vor allem auch dessen Doppelkreuzform, wirklichkeitsnah wiedergegeben. Bemerkenswert ist des Weiteren, dass zumindest die beiden unteren seitlichen Figuren, Maria und Johannes, abgebildet sind. Obwohl Haltung und Gestik beider Gestalten nicht dem Original entsprechen und die oberen, kleineren Figuren der Ecclesia und Synagoge nicht abgebildet sind, wird hier das Kreuz des zweiten Lateinerherrschers in Konstantinopel gemeint sein. ${ }^{108}$ Kein anderes erhaltenes oder in den Inventaren beschriebenes Reliquienkreuz kommt der Reliefdarstellung auch nur annähernd so nah wie dasjenige Heinrichs. Wahrscheinlich wurde das Kreuz, spätestens als es zu Beginn des 17. Jahrhunderts in sein Ostensorium kam und weitere Verzierungen erhielt, an seinem unteren Ende umgestaltet. Auffällig ist jedenfalls, dass die Reliquientafel am unteren Ende des vertikalen Kreuzbalkens eine Spitze zeigt, vermittels derer die Reliquie auf einen Stab gesteckt und beispielsweise bei Prozessionen umher getragen werden konnte. Mit an Sicherheit grenzender Wahrscheinlichkeit wurde diese Spitze erst angebracht, nachdem das Kreuz in lateinischen Besitz gelangt war, und sie wurde spätestens wieder entfernt, als man das Kreuz in dem Ostensorium platzierte.109 Das Relief bildet zudem die Fußstütze des Gekreuzigten ab, die, falls sie wirklich am Kreuz vorhanden war, wahrscheinlich ebenfalls im Zuge dieser Neupräsentation entfernt wurde.

106 Gallo, Il tesoro (wie Anm. 1), 276, Nr. 3 und 5. Auch unter Nr. 16 und 18 (ebd., 277) sind Kreuzreliquien in Kreuzesform erwähnt. Das Reliquiar Nr. 16, das mehrere Gegenstände beherbergte, wird jedoch als beschädigt aufgeführt, und zum Kreuzreliquiar, das erst unter Nr. 18 aufgelistet ist, wird vermerkt, dass es in camera Procuratiae aufbewahrt werde. Unter Nr. 14 erscheint zudem ein Kästchen cum duabus cruciculis (ebd.), wobei nicht klar ist, ob es sich hier um Reliquienkreuze handelt. In jedem Fall handelte es sich der Formulierung nach lediglich um kleine, also wenig repräsentative Kreuze.

107 Diese Identifikation auch bei Pincus, Christian Relics (wie Anm. 4), 42.

108 Danielle Gaborit-Chopin hielt es wegen des Fehlens der oberen Figuren für fraglich, ob mit dem Reliefkreuz links das Heinrichskreuz gemeint ist; Hellenkemper (Hrsg.), Schatz von San Marco (wie Anm. 23), 256. Das Argument wird dort (ebd., 252) jedoch durch die unzutreffende Meinung untermauert, das Heinrichskreuz sei in den Inventaren vor 1402 nicht aufgeführt.

109 Jannic Durand hat aufgrund der Maße des Heinrichskreuz wahrscheinlich gemacht, dass es eines von insgesamt drei Reliquienkreuzen war, die sich einst in der um 1240 nach Paris transferierten, großen Staurothek aus dem byzantinischen Kaiserpalast befunden hatten; vgl. Le trésor de la Sainte-Chapelle (wie Anm. 74), Nr. 17, bes. 64. Vgl. zu dieser Staurothek auch Durand, La relique impériale (wie Anm. 50), 100-105. Mit der Spitze, die ohnehin gänzlich untypisch für byzantinische Reliquienkreuze wäre, hätte das Kreuz nicht in das für sie vorgesehene Kompartiment der Staurothek gepasst. 
Die Abbildung des Heinrichskreuzes auf der Reliquientafel reflektiert dessen privilegierten Rang in San Marco, wenngleich dieses Kreuz, wie oben mit Blick auf die mittelalterlichen Schatzinventare begründet wurde, sicher nicht dasjenige war, welches mit der Feuerprobe von 1230 assoziiert wurde. Letzteres wird, wie man annehmen darf, wichtig genug für eine Abbildung auf der Reliquientafel gewesen sein, und so kann es sich bei ihm folglich nur um das vom Betrachter aus rechts dargestellte Kreuz handeln (Vgl. Abb. 6 a-b). Es hat auffälligerweise die für Kreuze aus dem byzantinischen Osten eher ungewöhnliche Form eines ,lateinischen“ Kreuzes mit nur einem Querbalken, und genau dieses Merkmal kennzeichnet auch das oben bereits beschriebene Irenenkreuz. ${ }^{110}$ Der Bildhauer hat sogar die metallene, leicht profilierte Basis unter dem vertikalen Balken im Relief angedeutet, wenngleich er auf eine Wiedergabe der ornamentierten bzw. beschrifteten Balkenenden verzichtet hat. Das Kreuz steht auf einer sich nach unten hin verbreiternden Basis, die wie die Spitze am Heinrichskreuz heute nicht mehr vorhanden ist. Derartige Vorrichtungen aus Edelmetall zur Aufstellung von Reliquien waren, zumindest im mittelalterlichen Westen, durchaus üblich. ${ }^{111}$ Es ist anzunehmen, dass die Basis abnehmbar war, so dass das Kreuz, wenn es nicht gerade zur Verehrung aufgestellt war, in seine in beiden Schatzinventaren beschriebene Staurothek gelegt werden konnte. Das Relief bildet die beiden Kreuze annähernd in ihrer Originalgröße ab, wobei es sogar der Tatsache Rechnung trägt, dass das Irenenkreuz in der Realität geringfügig kleiner ist als dasjenige Heinrichs von Flandern. ${ }^{112}$

Oben links und rechts sind zwei weitere Reliquiare abgebildet (Abb. 9 b-c). Auffällig ist, dass sie in deutlich geringerer Größe als die drei Herrenreliquien in der vorderen Bildebene erscheinen, womit visuell eine klare Hierarchisierung erfolgte. Zudem erscheinen die beiden oberen Artefakte vereinzelt im Bildraum, während die beiden Kreuze und die Engel mit dem Blut-Ostensorium auf einer einheitlichen ,Bodenlinie“ situiert sind. Dazu, was die beiden kleineren Gegenstände abbilden, hat es verschiedene Äußerungen gegeben, ohne dass allerdings je genauer auf Art und Aussehen der Objekte eingegangen worden wäre. Debra Pincus identifizierte das Artefakt vom Betrachter aus links als den Täuferschädel und dasjenige rechts als den Arm des heiligen Georg, weil beide Reliquien in den mittelalterlichen Quellen ausdrücklich als Kreuzzugsbeute der Venezianer von 1204 erwähnt werden. ${ }^{13}$ Dieser Annahme ist zuzustim-

110 Auch Pasini, Il tesoro (wie Anm. 1), 3, und Pincus, Christian Relics (wie Anm. 4), 43, sahen in dem Kreuz rechts das der Kaiserin Irene abgebildet, ohne es allerdings mit dem Schatzbrand in Verbindung zu bringen.

111 Ähnliche Standfüße an Reliquienkreuzen zeigen einige frühe bildliche Darstellungen des Schatzes der Pariser Ste-Chapelle seit dem frühen 14. Jahrhundert; vgl. Le trésor (wie Anm. 74), Nr. 24 u. Nr. 26-30. Es handelt sich auch in diesen Fällen um Vorrichtungen, die den byzantinischen Reliquien erst nach ihrer Ankunft im Westen zugefügt worden sind.

112 Das reliefierte Heinrichskreuz ist 29,5 cm hoch, das Irenes 27,5 cm. S. zu den Maßen der originalen Kreuze oben Anm. 48.

113 Pincus, Christian Relics (wie Anm. 4), bes. 43f. Zu den Quellen ausführlich weiter unten. 
men, wobei der Zeugniswert des Reliefs für die einstige Präsentation der Reliquien und ihr Aussehen bislang unterschätzt wurde.

Oben in der Mitte links ist ein kastenförmiges Reliquiar abgebildet, dessen Deckel

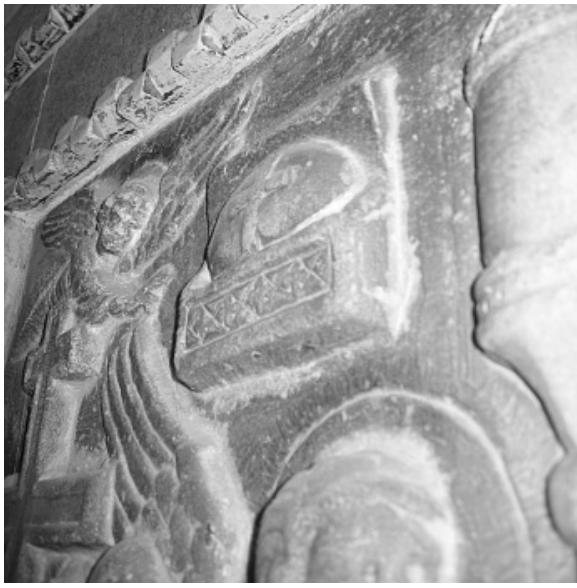

Abb. 9b: Reliquientafel im sog. Andito Foscari, S. Marco, Venedig; Detail des Schädelreliquiars (Foto: K. Krause)

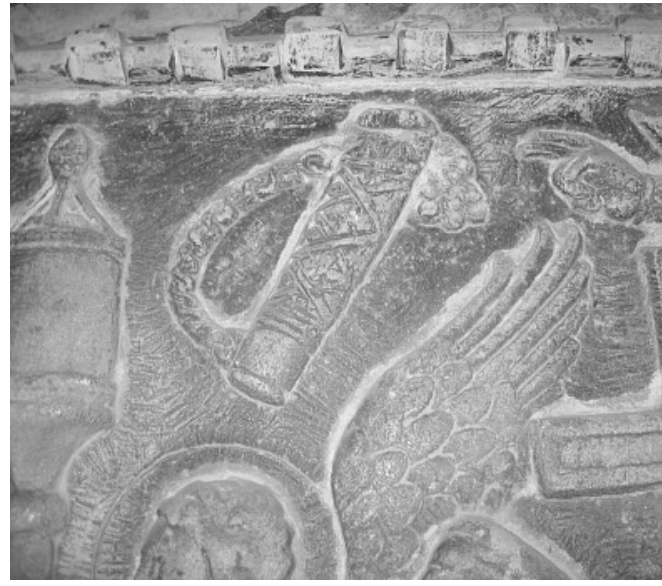

Abb. 9c: Reliquientafel im sog. Andito Foscari, S. Marco, Venedig; Detail des Olifanten-Reliquiars mit dem Arm des hl. Georg (Foto: K. Krause)

geöffnet und sogar leicht nach vorn gekippt ist, wodurch die Reliquie stärker ins Blickfeld des Betrachters gerückt erscheint (Abb. 9 b). ${ }^{114}$ Im Innern liegt, gut sichtbar, ein oval geformter plastischer Gegenstand, der mit einem großen, erhabenen Kreuz verziert ist. Es ist eindeutig, dass das ovale Objekt eine Schädelreliquie abbildet, und zwar tatsächlich eine, die aus Byzanz stammte. Von dort gelangten im Mittelalter zu verschiedenen Zeiten heilige Häupter in den Westen. ${ }^{15}$ Wie mehrere noch mit ihren ursprünglichen Zierden erhaltene Exemplare nahe legen, waren solche Schädelreliquien vielfach mit metallenem Dekor versehen, der direkt an dem Knochen befestigt wurde. Bei mehreren Exemplaren gehen von einem zentralen Medaillon mit der Büste des jeweiligen Heiligen kreuzförmig Bänder aus, beispielsweise bei der Schädelkalotte des H1. Akyndinos, die 1204 wahrscheinlich aus der Kirche der H1l. Kosmas und Damian in die Abtei von Rosières im Jura gelangte (Abb. 10). ${ }^{116}$ Ein im Zentrum appliziertes

114 Interessant ist, dass die Schmalseiten des Kastens nicht rechteckig geformt sind, sondern das Reliquiar in der Darstellung wie ein längs in der Mitte durchgeschnittener Schrein mit Satteldach wirkt. Möglicherweise lässt dies Rückschlüsse auf die Form des originalen Kastens zu.

115 Zuerst ausführlicher zu byzantinischen Schädelreliquien und Arten ihres Dekors sowie ihrer Präsentation Rainer Rückert, Zur Form der byzantinischen Reliquiare, in: Münchener Jahrbuch der bildenden Kunst 8, 1957, 8-20; jüngst Gia Toussaint, Konstantinopel in Halberstadt. Alte Reliquien in neuem Gewand, in: Das Mittelalter 10, 2005, bes. 40 u. 42f.

116 Rückert, Reliquiare (wie Anm. 115), 7f.; Byzance (wie Anm. 78), Nr. 226; Toussaint, Halber- 


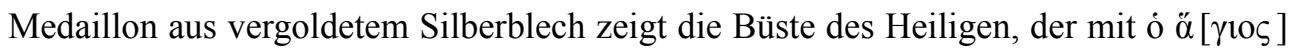
AK IN $\triangle$ INO C tituliert wird. Von dem Medaillon gingen in Kreuzform einst vier Stege aus vergoldetem Kupfer aus, von denen drei erhalten sind. In prinzipiell ähnlicher Wei-

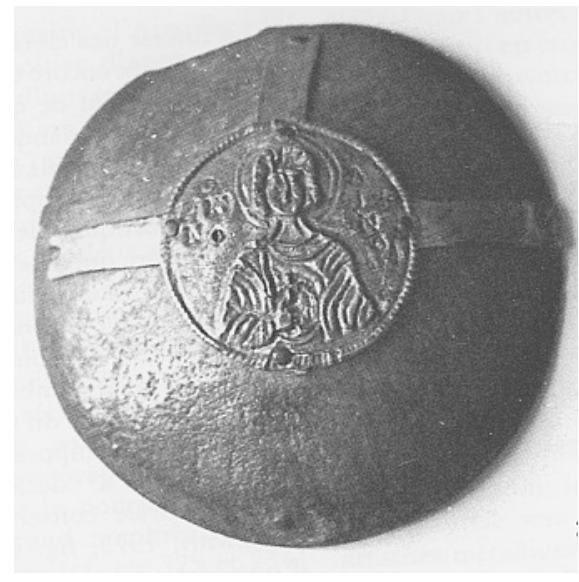

Abb. 10: Byzantinische Schädelreliquie des hl. Akyndinos, Saint-Just, Arbois (Byzance [wie Anm. 78], Nr. 226)

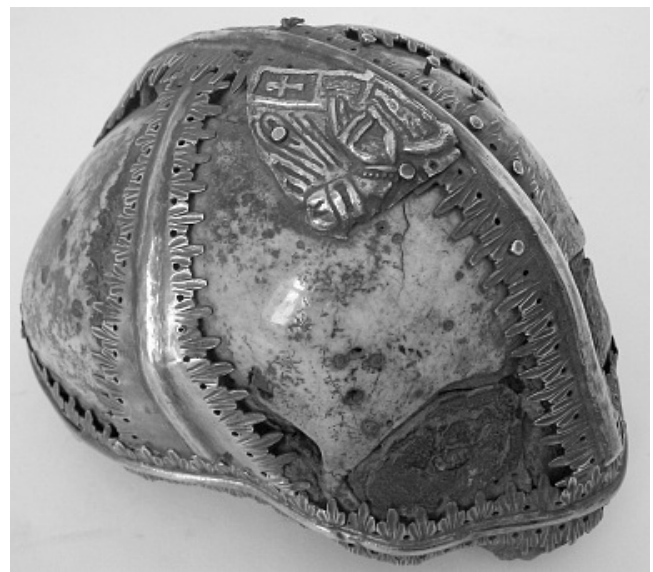

Abb. 11: Byzantinische Schädelreliquie Jakobus d. J. im Domschatz von Halberstadt (Foto: G. Toussaint)

se, wenngleich aufwendiger, ist die Schädelreliquie des Apostels Jakobus d. J. im Dom zu Halberstadt dekoriert, die 1205 Bischof Konrad von Krosigk aus Konstantinopel mitbrachte (Abb. 11). ${ }^{117}$ Auch hier befindet sich im Zentrum der Kalotte eine in Resten erhaltene Büste des Heiligen, die auf dem Schnittpunkt von sich überkreuzenden, ornamentierten Bändern appliziert wurde. ${ }^{118}$ Kreuzförmig angeordnete Bänder aus Metall stellten in Byzanz offenbar einen durchaus konventionellen Dekor für Schädelreliquien dar, wie die erwähnten Exemplare und mehrere weitere bezeugen. ${ }^{119}$ Daher erscheint der Schluss plausibel, dass mit dem erhabenen Kreuz auf dem rundlichen Objekt links im venezianischen Relief eben genau eine solche Metallapplikation auf einer Schädelkalotte angedeutet ist. Folglich war in der Markuskirche um 1300 in der Tat eine Schä-

stadt (wie Anm. 115), 42. Bis 1990/91 befand sich die Reliquie in Arbois, St-Just, wo sie in jenem Winter einem Diebstahl zum Opfer fiel; Byzance (wie Anm. 78), Nr. 226.

117 Johanna Flemming u. a. (Hrsg.), Dom und Domschatz zu Halberstadt. Berlin 1972, 159.

118 Rückert, Reliquiare (wie Anm. 115), 10-12; Toussaint, Halberstadt (wie Anm. 115), 40-42.

119 Bei der Schädelreliquie Symeons des Styliten, die sich heute im Kamaldulenserkloster bei Arezzo befindet, wurde im 10. Jahrhundert ein griechisches Distichon auf vier Bänder verteilt, die von einem großen zentralen Medaillon ihren Ausgang nehmen. Letzteres wird einst ein byzantinisches Büstenbild des Heiligen beherbergt haben. $\mathrm{Zu}$ dieser Reliquie und ihrem Epigramm ausführlich Guillou, Recueil (wie Anm. 49), Nr. 16, mit Taf. 6. Weitere Beispiele für Schädelreliquien mit Kreuzbanddekor sind diejenige des Hl. Mamas in Langres, Rückert, Reliquiare (wie Anm. 115), 14, und die des Hl. Sebastian in Ebersberg, ebd., 29, mit Abb. 15. 
delreliquie aus Byzanz vorhanden, nach dem Zeugnis der venezianischen Quellen diejenige des Täufers.

Das fünfte und letzte auf dem Relief abgebildete Artefakt erscheint als ein Gegenstand, der zunächst an ein Füllhorn oder einen Köcher ${ }^{120}$ erinnert (Abb. 9 c). An zwei seitlichen Ösen ist ein geflochtener Trageriemen oder eine Kette aus Metallgliedern befestigt. Sowohl Hahnloser als auch Pincus vermuteten, bei dem Gegenstand müsse es sich um das Reliquiar für den Arm des heiligen Georg handeln. ${ }^{121}$ Von dieser Armreliquie ist in den venezianischen Quellen erstmals im 14. Jahrhundert die Rede, wobei das Inventar von 1325 das früheste Zeugnis darstellt. Dort findet sich an dritter Stelle der Vermerk, dass zusammen mit dem Kreuz Heinrichs von Flandern - in demselben Kasten - der Arm des heiligen Georg aufbewahrt werde, welcher ,von glanzlos weißem Silber umgeben“" sei. ${ }^{122}$
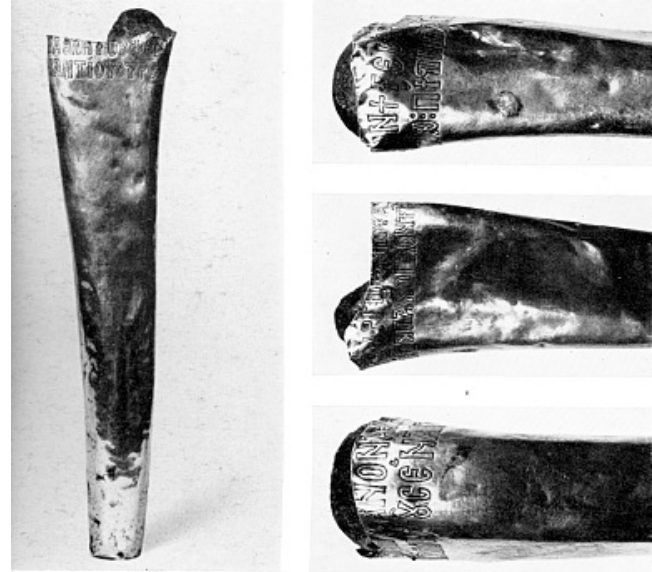

Abb. 12: Byzantinische Armreliquie des hl. Georg aus dem Schatz von S. Marco, Venedig (Fondazione Giorgio Cini, Venedig)

Mit dieser wenig euphorischen Be-

schreibung ist offenbar das einfache Silberblech aus Byzanz gemeint, in das die Armreliquie eingeschlagen ist (Abb. 12). Diese Verkleidung wurde an ihrem oberen Ende mit einer griechischen Majuskelinschrift versehen, die aus der Perspektive des Besitzers bzw. Trägers der Armreliquie verkündet:

„Die Reliquie des Athleten [Gotteskriegers] Georg, die fromme Universalwaffe tragend, vertreibe ich die Feinde." 123

Aufgrund des Wortlauts liegt die Annahme nahe, dass die Reliquie in Byzanz gezielt mit der Absicht in Silber gefasst und beschriftet wurde, um sie in Kriegen mitzuführen, eine Praxis, die für den griechischen Osten seit dem 6. Jahrhundert bezeugt ist. ${ }^{124}$ Das

120 Diese Identifikation bei Pasini, Il tesoro (wie Anm. 1), 3.

121 Il tesoro di San Marco (wie Anm. 1), 140; Pincus, Christian Relics (wie Anm. 4), 43. Beide Autoren äußern sich nicht zur Art des Behältnisses.

122 Item Crucem unam Christi, de ligno Domini, auro et argento ornatam, quae crux habet quatuor imagines ad ipsius latera positas, et est in una capsela; in qua capsela est brachium S. ${ }^{i}$ Jeorgii circundatum argento albo; Gallo, Il tesoro (wie Anm. 1), 276.

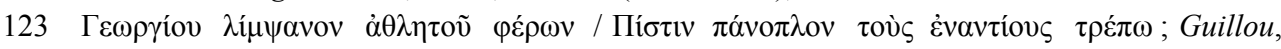
Recueil (wie Anm. 49), Nr. 101. Zu der Inschrift auch Pincus, Christian Relics (wie Anm. 4), 43; Il tesoro di San Marco (wie Anm. 1), 140; Pasini, Il tesoro (wie Anm. 1), 44.

$124 \mathrm{Zu}$ Reliquien in Kriegen z. B. Sophia Mergiali-Sahas, Byzantine Emperors and Holy Relics. 
Silberblech wurde an der Inschriftseite des Armknochens nachträglich abgeschnitten, wobei in Kauf genommen wurde, dass Teile der Buchstaben verloren gingen. Vermutlich beabsichtigte man, das Gelenkstück weiter aus seiner Verhüllung $\mathrm{zu}$ befreien, um dadurch mehr von der Reliquie selbst sehen und berühren zu können. ${ }^{125}$

Die Armreliquie befindet sich heute in einem aufwendig mit Emailplaketten dekorierten, vasenförmigen Behältnis, das in der Gesamthöhe mehr als einen halben Meter misst (Abb. 13, Tafel II 3). ${ }^{126}$ Dieses Artefakt befand sich, als das zweite Inventar am 5. September 1325 niedergeschrieben wurde, offensichtlich gerade in der Herstellung. Zumindest war der Auftrag erteilt, denn es heißt in dem Dokument: „Ebenso halten wir fest, dass der Arm des heiligen Georg mit Gold und Silber, versehen mit Email, umhüllt wird; mit einem reitenden heiligen Georg zuoberst und einem aus Silber gefertigten Fuß“.127 Es ist auf einen Blick evident, dass der Gegenstand oben in der Mitte rechts nicht das elaborierte, 1325 entworfene Reliquiar des Armknochens abbildet. Das Relief zeigt einen länglichen, schmalen Gegenstand, der sich nach oben hin leicht ver-

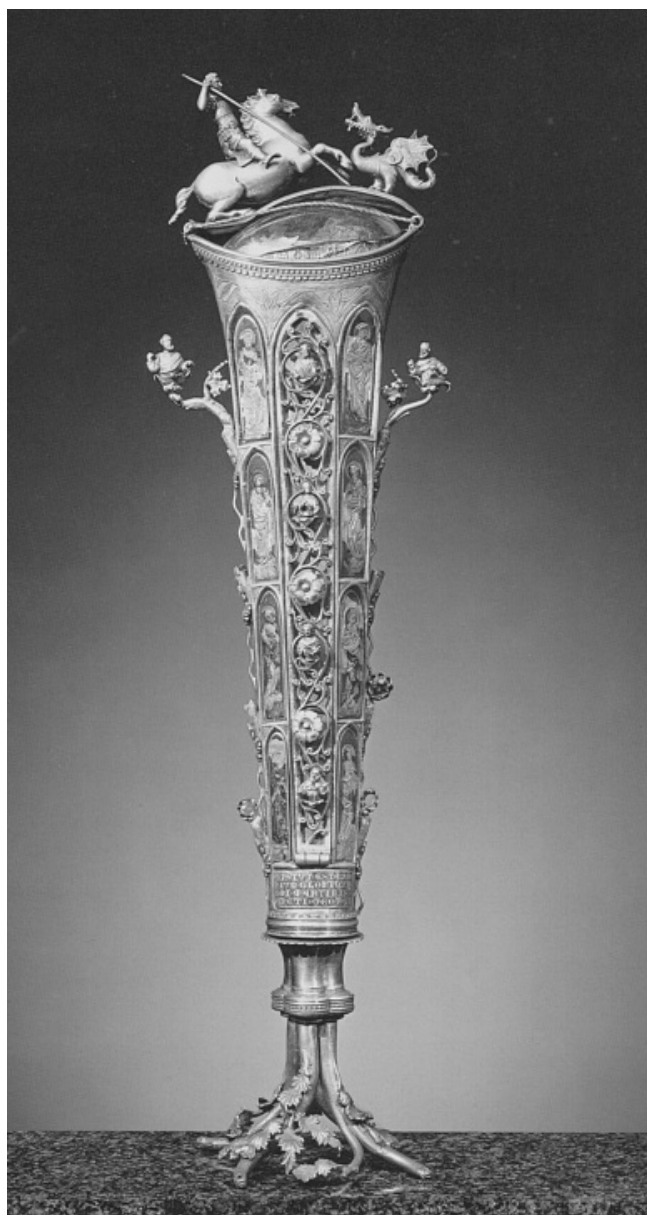

Abb. 13: Reliquiar für den Arm des hl. Georg im Schatz von S. Marco, Venedig (Fondazione Giorgio Cini, Venedig)

Use, and Misuse, of Sanctity and Authority, in: JÖB 51, 2001, 49-51, bes. 49; Michael McCormick, Eternal Victory. Triumphal Rulership in Late Antiquity, Byzantium and the Medieval West. Cambridge 1986, bes. 247 u. 314.

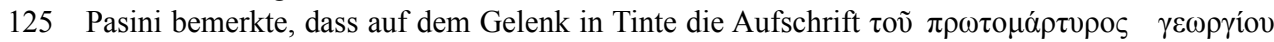
zu lesen sei; Pasini, Il tesoro (wie Anm. 1), 44, mit Kommentaren zum Wortlaut.

126 Ausführlich zu dem Reliquiar vgl. Il tesoro di San Marco (wie Anm. 1), Nr. 159; bes. auch Pasini, Il tesoro (wie Anm. 1), $43 \mathrm{f}$.

127 Item notamus quod brachium s. ${ }^{i}$ Georgii circumdatur auro et argento laboratum ad smaldum cum uno Sancto Georgio equitante a parte superiori et cum uno pede argenteo laborato; Gallo, Il tesoro (wie Anm. 1), 276, I, 4. Il tesoro di San Marco (wie Anm. 1), 163. 
breitert, und dessen Öffnung schräg verläuft. Das Objekt selbst ist mit Reliefdekor aus sich kreuzenden Bändern und stilisierten Blüten beschnitzt. Am oberen Ende ist klar zu erkennen, dass ein unregelmäßig geformter Gegenstand aus dem Behälter heraus ragt (Abb. 9 c), ein wichtiges Detail, das bislang übersehen wurde. Dieser Gegenstand erinnert stark an das aus der byzantinischen Silberverkleidung befreite Gelenkstück des Knochens (Abb. 12), was die These bekräftigt, dass es sich bei dem auf der Tafel abgebildeten Behältnis in der Tat um dasjenige handelt, welches bis 1325 den Armknochen aus Byzanz beherbergte. Von seinem oberen Rand hängen dekorativ geflochtene Bänder herab, die mittels einer Öse an dem Artefakt befestigt sind. ${ }^{128}$ Doch welche Art Behältnis ist hier eigentlich abgebildet? Antonio Pasinis Identifikation mit einem Köcher würde nicht zuletzt vor dem Hintergrund einen Sinn ergeben, dass die Reliquie in Byzanz dazu diente, in Feldzügen mitgeführt zu werden. Die Unterbringung einer Reliquie in einem (realen) Köcher wäre allerdings ungewöhnlich und für das gesamte Mittelalter meines Wissens singulär. Avinoam Shalem ging davon aus, dass es sich bei dem abgebildeten Gegenstand um einen Elefantenstoßzahn handelt, versehen mit typisch ,sarazenischen' Schnitzereien sowie mit einer Aufhängevorrichtung. ${ }^{129}$ Dieser Sichtweise möchte ich zustimmen, wenngleich auffällig ist, dass das untere Ende des Reliquiars nicht spitz zuläuft, sondern begradigt erscheint. Mehrere Dutzend elfenbeinerne Stoßzähne, die meist eine Länge von etwa 50-70 cm erreichen, sind aus dem Mittelalter erhalten. ${ }^{130}$ Sie wurden, vollständig ausgehöhlt, zumeist als Signal- bzw. Jagdhörner präpariert, wobei man ihre Spitze als das Mundstück mehr oder weniger stark begradigt hat. ${ }^{131}$ Es ist $\mathrm{zu}$ vermuten, dass das Relief in etwas übertriebener Weise eine derartig abgeflachte Spitze wiedergibt. Hörner und Stoßzähne waren im Mittelalter nicht nur begehrte Artefakte für geistliche und weltliche Schatzkammern. Sie waren, in Sekundärverwendung, auch als Reliquienbehälter beliebt, wie mehrere Textquellen seit dem

128 Es ist aufgrund der Struktur dieses Geflechts auszuschließen, dass es sich etwa um ein Textil zum Verschließen der Öffnung handelt. Martina Papiro (Berlin) verdanke ich die Idee, dass das Material des Flechtwerks vielleicht identisch mit dem des Riemens ist, der an dem Behälter befestigt ist.

129, ,...) perhaps a little clumsily drawn, is an oliphant which is hung on its upper and lower parts by a chain. On its body is a pattern which consists of intersecting lines, forming a series of lozenges. This pattern might be a stylized simplification of the ,inhabited scroll' design which is so characteristic of a large group of ,Saracenic“ oliphants“; Shalem, Islam Christianized (wie Anm. 25), 163; wiederholt in Shalem, Oliphant (wie Anm. 27), 125. Eine Assoziation des Stoßzahns mit der Georgsreliquie geschieht hier nicht.

130 Grundlegend zu geschnitzten Olifanten des Mittelalters Ernst Kühnel, Die islamischen Elfenbeinskulpturen, VIII.-XIII. Jahrhundert, Berlin 1971, 6-24; Shalem, Oliphant (wie Anm. 27); Ralph Pinder-Wilson/Avinoam Shalem, A Newly Discovered Oliphant in a Private Collection in London, in: Mitteilungen zur spätantiken Archäologie und byzantinischen Kunstgeschichte 2, 2000, 79-85. Zur Zahl der erhaltenen Olifanten und den Maßen Kühnel, Elfenbeinskulpturen, 14; Pinder-Wilson/Shalem, Oliphant, 80.

$131 \mathrm{Zu}$ den verschiedenen Verwendungarten ,sarazenischer' Olifanten Kühnel, Elfenbeinskulpturen (wie Anm. 130), 6-15; Shalem, Oliphant (wie Anm. 27), Kap. 6, bes. 80. 
11. Jahrhundert und zudem vereinzelt erhaltene Exemplare dokumentieren. ${ }^{132}$ Auch auf die Art der Zurschaustellung solcher Artefakte gibt es Hinweise: So ist beispielsweise für die Kathedrale von Canterbury um 1300 bezeugt, dass von einem Balken über dem Hauptaltar ein Reliquien-Olifant herab hing. ${ }^{133}$ In einer solchen, materiell wertvollen und schön anzusehenden Hülle konnte die mit ihrer byzantinischen Silberverkleidung unscheinbare Reliquie in Venedig ihrem Rang würdig präsentiert werden. Ob die Markuskirche um 1300 selbst über einen Olifant verfügte, der zur Unterbringung der Georgsreliquie diente, ist unbekannt. ${ }^{134}$ Möglich ist, dass sich ein solcher Stoßzahn im Besitz der Dogen befand, der verschiedenen Zwecken der Repräsentation diente, wobei die Georgsreliquie nur zu besonderen Gelegenheiten, anlässlich ihrer öffentlichen Zeigung, in ihm platziert wurde. Das vasenähnliche Gefäß, das für die Armreliquie 1325 in Auftrag gegeben wurde, wäre dieser Hypothese nach das erste eigene Reliquiar des Georgsarmes, welcher - nur mit seiner byzantinischen Silberhülle - gemäß dem zweiten Inventar noch zusammen mit dem Heinrichskreuz in einem Kasten aufbewahrt wurde. ${ }^{135}$ Das 1325 gefertigte Reliquiar (Abb. 13, Tafel II 3) ist in seiner Machart höchst ungewöhnlich, vor allem auch, weil aus dem Hoch- und Spätmittelalter Dutzende ,konventioneller' Armreliquiare erhalten sind, die einen menschlichen Arm mit nach oben zeigender bzw. segnender Hand nachbilden. Das Georgsreliquiar ist in seiner aktuellen Präsentation zusammen mit vier solchen herkömmlichen Armreliquiaren in einer Vitrine aufgestellt, wodurch seine extravagante Form noch betont wird. Es ist zu vermuten, dass es die alte Elefantenzahn-Hülle der Armreliquie gewesen ist, die die Form des neuen Behälters inspirierte: Schließlich handelt es sich bei letzterem ebenfalls um ein nach oben hin breiter werdendes Gefäß mit runder bzw. ovaler Öffnung, in der das Gelenkstück des Knochens sichtbar ist.

Wegen der Abbildung der Heilig-Blut-Ampulle schon mit ihrer höchst wahrscheinlich erst nach Ranieris Brief angefertigten Goldfassung und des Georgsarmes noch in seinem alten Olifanten-Reliquiar lässt sich die Entstehung des Reliefs auf die Zeit zwischen 1265 und 1325 eingrenzen. Die Tatsache, dass insgesamt fünf Reliquien aus

132 Vgl. bes. Braun, Reliquiare (wie Anm. 29), 249-254; Kühnel, Elfenbeinskulpturen (wie Anm. 130), 14; Gauthier, Strassen (wie Anm. 83), 37f. u. Nr. 15; Ornamenta Ecclesiae (wie Anm. 43), Bd. 3, Nr. H 13, H 13A; Wilfried Seipel (Hrsg.), Schätze der Kalifen. Islamische Kunst zur Fatimidenzeit. Wien 1999, Nr. 232, bes. 231.

133 Kühnel, Elfenbeinskulpturen (wie Anm. 130), 14 u. 85, Nr. 5; Gauthier, Strassen (wie Anm. 83), 38; Shalem, Oliphant (wie Anm. 27), 126 u. ebd., 125-130 zu vergleichbaren Arten der Präsentation von Olifanten.

134 Mit dem im Inventar von 1325 verzeichneten „Horn eines Einhorns“ (Cornum unum de unicorno ornatum de argento; Gallo, Il tesoro, wie Anm. 1, 277, II, 3), das an hohen Festtagen auf dem Hochaltar ausgestellt wurde (ebd., 277, II), ist vermutlich kein Elefantenstoßzahn gemeint, sondern das dünne und gerade Horn eines Narwals; vgl. zu derartigen noch erhaltenen Artefakten im Schatz von San Marco Il tesoro di San Marco (wie Anm. 1), Nr. 113; Gallo, Il tesoro (wie Anm. 1), 267-272.

135 S. das Zitat oben in Anm. 122. 
Konstantinopel dargestellt sind und nicht nur die drei, von denen im Mai 1265 Ranieri Zen dem Papst berichtete, legt die Annahme nahe, dass das Relief erst einige Zeit nach diesem Datum angefertigt wurde. Dafür spricht auch der Umstand, dass Ranieri noch

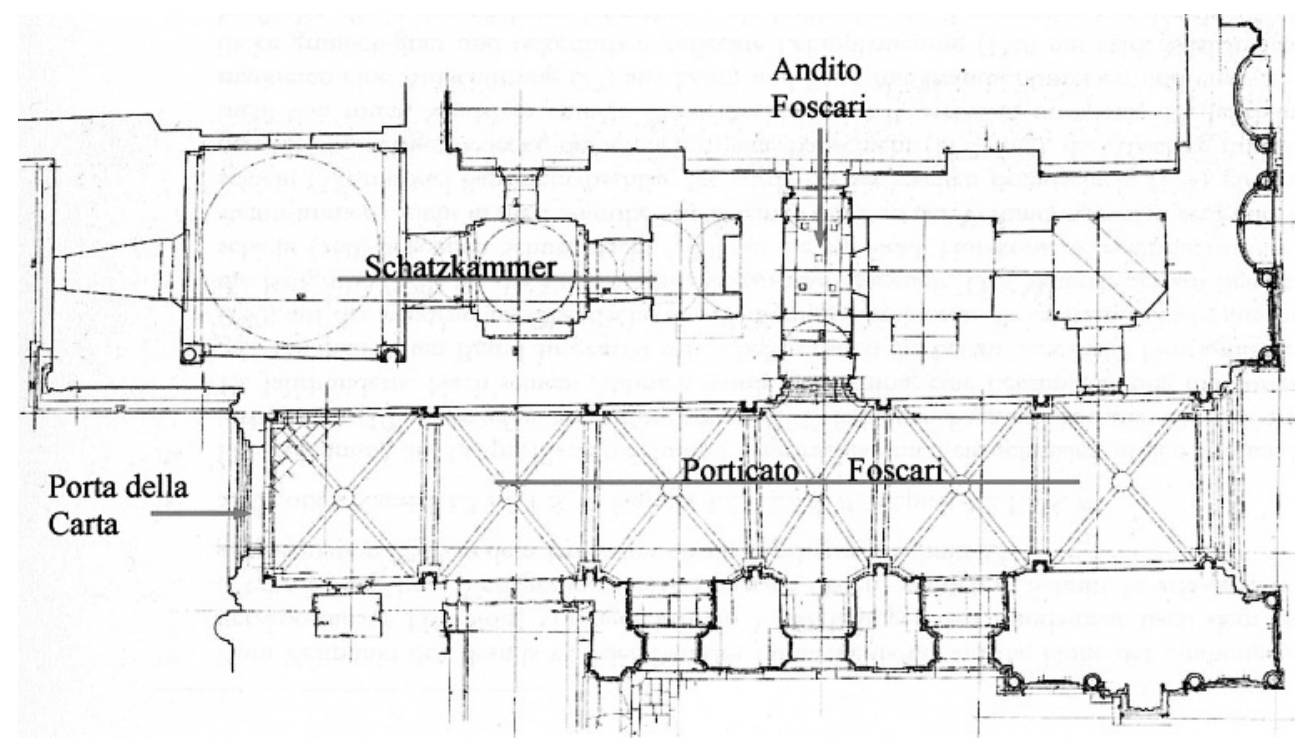

Abb. 14: Grundriss der südlichen Annexräume des Südarms von S. Marco und des sog. Porticato Foscari (unter Verwendung einer Zeichnung von F. Becker/B. Meissner, Okt. 1997-Feb. 1998; nach Cecchi, La basilica [wie Anm. 136], 90)

dem Reliquienkreuz den ersten Rang eingeräumt hatte, das Relief aber die Blutampulle privilegiert, die auch in den Inventaren an erster Stelle erscheint. Die Entstehung des Reliefs in einem nicht unbeträchtlichen zeitlichen Abstand zum Brief des Dogen anzusiedeln drängt sich nicht zuletzt deshalb auf, weil zwei der Reliquien - das Heinrichskreuz und der Georgsarm - überhaupt erstmals im zweiten Schatzinventar genannt sind. Daher erscheint eine weitere Eingrenzung der Entstehungszeit der Tafel möglich, nämlich auf die Jahrzehnte zwischen 1283 und 1325. Die Tatsache, dass der Georgsarm, wie das zweite Inventar nahe legt, erst 1325 sein erstes eigenes Reliquiar erhielt, könnte ein Indiz dafür sein, dass die Reliquie überhaupt erst wenig vorher in die Dogenkirche gelangt ist.

Die bisherige Forschung hat nie in Frage gestellt, dass der Platz, an dem sich das Relief heute befindet, identisch mit dessen ursprünglichem Anbringungsort ist (Abb. 14-15, Tafel II 4). Zwar ist dies nicht mit Sicherheit auszuschließen, jedoch erscheinen Zweifel an dieser Sichtweise durchaus angebracht. Eindeutig handelt es sich beim Andito Foscari um einen nachträglichen Einbau, denn mit seinem hohen Tonnengewölbe verdeckte man die unteren Partien eines der ursprünglichen Fenster des Süd- 
arms (Abb. 15, Tafel II 4).136 Daher erscheint es möglich, dass der Gang etwa gleichzeitig mit der großen gotischen Fensterrosette des südlichen Querarmes errichtet wurde, deren Einfügung um 1300 angenommen wird.137 Mit dieser hypothetischen

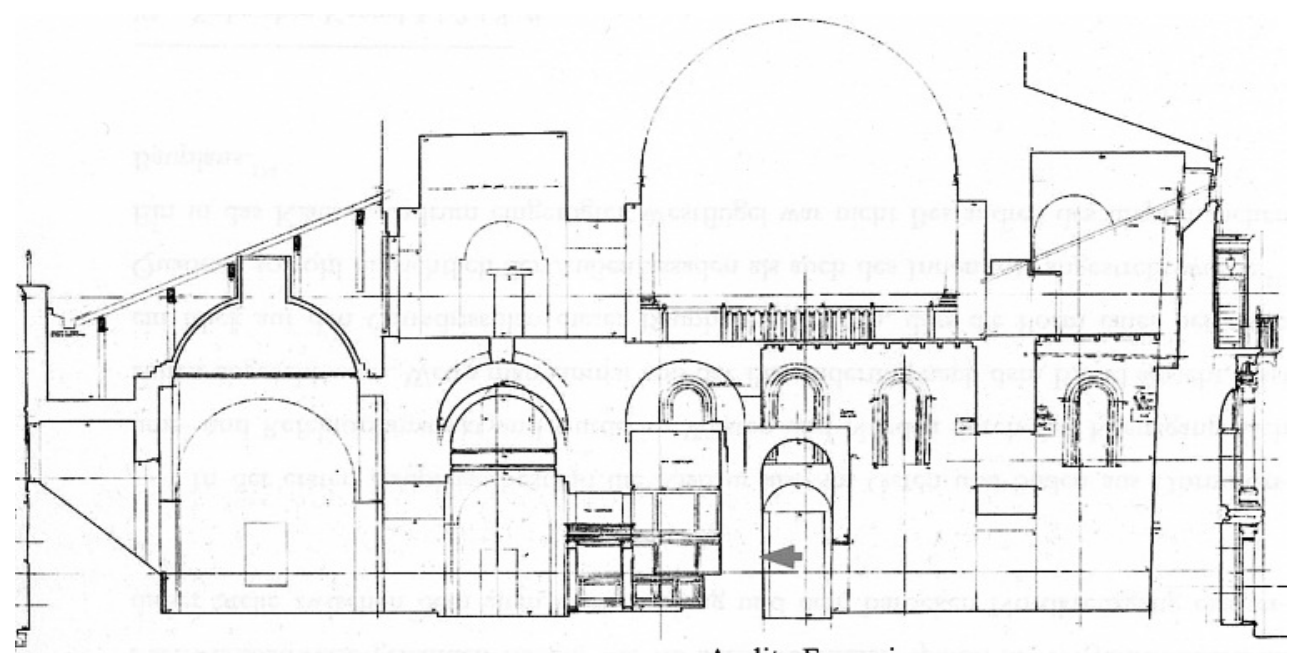

Andito Foscari

$A b b$. 15: Längssschnitt durch die südlichen Annexräume des Südarms von S. Marco; der Pfeil markiert den Anbringungsort des Reliquienreliefs (unter Verwendung einer Zeichnung von F. Becker/B. Meissner, Okt. 1997-Feb. 1998; nach Cecchi, La basilica [wie Anm. 136], 91)

Entstehungszeit gut in Einklang zu bringen wäre die Freskierung der oberen Wandpartien des Korridors sowie seines Gewölbes. Bei dieser nur sehr fragmentarisch erhaltenen Ausmalung handelte es sich um einen aus vier Szenen bestehenden kleinen Zyklus mit der Verkündigung an Maria sowie der Geburt, der Kreuzigung und der Grablegung Christi, überfangen von einem Sternenhimmel. Ettore Merkel hat diese Ausmalung mit der Tätigkeit der Giotto-Werkstatt in Norditalien in Verbindung gebracht, wobei angesichts des beklagenswerten Zustandes der Fresken eine exaktere Einordnung als allgemein in die erste Hälfte des 14. Jahrhunderts kaum möglich ist. ${ }^{138}$ Die anzunehmende Bau- und Ausmalungschronologie des Korridors würde grundsätzlich die Vermutung

136 Roberto Cecchi, La basilica di San Marco. La costruzione bizantina del IX secolo. Permanenze e trasformazioni. Venedig 2003, Abb. 36 (vgl. Abb. 15 des vorliegenden Beitrags).

$137 \mathrm{Zu}$ der Fensterrose Herbert Dellwing, Il traforo, in: L'architettura gotica veneziana. Atti del Convegno internazionale di studio. Venezia, 27-29 novembre 1996, Venedig 2000, 195-203. Die Datierung wird dort (ebd., 195) allerdings nicht begründet.

138 Ettore Merkel, Gli affreschi dell',Andito Foscari“ a San Marco, in: Quaderni della Soprintendenza ai Beni Artistici e Storici di Venezia 7, 1987, 63-71. Zur Datierung ebd., bes. 65, mit dem Hinweis, dass eine exaktere Datierung und Zuschreibung der Fresken noch der Klärung bedürfen. Vgl. auch Ettore Merkel, Affreschi poco noti a San Marco, in: Renato Polacco (Hrsg.) 
zulassen, dass die Fresken und das Reliquienrelief an der Wand darunter Teile einer einheitlichen Dekorationskampagne sind, die aus unbekannten Gründen im Ansatz stecken blieb. Die unteren Wandpartien des Korridors wurden, mit dem Reliquienrelief als einzigem Dekor, ziegelansichtig belassen. Es muss in aller Deutlichkeit gesagt werden, dass der Gang zu den am wenigsten repräsentativen Örtlichkeiten in der gesamten Markuskirche gehört. Er dient heute als Abstellraum für defekte Kirchenbänke und Altpapier. Wenngleich sich die Ausmalung im 14. Jahrhundert um ein Vielfaches prächtiger präsentiert haben wird, mutet bereits das gewählte Medium im Vergleich zu der reichen Mosaizierung von San Marco bescheiden an. Diesen Eindruck bestätigt auch der Fußboden des Ganges: Während die Böden im Innern von San Marco und in den meisten anderen Annexräumen der Kirche bekanntlich mit aufwendigem opus sectile ausgestattet worden sind, besitzt der Andito Foscari lediglich einen einfachen, mit Steinplatten belegten Boden. ${ }^{139}$ Alles in allem vermittelt der Korridor den Eindruck eines Provisoriums.

Verschiedene Forscher haben argumentiert, dass der Andito Foscari schon im Mittelalter als einer der Haupteingänge in die Kirche für die Regierungsangehörigen gedient habe und regulär bei Prozessionen genutzt worden sei. Mit diesen prominenten Funktionen des Korridors begründeten sie die Platzierung des Reliefs und erklärten gleichzeitig dessen Abnutzungsspuren. ${ }^{140}$ Sofern eine so geartete Nutzung des Ganges überhaupt mit konkreten Textquellen belegt worden ist, datieren diese frühestens aus dem 16. Jahrhundert und äußern sich zudem nicht präzise dazu, wer genau diesen Durchgang zu welchen Gelegenheiten benutzte. ${ }^{141}$ Gestatten schon die frühneuzeitlichen Dokumente zur Funktion der Passage keine genauen Aussagen, so fehlen Quellen für die mittelalterliche Nutzung vollständig. ${ }^{142}$ Angesichts der räumlichen Enge des Korridors sowie seiner wenig repräsentativen, zudem unvollendet gebliebenen Ausstattung er-

Storia dell'arte marciana: i mosaici. Atti del Convegno internazionale di studi Venezia, 11-14 ottobre 1994. Venedig 1994, 135-145, bes. 140-142.

139 Teils handelt es sich hierbei um Steinplatten in Zweitverwendung: Leicht schräg, unmittelbar in der Mitte des Ganges befindet sich die Bodenplatte eines ehemaligen Altars mit fünf Stützen; vgl. Cecchi, La basilica (wie Anm. 136), Abb. 34. Es ist höchst unwahrscheinlich, dass an dieser Stelle, unmittelbar vor dem Eingang in den Südarm, jemals ein Altar gestanden hat.

140 Sinding-Larsen, Christ (wie Anm. 96), 161, 199, 211f. u. 215; Pincus, Christian Relics (wie Anm. 4), bes. 39f. u. 49; Polacco, Proposte (wie Anm. 96), bes. 135-137.

141 Es handelt sich um das Zeremonienbuch des Bartolomeo Bonifacio (1564) und Stringas Beschreibung von San Marco; Giovanni Stringa, La chiesa di San Marco. Cappella del Serenissimo Principe di Venetia. Venedig 1610. Zu den einschlägigen Textstellen s. die Literaturverweise oben in Anm. 96. Eine von Debra Pincus, Arco Foscari (wie Anm. 93), 70-71, zitierte Quelle des späten 15. Jahrhunderts bezieht sich m. E. nicht auf den Andito Foscari, sondern auf das Portal im Süden des Sanktuariums von San Marco, bei der Cappella di San Clemente.

142 Sinding-Larsen, Christ (wie Anm. 96), 161, vermutete, allerdings ohne Begründung, dass ,prior to the fourteenth century" der Doge durch diesen Gang die Markuskirche betreten habe. 
scheint die von der Forschung vermutete zeremonielle Einbindung, erst recht bei Prozessionen mit einem gewissen Menschenaufkommen, wenig überzeugend.

Eines der Hauptcharakteristika des Reliquienreliefs ist seine demonstrative, ja geradezu plakative Ikonographie (Abb. 9 a, Tafel II 1). Daher erscheint es nicht weit hergeholt, es sich ursprünglich an einem Ort vorzustellen, wo möglichst viele Bürger und Besucher Venedigs in Stein portraitiert sehen würden, welche von Gott und seinen Engeln gesegneten Reliquienschätze die Markuskirche in ihrem Inneren birgt. Überdies ermöglichten die steinernen Repliken, stellvertretend für das Heiltum selbst, letzteres mit Händen zu greifen. Dass dies von vielen beherzt wurde, darauf deuten die starken Abnutzungsspuren der abgebildeten Artefakte. Deshalb ist davon auszugehen, dass sich die Tafel über längere Zeit hinweg an exponierter Stelle befand - an einem Ort, der wesentlich stärker frequentiert war als es der Andito Foscari aufgrund seiner Enge und seiner Lage je gewesen sein kann. Eine Platzierung des Reliefs an einer der zum öffentlichen Bereich hin ausgerichteten Fassaden der Dogenkirche wäre gut vorstellbar. Aus verschiedenen Gründen bieten sich für eine hypothetische Verortung am ehesten die südlichen Fassadenpartien von San Marco an, vielleicht die Fassaden der Schatzkammer (Abb. 16, Tafel II 5). ${ }^{143}$ Nicht zuletzt die Tatsache, dass die auf dem Relief abgebildeten Reliquien von den Dogen stolz als Beutestücke aus Konstantinopel propagiert wurden, erscheint bedeutsam: Gerade deshalb hätte eine ursprüngliche Platzierung in direkter Nachbarschaft mit den übrigen an und vor der Südfassade versammelten Spolien aus Konstantinopel und dem östlichen Mittelmeerraum durchaus Sinn gemacht.144 Über eine exaktere Lokalisierung des Reliefs in diesem Bereich kann nur spekuliert werden, denn ein nicht geringes Problem besteht in der Tatsache, dass sowohl die Datierung als auch die zeitliche Abfolge der An- und Umbauten im Süden vor der Kirche - also der Schatzkammer und des Baptisteriums sowie eventueller Vorgängerbauten -

143 Hier hätte sich das Relief zum einen in räumlicher Nähe zu den realen Reliquien befunden, zum anderen bieten diese beiden Fassaden - zumindest im heutigen Zustand - genügend Freiflächen, wo theoretisch einst das Relief platziert gewesen sein könnte.

$144 \mathrm{Zu}$ den Spolien z. B. Otto Demus, The Church of San Marco in Venice. History, Architecture, Scultpure. Washington (DC) 1960, 113 u. 145; Patricia Fortini Brown, The Self-Definition of the Venetian Republic, in: Anthony Molho u. a. (Hrsg.), Athens and Rome, Florence and Venice. City States in Classical Antiquity and Medieval Italy. Stuttgart 1991, 521f.; Marina Belozerskaya/Kenneth Lapin, Antiquity Consumed. Transformations at San Marco, Venice, in: Alina Payne u. a. (Hrsg.), Antiquity and its Interpreters. Cambridge u. a. 2000, bes. 90-92; Rebecca Müller, Sic hostes Ianua frangit. Spolien und Trophäen im mittelalterlichen Genua. Weimar 2002, 55f.; jüngst Robert S. Nelson, High justice: Venice, San Marco, and the spoils of 1204, in: Panayotis L. Vocotopoulos (Hrsg.), Byzantine Art in the Aftermath of the Fourth Crusade. International congress, March 9-12, 2004. Athen 2007, 143-151. 


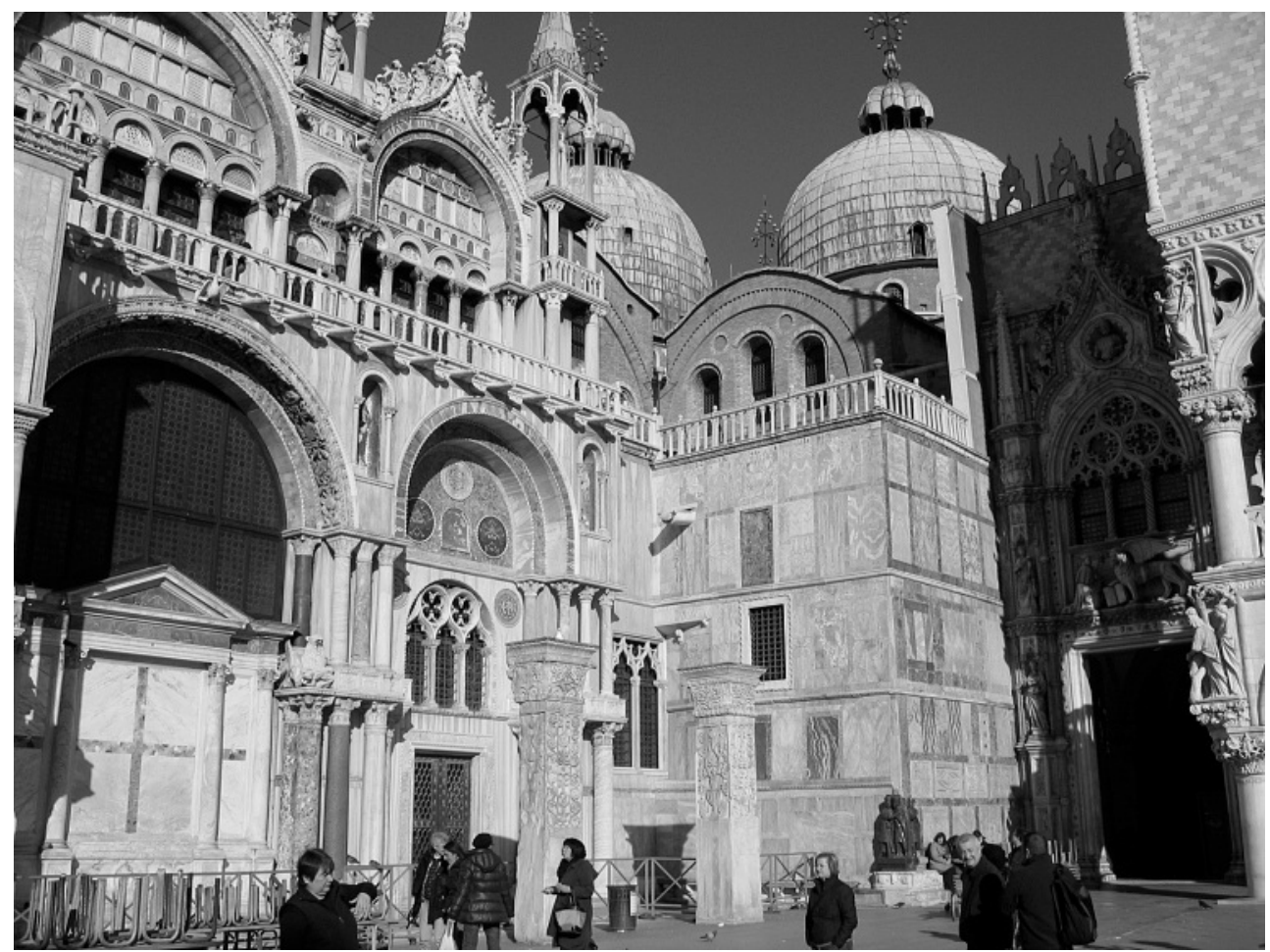

Abb. 16: S. Marco, Venedig, von Südwesten (Foto: K. Krause)

weitgehend auf Hypothesen basieren. ${ }^{145}$ Für die Jahrzehnte um 1300 gleichfalls schwer einzuschätzen ist die bauliche Situation des Palastareals vor dem Südarm der Kirche bzw. im Bereich vor deren Schatzkammer, dort, wo sich heute die ab 1438 errichtete Porta della Carta mit dem sich ihr anschließenden Porticato Foscari befindet (Abb. 14). Möglicherweise waren es gerade diese Baumaßnahmen im Quattrocento, die die Abnahme des Reliefs erforderten. ${ }^{146}$ Von mindestens einer nachträglichen Versetzung des

145 Vgl. das kritische Referat des Forschungsstandes bei Gabriele Horn, Das Baptisterium der Markuskirche in Venedig. Baugeschichte und Ausstattung. Frankfurt a. M. u. a. 1991, 37-56. In jüngerer Zeit Ettore Vio, Dai restauri del battistero della basilica di San Marco. Alcune indicazioni per la facciata sud, in: Scienza e tecnica del restauro della Basilica di San Marco. Venedig 1999, Bd. 2, 515-527.

146 Ein Indiz hierfür könnte sein, dass man für die farbliche Fassadengestaltung des Porticato in großem Umfang Rosso di Verona verwendete, aus dem auch die äußeren, sehr wahrscheinlich später zugefügten Rahmenleisten des Reliquienreliefs an seinem derzeitigen Anbringungsort bestehen (vgl. oben Anm. 102). Zu den Baumaßnahmen am Palasteingang s. oben die Literaturangaben in Anm. 93. 


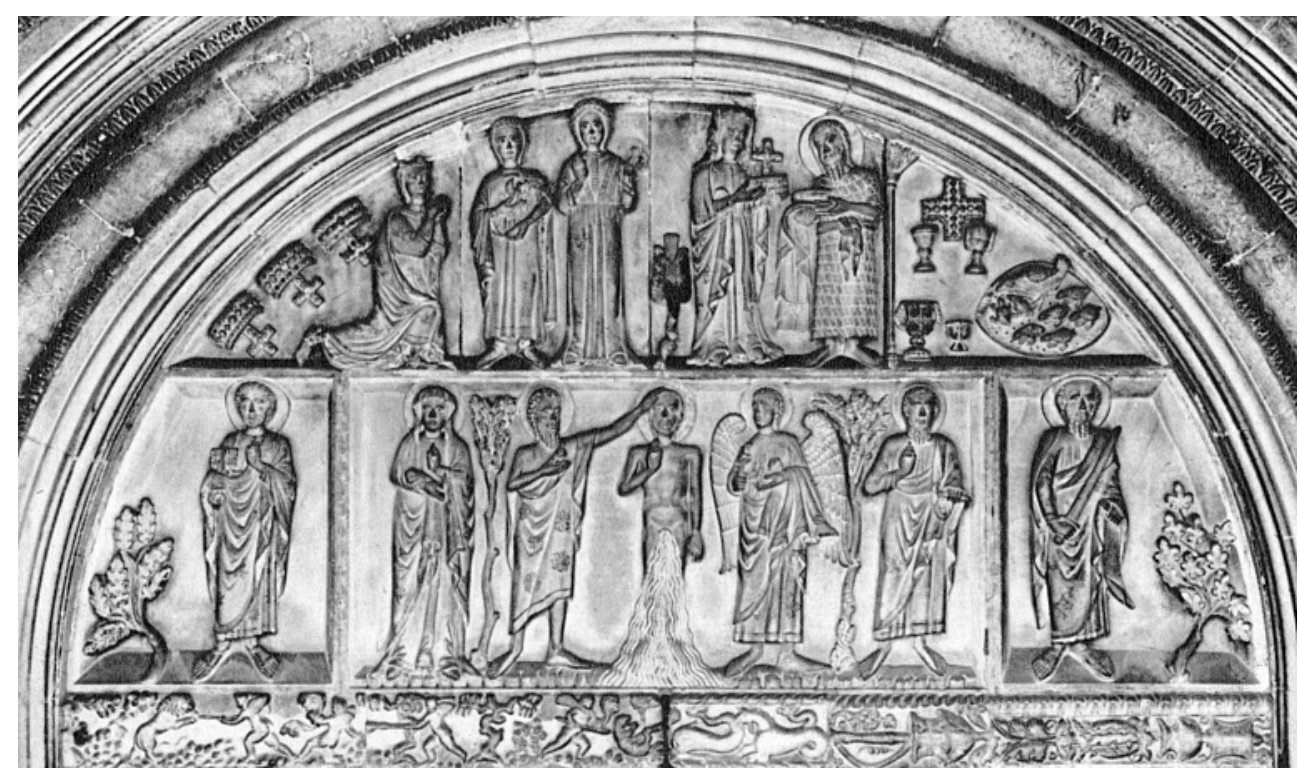

Abb. 17: Monza, Kathedrale, Tympanon des Westportals (Il tesoro del Duomo di Monza [wie Anm. 178], 12)

Steins zeugen wohl auch die Spuren mechanischer Einwirkung, die das Relief, besonders an seiner unteren linken Ecke, zeigt.

Ein vergleichbares, noch in situ erhaltenes Beispiel mittelalterlicher Plakatwerbung im öffentlichen Raum stellt das Westportaltympanon der Kathedrale von Monza dar (Abb. 17). Mit seiner Entstehung im späten 13. Jahrhundert oder - wahrscheinlicher im ersten Viertel des folgenden Jahrhunderts (nach 1319) rückt es auch zeitlich in die Nähe der venezianischen Reliquientafel. ${ }^{147}$ In seinem oberen Register sind mehrere Artefakte aus dem Domschatz abgebildet. Außen links sind drei Votivkronen zu sehen, und im Zwickel gegenüber erscheinen gut erkennbar vier Kelche, das so genannte Reliquienkreuz Berengars sowie die kuriose Henne mit ihren Küken. ${ }^{148}$ Wie beim Reliquienrelief von San Marco legte man offensichtlich auch in Monza großen Wert auf

147 In der älteren Literatur wurde die Entstehung des Tympanons vielfach im (späten) 13. Jahrhundert vermutet. Aus stilistischen und historischen Erwägungen erscheint jedoch die Datierung ins erste Viertel des Trecento, wahrscheinlich sogar präziser in die Zeit kurz nach 1319, plausibler; vgl. zur Datierungsfrage bes. Saverio Lomartire, Scultura „gotica“, in: Roberto Conti (Hrsg.), Il Duomo di Monza. La storia e l'arte. Mailand 1990, 101 u. 103; zuvor auch Sir Francis Oppenheimer, Frankish Themes and Problems. London 1952, Part Four: The tympanum of the church of St. John in Monza, 109f. u. 124-128.

148 Lomartire, Scultura (wie Anm. 147), 101-103, mit weiterer Lit.; Angelo Paredi, Storia del tesoro di Monza, in: Lamberto Vitali (Hrsg.), Il tesoro del duomo di Monza. Mailand 1966, 9-22, bes. $16 \mathrm{f}$. $\mathrm{Zu}$ den abgebildeten Objekten vgl. auch Il Duomo di Monza (wie Anm. 147), darin 
eine möglichst genaue Abbildung der gemeinten Gegenstände. Ganz eindeutig reflektiert der Bildort der Monzeser ,Portraits' die Absicht, an einer besonders stark frequentierten Stelle den Schatz der Kirche für alle jederzeit sichtbar zur Schau zu stellen. Es ist schwer vorstellbar, dass man in Venedig zwar ein Relief schuf, welches plakativ die Präsenz bedeutender, von Gott und seinen Engeln gesegneter Reliquien illustriert, dass man dieses dann aber an einer Stelle platziert haben soll, an der nur wenige es gelegentlich hätten wahrnehmen können.

\section{Wie erfolgreich waren die spätmittelalterlichen Werbemaßnahmen für die neuen Reliquien aus Konstantinopel und ihre Kulte?}

Der Wunderbericht im Brief des Dogen Ranieri an den Papst und die Reliquientafel von San Marco sind allem voran als Zeugnisse dafür aufzufassen, dass man sich in den Jahrzehnten um 1300 von offizieller Seite darum bemühte, Werbung für das Heiltum aus Konstantinopel in der Dogenkirche zu betreiben. Nicht nur konnte man damit das Ansehen der Seerepublik und ihrer Regenten steigern, sondern man verband mit der Förderung der noch vergleichsweise jungen Reliquienkulte, wie oben argumentiert wurde, sicher auch wirtschaftliche Interessen. Auch die ästhetische Aufwertung des Blut-Reliquiars und des Georgsarmes sind in diesem Licht zu sehen. Bereits die Tatsache, dass in dem Brief des Ranieri Zen nur drei Reliquien aus Konstantinopel erwähnt werden, während das einige Jahrzehnte später entstandene Relief fünf abbildet, legt den Schluss nahe, dass sich die Kulte um diese Reliquien im 13. und frühen 14. Jahrhundert erst allmählich herausbildeten. Weil zwei der abgebildeten Reliquien, das Heinrichskreuz und der Arm des heiligen Georg, überhaupt erstmals im zweiten Inventar von 1325 dokumentiert sind, ist es möglich, wenn nicht sogar wahrscheinlich, dass das Heiltum aus Konstantinopel von den Dogen sukzessive erworben wurde, auch noch nach dem Ende der Lateinerherrschaft in Byzanz.

Um die Frage nach der Entwicklung und dem Status der Kulte für die Reliquien aus Byzanz in der spätmittelalterlichen Dogenkirche zu vertiefen, werden im Folgenden weitere zeitgenössische Dokumente des fortgeschrittenen 13. und 14. Jahrhunderts auf die Wahrnehmung des Heiltums hin befragt.

Es ist bemerkenswert, dass in der zwischen 1267 und 1275 verfassten Chronik Les Estoires de Venise des Martin da Canal, die zum größten Teil während der Amtszeit des Ranieri Zen (gest. 7. Juli 1268) entstanden ist, ${ }^{149}$ an keiner Stelle explizit auf die Herkunft von Reliquien aus Konstantinopel Bezug genommen wird. Vor allem erstaunt, dass - nur wenige Jahre, nachdem Ranieri seine Mär von der wunderbaren Feuerprobe

bes. Margaret Frazer, Oreficerie altomedievali, 15-48; David Talbot Rice, Opere d'arte paleocristiane e altomedievali, 23-38.

149 Martin da Canal, Les estoires de Venise. Cronaca veneziana in lingua francese dalle origini al 1275. Ed. Alberto Limentani. (Civiltà veneziana, fonti e testi, 12, Serie terza, Bd. 3.) Florenz 1972. Zur Entstehungszeit der Chronik vgl. ebd., bes. XXVIII-XXIX, 1, I u. 2, I. 
mit großem diplomatischen Aufwand hatte verbreiten wollen - in der Chronik Martins jeglicher Hinweis auf ein solches Ereignis fehlt. Hingegen bezieht sich Martin eher beiläufig auf „die wertvollen Reliquien, sowohl das Blut unseres Herrn als auch das heilige Kreuz“, welche der Doge jedes Jahr am Karfreitag in San Marco zur Verehrung durch das gesamt Volk ausstellen ließ. ${ }^{150}$ Hier überrascht zunächst der Tag der Reliquienpräsentation, denn in Ranieris nur wenige Jahre zuvor verfasstem Brief war noch davon die Rede, es sei Usus, die Reliquien aus Konstantinopel an Christi Himmelfahrt zu präsentieren. ${ }^{151}$ Eine Verehrung derselben Herrenreliquien an mehreren hohen Feiertagen ist zwar grundsätzlich vorstellbar, allerdings erwähnt Martin im Zuge seiner relativ ausführlichen Schilderungen der Feierlichkeiten in San Marco an Himmelfahrt keinerlei Reliquien. ${ }^{152}$ Nennt der Chronist immerhin zwei der von Ranieri geförderten Reliquien, so ist gleichzeitig festzustellen, dass in seinem gesamten Werk weder der Schädel des Täufers aus der Feuerprobe begegnet noch die später auf dem Marmorrelief dargestellte Armreliquie Georgs. Bei seinen Schilderungen von Kirchenfesten, die in der Dogenkirche feierlich begangen wurden, lässt der Chronist Gedenktage der beiden Heiligen zudem gänzlich unerwähnt. ${ }^{153}$ Bezeichnend ist ferner, dass nur von einem Reliquienkreuz die Rede ist.

Nun könnte man einwenden, dass Martin eben mehr an anderen Dingen interessiert war als an Reliquien und ihren Kulten in der Markuskirche. Dem steht allerdings entgegen, dass lange Passagen der Chronik den diversen Zeremonien zu hohen Festtagen in der Kirche des Dogen gewidmet sind und der Chronist darüber begeistert und mit nicht geringem bürgerlichem Stolz berichtet. ${ }^{154}$ Im Zentrum seines Interesses stehen dabei ganz eindeutig die Markusreliquien und die Feierlichkeiten anlässlich ihrer Verehrung. Immer wieder referiert der Chronist Episoden aus der Vita des Evangelisten sowie Wunderberichte um den Heiligen selbst und seine Reliquien. ${ }^{155}$ Dabei wird auch berichtet, dass sich der Doge Raneri um die Wiedereinsetzung bzw. Aufwertung des Festes der so genannten ,apparitio“ des Evangelisten am 25. Juni verdient gemacht habe. ${ }^{156}$

150 Li vendredi fait monsignor li dus mostrer en l'iglise de monsignor saint Marc les preciouses reliques et li sanc de Nostre Signor et la sainte Cruis; et sachés que tot li peuple, dames et damoiselles, les vont veoir; Martin da Canal, Les estoires (wie Anm. 149), 2, CI, 2. Die Übersetzung wie oben als Alternative zu ,(...) die wertvollen Reliquien und das Blut unseres Herrn und das heilige Kreuz (...)“ (vgl. die italienische Übersetzung ebd.) erscheint logischer.

151 S. oben Anm. 87.

152 Martin da Canal, Les estoires (wie Anm. 149), 2, LXXXIX, 2-6.

153 Vgl. ebd., 2, LXXXVI, 3-2, CI.

154 Vgl. zu den diversen Kirchenfesten die langen Schilderungen ebd., 2, LXXXVI, 3 - 2, CI.

155 Vgl. für die einzelnen Texstellen ebd., Index, 420f.; vgl. auch Dale, Pictorial Narratives (wie Anm. 10), bes. 100f.

156 Einer im 13. Jahrhundert aufgekommenen Legende nach hatte man zum Zeitpunkt der Weihe des Contarini-Baues (1094) vergessen, wo genau in der Dogenkirche sich die Markus-Reliquien befanden. Nach tagelangem Fasten und Gebet der gesamten venezianischen Bürgerschaft öffnete sich einer der Kuppelpfeiler von selbst und gab den Blick auf die Reliquien des Evangelisten 
Das lebhafte Interesse, das Martin da Canal in seiner Chronik den Zeremonien in San Marco, dem Markuskult und der Vita des Evangelisten entgegen bringt, steht in einem auffälligen Kontrast zum weitgehenden Schweigen über die Reliquien aus Konstantinopel. Es ist höchst bezeichnend, dass Ranieri Zen explizit als Förderer des Markuskultes vorgeführt wird, gleichzeitig jedoch seine im Schreiben an den Papst evidenten Bemühungen um die Kulte der Reliquien aus Byzanz unerwähnt bleiben. Man sollte hieraus freilich nicht den Schluss ziehen, dass diese Reliquien etwa nicht angemessen verehrt worden seien, denn schließlich bezeugen die Quellen ihre öffentliche Präsentation an hohen Feiertagen. Allerdings kann die Zurückhaltung des Martin da Canal durchaus als Signal dafür aufgefasst werden, dass zu Ranieris Regierungszeit die Propaganda für das Heiltum aus Konstantinopel nicht konsequent und wirksam genug vorangetrieben wurde. Hingegen reflektiert die Chronik Martins deutlich die Dominanz des bereits seit Jahrhunderten etablierten Markuskultes. Dessen prominente Rolle in der ihm geweihten Dogenkirche und für Venedig insgesamt unterstrich man gerade im fortgeschrittenen 13. Jahrhundert nochmals visuell, und zwar mit den Mosaikzyklen zur Vita des Evangelisten und zur Translation seiner Reliquien im Gewölbe vor dem einstigen Südeingang sowie an der Westfassade. ${ }^{157}$

Das gleiche Bild wie die Chronik Martins da Canal vermittelt eine andere, größtenteils noch unedierte Venedig-Chronik, 1292 vollendet von einem Autor namens Marco. ${ }^{158}$ Hier werden überhaupt keine Reliquien aus Konstantinopel in der Lagunenstadt erwähnt, und dies, obwohl lange Passagen der byzantinischen Hauptstadt gewidmet sind. ${ }^{159}$ In dem Geschichtswerk sucht Marco zu begründen, weshalb die lateinische Eroberung 1204 als Resultat unausweichlicher göttlicher Vorsehung anzusehen sei. 160 Ein Verweis auf Ranieris Argument der durch Christus persönlich von Konstantinopel nach Venedig gelenkten ehrwürdigen Reliquien hätte sich hier gut ein-

frei; Martin da Canal, Les estoires (wie Anm. 149), 2, LX. In der Formulierung Martins erscheint Ranieri Zen als ,Erneuerer' dieses Festes, was wahrscheinlich macht, dass schon vorher dieser Festtag begangen wurde (E messere il doge Ranieri Zeno rinnovò quella onorata festa (...); ebd., 2, LX, 6). Otto Demus interpretierte die Textstelle dahingehend, dass es wahrscheinlich Ranieri gewesen sei, der das Fest überhaupt erst einrichtete; vgl. Demus, Mosaics (wie Anm. 88), Bd. 2/1, 27-32, bes. 27 u. 29; im Anschluss daran genauso Dale, Pictorial Narratives (wie Anm. 10), 85. Die Chronik Martins lässt eine solche Deutung m. E. jedoch nicht zu. Auch die Tatsache, dass sowohl die Episode als auch das daraufhin eingerichtete Kirchenfest bereits in der hauptsächlich in den 1260er und 70er Jahren entstandenen ,Legenda aurea' des Jakobus von Voragine erwähnt sind, deutet auf eine ältere Geschichte hin; Iacopo da Varazze, Legenda aurea (wie Anm. 80), Bd. 1, 404/5 (78-83); zur Entstehungszeit ebd., XIII.

157 Zu diesen Zyklen vgl. Dale, Pictorial Narratives (wie Anm. 10), 85-101 u. 102.

158 Venedig, Biblioteca Nazionale Marciana, Cod. It. XI, 24 (6802).

$159 \mathrm{Zu}$ Konstantinopel vgl. die Edition der betreffenden Textstellen und den Kommentar von Agostino Pertusi, Le profezie sulla presa di Costantinopoli (1204) nel cronista veneziano Marco (c. 1292) e le loro fonti bizantine, in: Studi veneziani, n. s. 3, 1979, 13-46.

160 Pertusi, Le profezie (wie Anm. 159), bes. 13, 15, 29 u. 44f. 
gefügt. Sehr wohl hebt der Chronist hingegen die Bedeutung des heiligen Markus und seiner Reliquien für die Lagunenstadt hervor. ${ }^{161}$ Auf der Basis der zitierten Chroniken ergibt sich folglich zumindest für das 13. Jahrhundert der Eindruck, dass die Kulte um das neue Heiltum aus Konstantinopel in der Kirche des Evangelisten Markus, wo dessen Verehrung schon seit Jahrhunderten blühte, erschwerte Startbedingungen hatten.

Mehr Würdigung als in den älteren Geschichtswerken erfahren die Reliquien aus Konstantinopel in der zwischen 1344 und 1351/52 verfassten, ausführlichen Chronik des Dogen Andrea Dandolo. ${ }^{162}$ Allerdings ist gleich einschränkend zu sagen, dass auch hier das Heiltum aus Byzanz im Vergleich zu den Markusreliquien von nur marginaler Bedeutung ist. ${ }^{163}$ Zunächst fällt auf, dass Andrea den Schatzbrand von 1230 im Gegensatz zu den älteren Chronisten erwähnt, wenngleich nur am Rande, obwohl ihm die Korrespondenz seines Amtsvorgängers zwecks päpstlicher Anerkennung des mit dem Brand assoziierten Reliquienwunders mit hoher Wahrscheinlichkeit bekannt war. ${ }^{164}$ Vor allem mutet merkwürdig an, dass im Zusammenhang mit dem Feuer allein ein unbeschädigt gebliebenes Reliquienkreuz Erwähnung findet. ${ }^{165}$ Diese Information deckt sich mit den Angaben in den beiden frühesten Schatzinventaren, die ebenfalls nur ein Kreuz nennen, „das im Feuer war" (höchst wahrscheinlich identisch mit demjenigen aus dem Besitz der byzantinischen Kaiserin Irene Dukaina). ${ }^{166}$ Weder wird die unver-

161 Vgl. Dale, Pictorial Narratives (wie Anm. 10), 100.

162 Der Doge ist Autor zweier Chroniken: Außer der ausführlichen ,Chronica', der Jahre 46-1280 (zur Datierung Andreae Danduli Chronica, wie Anm. 8, XV u. XXXVI), verfasste er vor 1342 die um ein Vielfaches kürzere ,Chronica brevis'; zu deren Textgeschichte und den erhaltenen Codices vgl. Andreae Danduli Chronica (wie Anm. 8), 333-347. Alle folgenden Zitate stammen aus der langen Chronik.

163 Auch Andrea Dandolo bezieht sich häufig auf die Geschichte des heiligen Markus und die Verehrung seiner Reliquien; vgl. für die Textstellen ebd., Indice, 528f.

164 Die älteste erhaltene Abschrift des Briefes befindet sich als Teil einer Dokumentensammlung in Manuskripten des 14. Jahrhunderts; Andreae Danduli Chronica (wie Anm. 8), Documenti, 393, Anm. 1, vgl. zu den Codices auch ebd., LV, 333 u. 343). Ester Pastorello vermutete, dass diese Sammlung ihre Entstehung dem unmittelbaren Umkreis des Andrea Dandolo verdanke; ebd., $342 \mathrm{f}$., bes. 343 .

165 Secundo anno [1230], ignis in sanctuario sancti Marci casualiter eveniens, reliquias plures, et ducalia privilegia concremavit; sed crux quedam, de Ligno Domine tabule impressa, aliquali parte tabule combusta, illesa inventa est; ebd., 292, 16-18. Die Tradition, dass allein ein Reliquienkreuz den katastrophalen Brand überstand, ist noch in der frühen Neuzeit lebendig: Eine kurze Chronik des 16. Jahrhunderts paraphrasiert die Version des Andrea Dandolo; Venedig, Biblioteca Nazionale Marciana, Cod. It. Cl. VII, 125 (7460), c. 200v. Auch Marin Sanudo erwähnt im frühen 16. Jahrhundert allein „Del legno della croce approvato nel foco“ bzw. „Del legno della Croce brusà attorno senza toccar il legno“; Marin Sanudo il giovane, De origine, situ et magistratibus urbis Venetae ovvero la città di Venetia (1493-1530). Ed. Angela Carracciolo Aricò. Mailand 1980, 160, 180.

166 S. die Zitate oben in Anm. 43 und 44. Das Inventar von 1283 scheint auch im Falle der Schädelreliquie des Täufers auf den Schatzbrand von $1230 \mathrm{zu}$ verweisen (s. das Zitat oben in Anm. 58). 
sehrte Auffindung der Kreuzreliquie von Andrea explizit als Wunder herausgestellt, noch hebt der Doge deren Herkunft aus Konstantinopel hervor. Dass die Widersprüche zu dem Wunderbericht Ranieris etwa auf eine unzureichende Vertrautheit des Chronisten mit den Reliquien und der Geschichte der Markuskirche zurückzuführen wäre, ist auszuschließen. Andrea war seit 1328, also bereits lange vor seiner Wahl zum Dogen (1343), Prokurator von San Marco. ${ }^{167}$ An früherer Stelle derselben Chronik geht der Doge auf vier (sic) Reliquien in San Marco ein, die nach der lateinischen Eroberung Konstantinopels in die Dogenkirche gelangt seien. Es steht dort im Zusammenhang der Plünderung der byzantinischen Hauptstadt zu lesen:

„Und der Doge [Enrico Dandolo] erlangte das ruhmreiche, vergoldete Kreuz, das Konstantin, nach der Auffindung durch seine Mutter, in Kriegen mit sich führte, und die Ampulle mit dem wunderbaren Blut Jesu Christi sowie den Arm des heiligen Märtyrers Georg, mit einem Stück vom Schädel des heiligen Johannes Baptist; die der Doge, indem er sie nach Venedig schickte, befahl, in seiner Kapelle zu beherbergen."168

Die Chronik stellt die älteste Quelle dar, in der die vorher bereits auf dem Marmorrelief abgebildete und im Inventar von 1325 aufgeführte Armreliquie des heiligen Georg explizit als venezianische Beute des vierten Kreuzzuges deklariert ist. Die Erwähnung der anderen drei Reliquien - eines Reliquienkreuzes, der Ampulle mit dem Heiligen Blut und der Schädelreliquie des Täufers - scheint zunächst die Vermutung nahe zu legen, dass hiermit das Heiltum des angeblichen Wunders von 1230 gemeint ist. ${ }^{169}$ Abgesehen davon, dass Andrea vier, nicht drei Reliquien auflistet, ist merkwürdig, dass er in seiner Skizze ihrer ehrwürdigen Provenienz nicht auch an die bestandene Feuerprobe erinnert. Nur das Heilige Blut ist mit dem Attribut des ,Wunderbaren' versehen, wobei nicht zu entscheiden ist, ob der Doge hierbei an den Schatzbrand dachte. Nach der Version Andrea Dandolos verdankt Venedig zudem die Reliquien allein seinem Ahnen, nicht mehr göttlicher Fügung. Im Vergleich zu Ranieris phantasievoller Propaganda der Reliquien aus Konstantinopel könnten die knappen Angaben seines Amtsnachfolgers zu ihnen kaum nüchterner sein. Zudem reflektiert Andreas Liste von

167 Vgl. Andreae Danduli Chronica (wie Anm. 8), IV; Andrea Dandolo ist der Autor mehrerer Nachträge im Inventar von 1325; vgl. Gallo, Il tesoro (wie Anm. 1), 284, 286.

168 (...) et optinuit dux [Enrico Dandolo] mi'rificam crucem auro inclusam, quam, post inventionem matris, Constantinus in bellis secum detulerat, et ampulam sanguinis miraculosi Iesu Christi, et brachium sancti Georgii martiris cum parte capitis sancti Iohanis Baptiste, quas dux mictens Veneciam, in sua çapela colocari iussit; Andreae Danduli Chronica (wie Anm. 8), 280, 7-11. Angespielt wird auch hier freilich auf die legendäre Entdeckung des ,wahren Kreuzes ‘ in Jerusalem durch Helena und den anschließenden Versand eines Teils der Reliquie nach Konstanti-nopel; vgl. hierzu ausführlich Holger A. Klein, Byzanz, der Westen und das ,wahre“ Kreuz. Wiesbaden 2004, 23-27 u. 32-34. Der von Helena veranlasste Reliquientransfer betraf der Tradition gemäß jedoch allein das Kreuz, nicht auch andere Reliquien, wie Ranieri Zen behauptete.

169 Dies setzte Pincus, Christian Relics (wie Anm. 4), passim, bes. 39 u. 42-44, als selbstverständlich voraus. 
Reliquien aus Konstantinopel, rund achtzig Jahre später, einen gewissen Wandel in deren Relevanz. So fällt in Bezug auf das Reliquienkreuz die Behauptung auf, es handele sich um dasselbe, welches einst Konstantin der Große auf Feldzüge mitgenommen habe. ${ }^{170}$ Debra Pincus ging davon aus, dass Andrea Dandolo damit das Kreuz aus dem Schatzbrand von 1230 meinte. ${ }^{171}$ Dies erscheint jedoch alles andere als zwingend, denn spätestens 1325 befanden sich, wie bereits erwähnt, zwei vollständige Reliquienkreuze aus Byzanz im Schatz von San Marco, die beide auch auf der Reliquientafel abgebildet sind. Frühneuzeitliche Quellen differenzieren zudem klar zwischen dem Reliquienkreuz aus der Feuerprobe von 1230 und demjenigen, welches Konstantin auf Feldzüge mitnahm. ${ }^{172}$ Wenn Andrea Dandolo mit dem Reliquienkreuz Konstantins ein anderes im Sinn hatte als das aus der Feuerprobe des Jahres 1230, so kann es sich nur um dasjenige Heinrichs von Flandern handeln. Andreas Hinweis, besagtes Kreuz sei „,in Gold gefasst" (auro inclusam ${ }^{173}$ ), ist gut mit dem Heinrichskreuz in Einklang zu bringen, das bereits im 13. Jahrhundert seine goldene Fassung erhalten hatte. Zudem ist es durch seine Inschrift mit kriegerischen Unternehmungen assoziiert. ${ }^{174}$ Die insgesamt fünf Reliquien, die in den beiden zitierten Textpassagen der Dandolo-Chronik genannt sind, wären folglich identisch mit denjenigen, die man Jahrzehnte zuvor bereits auf der Reliquientafel von San Marco abgebildet hatte. Man muss auf der Grundlage der Dokumente und des Reliefs also folgern, dass in San Marco spätestens im frühen 14. Jahrhundert insgesamt fünf Reliquien aus Konstantinopel besonders verehrt wurden:175 Diese waren das mit dem Schatzbrand von 1230 assoziierte Kreuz, das einst der byzantinischen Kaiserin Irene Dukaina gehört hatte, das Heinrichskreuz, die Ampulle mit dem Heiligen Blut Christi, die Schädelreliquie des Täufers sowie der Arm des heiligen Georg.

Weshalb aber greift Andrea Dandolo nicht die von seinem Amtsvorgänger 1265 verbreitete Mär vom Reliquienwunder beim Brand von 1230 auf? Könnte es sein, dass ihm die Schilderungen des Ranieri allzu wunderbar erschienen sind? Dass es sich bei dem Feuer des Jahres 1230 mit seinem vom Dogen plastisch geschilderten verheerenden Ausmaß um ein reales Ereignis gehandelt hat, ist von der modernen Forschung nie

170 Die im Mittelalter im christlichen Osten und Westen verbreitete Praxis, Reliquien in Feldzügen mitzuführen, ist allerdings erst seit dem 6. Jahrhundert bezeugt; s. oben Anm. 124.

171 Pincus, Christian Relics (wie Anm. 4), passim, bes. 39 u. 42-44.

172 Marin Sanudo il giovane, De origine (wie Anm. 165), 160 u. 180; Francesco Sansovino, Venetia città nobilissima et singolare, descritta in XIIII. libri. Venedig 1581, ND Bergamo 2002, 38.

173 Vgl. das Zitat in Anm. 168.

174 Zur Assoziation des Kreuzes mit siegreichen Feldzügen auch Pincus, Christian Relics (wie Anm. 4), 42.

175 Es kann hier nur angedeutet werden, dass sich bereits um 1325 nach dem Zeugnis des zweiten Schatzinventars mehr Reliquien aus Konstantinopel in der Markuskirche befanden als auf dem Relief abgebildet bzw. in der Dandolo-Chronik erwähnt wurden. 
explizit in Frage gestellt worden. ${ }^{176}$ Dabei hat die Tatsache, dass der Tesoro bis heute zahlreiche Artefakte aus Konstantinopel beherbergt, einiges Kopfzerbrechen bereitet. ${ }^{177}$ Auch wenn man prinzipiell an Wunder glaubt, besteht ausreichend Anlass zu fragen, inwieweit dem Bericht des Dogen Ranieri zu trauen ist. Verräterisch ist zunächst das früheste Schatzinventar, das insgesamt einundvierzig Artefakte verzeichnet, darunter allerdings nur zehn Reliquiare. ${ }^{178}$ Vier davon werden explizit als von Feuer beschädigt beschrieben, was beweist, dass es zuvor mindestens einen Brand in San Marco gegeben haben muss. ${ }^{179}$ Allerdings lässt die Tatsache, dass die Behältnisse 1283 zwar lädiert, jedoch immerhin noch vorhanden waren, erahnen, dass der Doge die Auswirkungen des Feuers stark übertrieben haben muss. Ob Andrea Dandolo nun an Wunder glaubte oder nicht, solche Ungereimtheiten werden ihm wohl kaum entgangen sein.

Sind die Reliquien aus Konstantinopel in den venezianischen Chroniken des 13. und 14. Jahrhunderts auffällig wenig präsent, so ist nachfolgend zu untersuchen, wie es im gleichen Zeitraum um ihre Wahrnehmung außerhalb der Lagunenstadt stand - immerhin hatte Ranieri Zen in seinem Brief nach Rom das Anliegen geäußert, das Reliquienwunder von 1230 solle ,über alle Teile der Erde feierlich und mit seiner [des Papstes] Erlaubnis verbreitet" werden. 180

Zwei im ausgehenden 13. Jahrhundert verfasste genuesische Chroniken sind die frühesten erhaltenen Zeugnisse dafür, dass zumindest eine von Venedigs Reliquien aus Konstantinopel außerhalb der Lagunenstadt bekannt war. Eines der Werke stammt von dem offiziellen Annalisten Genuas, Iacopo Doria, aktiv zwischen 1280 und 1293.181

176 Wenige moderne Autoren haben Zweifel bezüglich der Schwere des Brandes zumindest angedeutet; Donald M. Nicol, Byzantium and Venice. A Study in Diplomatic and Cultural Relations. Cambridge 1988, 168: „It is impossible to know what or how much was lost"; vgl. auch Sinding-Larsen, Christ (wie Anm. 96), 183, mit Anm. 5.

177 André Grabar implizierte, dass die byzantinischen Artefakte im Schatz der Dogenkirche, die in den Jahrzehnten nach 1204 aus Konstantinopel nach Venedig gelangten, sich kaum erhalten haben können, ,poiché si sa (sic!) che un gran numero di pezzi bizantini (...) andarono bruciati nel grande incendio della Basilica di S. Marco“, und vermutete deshalb eine Ankunft der heute noch erhaltenen Stücke in Venedig erst nach 1230; Il tesoro di San Marco (wie Anm. 1), 15. Hahnloser hielt es für sicher, dass man die Artefakte aus Konstantinopel eben zur Zeit des Brandes der Schatzkammer in der Sakristei aufbewahrt habe; ebd., XIII. Molinier vermutete, dass wegen des Brandes heute nur ein Teil der einst vorhandenen byzantinischen Artefakte erhalten sei; Le trésor (wie Anm. 2). Diese Theorie ist jedoch schwerlich mit dem Bericht Ranieri Zens zu vereinbaren, dass das Feuer den Schatz, bis auf die drei Reliquien, vollständig zerstört habe.

178 Gallo, Il tesoro (wie Anm. 1), 273-275; die Reliquiare sind zu Beginn aufgeführt. Es ist nicht klar, weshalb das Inventar derartig knapp ausgefallen ist, da es sehr wahrscheinlich ist, dass der größte Teil der byzantinischen Artefakte im Dogenschatz vor 1261 nach Venedig gelangt ist.

179 Ebd., Nr. 3-6.

180 S. oben Anm. 86.

181 Zum Autor Valeria Polonio, Le maggiori fonti storiche del Medioevo ligure, in: Studi genuesi 5, 1964-65, 24; Valeria Polonio, Devozioni di lungo corso: lo scalo genovese, in: Gherardo Or- 
Die zweite ist die Stadtchronik, die Genuas Erzbischof und Autor auch der berühmten ,Legenda aurea', Jakobus von Voragine, zwischen 1292 und 1298 verfasste. ${ }^{182}$ Beide Quellen implizieren, dass Genua - nicht Venedig - in den Besitz des einst von Helena an Konstantin gesandten Reliquienkreuzes gelangt sei. Man behauptete nämlich, dass die Galeere, auf der das prestigeträchtige Kreuz nach der lateinischen Eroberung von Konstantinopel gen Westen segelte, überhaupt nie in Venedig hatte ankommen können. Stolz berichtete man, dass ein Genueser Bürger, der „die Kunst der Piraterie ausübte“ (pyraticam artem exercens), die venezianische Galeere kaperte und die Reliquien in Besitz nahm. Das sogenannte „Kreuz der Helena“ (crux Elene) stiftete er daraufhin der Kathedrale Genuas mit großem Pomp. ${ }^{183}$ Die genuesische Legende ist ein sprechendes Zeugnis für die Rivalität der beiden Seerepubliken im ausgehenden 13. Jahrhundert sowie für den kreativen Umgang mit Neid. Wichtig für unsere Zusammenhänge ist aber vor allem, dass zumindest die venezianische Propaganda für das hochberühmte Kreuz aus Konstantinopel über die Lagune hinaus Erfolg hatte und immerhin bis nach Genua vorgedrungen war.

Rund hundert Jahre später war im Ausland bekannt, dass man in San Marco eine Blutreliquie verehrte: $\mathrm{Zu}$ ihr äußert sich in einem Reisebericht der Florentiner Adlige Simone Sigoli, der sich im Jahre 1384 mit einer Gruppe von insgesamt dreizehn Toskanern auf eine Pilgerreise ins Heilige Land begab. ${ }^{184}$ Im Zusammenhang mit Pilgerstätten in Syrien kommt er auch auf die Blut-Ampulle in San Marco zu sprechen und bezeugt mit seinem Bericht indirekt, dass schon im späten 14. Jahrhundert verschiede-

talli/Dino Puncuh (Hrsg.), Genova, Venezia, il Levante nei secoli XII-XIV. Atti del Convegno Internazionale di Studi; Genova - Venezia, 10-14 marzo 2000. (Atti della Società ligure di storia patria, N. S., Bd. $41=115$, Fasc. 1.) Venedig 2001, 362.

182 Zu der Chronik und dem Bischof als Chronisten vgl. Polonio, Fonti (wie Anm. 181), 28-30, bes. 30 .

183 Annali Genovesi di Caffaro e de' suoi continuatori dal MXCIX al MCCXCIII. Ed. Luigi Tommaso Belgrano. 5 Bde. Rom 1890-1929. Bd. 1: Dal 1099 al 1173. (Fonti per la storia d'Italia, Bd. 11.) Rom 1890, 141. Es handelt sich bei der Geschichte um eine Interpolation Iacopo Dorias in die ,Regni Iherosolymitani brevis historia“. Zu dieser Quelle vgl. ebd., XCVIII-IX. Zur Autorschaft der Passage ebd., XCIX. Zum so genannten „Kreuz der Helena“ in Genua vgl. Frolow, La relique (wie Anm. 48), Nr. 449; Clario Di Fabio, Il tesoro della cattedrale di Genova. Le origini (XII -XIV secolo), in: Anna Rosa Calderoni Masetti u. a. (Hrsg.), Tessuti, oreficerie, miniature in Liguria XIII-XV secolo. Atti del Convegno Internazionale di Studi; Genova - Bordighera, 22-25 maggio 1997. Bordighera 1999, 124f.; Polonio, Devozioni (wie Anm. 181), 364f. u. 379, Anm. 58. Die gleiche Legende findet sich in der Chronik des Jakobus von Voragine weiter ausgeschmückt; Iacopo da Varagine, Cronaca di Genova. Ed. Giovanni Monleone. 3 Bde. Rom 1941, Bd. 2, 366f.; Iacopo da Varagine, Cronaca della città di Genova dalle origini al 1297. Ed. Stefania Bertini Guidetti. Genua 1995, 486, ital. Übersetzung ebd., $305 f$.

184 Visit to the Holy Places of Egypt, Sinai, Palestine and Syria in 1384 by Frescobaldi, Gucci \& Sigoli. Translated from the Italian by Fr. Theophilus Bellorini O.F.M. and Fr. Eugene Hoade O.F.M. with a Preface and Notes by Fr. Bellarmino Bagatti O.F.M. Jerusalem 1984, 157-201, zum Autor ebd., $3 \mathrm{f}$. 
ne Legenden zu deren Herkunft kursierten: Laut Sigoli stammte die venezianische Blutreliquie nämlich aus Beirut, wobei seine Schilderungen durch die weit verbreitete Legende von der Kreuzigungsikone im Haus eines Christen inspiriert sind, die von Juden mit Waffen traktiert wurde und daraufhin zu bluten anfing. ${ }^{185}$ Ein Kaufmann aus Brügge habe von dem Wunder erfahren und sei in den Besitz eines Teils des Blutes aus der Ikone gelangt. Er habe Beirut verlassen, sei mit dem Schiff nach Venedig gefahren und habe dort einem Freund von dem Wunder des blutenden Bildes erzählt. Der Venezianer habe den Kaufmann daraufhin gedrängt, ihm die Hälfte dieses Blutes zu überlassen, um die wertvolle Reliquie später der Markuskirche zu stiften. ${ }^{186}$ Über dieses Heilige Blut weiß Sigoli ferner zu berichten, dass es in San Marco „Zweimal im Jahr mit großer Feierlichkeit" gezeigt werde, am Karfreitag und zu Christi Himmelfahrt. ${ }^{187}$ Damit scheinen die widersprüchlichen Informationen im Brief des Ranieri Zen und in der Chronik des Martin Da Canal, die von der Verehrung besagter Reliquie jeweils an einem dieser Tage sprechen, eine Erklärung zu finden. Sigolis Bericht ist der früheste Beleg dafür, dass die Ampulle offenbar nicht lange nach ihrer Ankunft in der Lagunenstadt mit einer neuen Herkunftslegende versehen wurde, die bis zur frühen Neuzeit in Venedig weitgehend Akzeptanz gefunden hatte. ${ }^{188}$ Reliquien aus Konstantinopel lässt Sigoli bei der Beschreibung Venedigs und seiner Lagune im Übrigen gänzlich unerwähnt, geht dafür allerdings mit vergleichsweise großer Ausführlichkeit auf die Markusreliquien ein. ${ }^{189}$ Dass dies nicht etwa ein Resultat individueller Wahrnehmung war, bezeugen mehrere weitere Pilgerberichte aus dem 14. Jahrhundert, von denen keiner die Reliquien aus Konstantinopel in der Dogenkirche kommentiert, dafür aber alle sehr wohl die Markusreliquien. ${ }^{190}$ Die Berichte von Venedig-Besuchern bestätigen folglich, was bereits die Lektüre der venezianischen Chroniken nahe legte: Es war der im Spätmittelalter längst etablierte Markuskult, welcher auch nach der Ankunft der

185 Ebd., 194. Zu dieser Legende vgl. Maria Vassilaki, Bleeding Icons, in: Anthony Eastmond/Liz James (Hrsg.), Icon and Word. The Power of Images in Byzantium. Studies Presented to Robin Cormack. Aldershot 2003, 124 u. 125; vgl. auch Vincent, Holy Blood (wie Anm. 76), 46-48.

186 Visit to the Holy Places (wie Anm. 184), 194.

187 Ebd.

188 Hierfür spricht z. B. die Verteidigung des Blutes in der Ampulle als ,echtes' Blut aus der Seitenwunde Christi durch Giovanni Tiepolo [Thiepolo], Trattato delle santissime reliquie. Venedig 1617, 31-33, bes. 33; vgl. auch Bianca Tamassia Mazzarotto, Le feste veneziane. I giochi popolari, le cerimonie religiose e di governo. Florenz 1961, 160f.

189 Visit to the Holy Places (wie Anm. 184), 159f., bes. 160.

190 Es handelt sich um die Berichte des Lionardo Frescobaldi aus der Reisegruppe Sigolis von 1384 (ebd., 32f., zum Autor ebd., 2f.), des englischen Mönches Simon Fitzsimons von 1322 (Eugene Hoade, Western Pilgrims. Jerusalem 1952, ND Jerusalem 1970, iv-vi u. 7), eines anonymen englischen Pilgerreisenden von 1344/45 (ebd. vii u. 48f.), sowie des Fra Niccolò aus Poggibonsi (Fra Niccolò of Poggibonsi. A Voyage beyond the Seas; 1346-1350. Translated by Fr. Theophilus Bellorini O.F.M. and Fr. Eugene Hoade O.F.M. on the Occasion of the Sixth Centenary. Jerusalem 1945, VIII u. 2). 
Reliquien aus Konstantinopel weitgehend die Wahrnehmung der Dogenkirche bestimmte.

Andernorts installierte man Kulte um im 13. Jahrhundert aus Konstantinopel erworbene Reliquien mit mehr Entschlossenheit und entsprechend größerer Wirkung, was hier lediglich angedeutet werden kann: Die eingangs bereits erwähnten hochrangigen Reliquien aus dem ehemaligen Besitz der byzantinischen Kaiser, die um 1240 an König Ludwig IX. von Frankreich verkauft wurden, erfreuten sich schon bald nach ihrer Ankunft in Paris einer lebhaften Verehrung. Diese wurde nicht nur durch Ludwig selbst, sondern auch seitens der Päpste mit den oben erwähnten großzügigen Ablässen gezielt gefördert. Die beachtliche Außenwirkung, die diese Reliquien frühzeitig hatten, ist beispielsweise an den bis 1259 in der Benediktinerabtei von St. Albans verfassten Chroniken des Mönches Matthew Paris (Matthaeus Parisiensis) ablesbar, der ,Chronica majora' und der ,Historia anglorum '.191 Der englische Historiker bezieht sich nicht nur an verschiedenen Stellen seiner Werke auf den Transfer der Reliquien nach Paris und ihre dortige Verehrung, die Chroniken enthalten zudem mehrere vom Autor angefertigte Miniaturen, die nicht nur die Reliquien selbst, sondern diese auch in verschiedenartiger zeitgenössischer Verwendung abbilden. ${ }^{192}$

Zur raschen und äußerst erfolgreichen Etablierung der Pariser Kulte um die neu erworbenen Reliquien aus Byzanz wird auch beigetragen haben, dass Ludwig in seinem Palastareal eigens zu ihrer Aufnahme die 1248 geweihte Ste-Chapelle errichten ließ.193 Im Gegensatz zu den seitens der venezianischen Dogen in der Markuskirche deponierten Reliquien aus Konstantinopel erhielt das Heiltum gleicher Provenienz in Paris folglich einen neu geschaffenen, eigenen Kultort. Ähnliches ist andernorts auch für Reliquien bezeugt, die bereits unmittelbar nach der lateinischen Eroberung Konstantinopels in den Westen gelangt waren, beispielsweise für den 1206 nach Amiens transferierten Täuferschädel. Für ihn wurde sofort eine neue Kapelle gestiftet, die bald hochrangige Besucher anzog. ${ }^{194}$

Was die Markuskirche betrifft, so trieb man im 13. Jahrhundert deren Vollendung mit großem Aufwand voran, und auch noch im 14. Jahrhundert wurde der Bau wesentlich gefördert. Vor allem sind hier Andrea Dandolos bedeutende Stiftungen der Isidor-

191 Zu Texteditionen und Übersetzungen vgl. The Illustrated Chronicles of Matthew Paris. Observations of Thirteenth-century Life. Ed. Richard Vaughan. Cambridge 1993, xiii u. die Bibliographie.

192 Zu den Illustrationen bes. Suzanne Lewis, The Art of Matthew Paris in the Chronica Majora. Berkeley (CA) u. a. 1987, 304-310. Vgl. auch Illustrated Chronicles (wie Anm. 191), 50f. u. 176, allerdings mit irreführender Zuordnung von Bild und Text, denn die abgebildeten Miniaturen stammen überwiegend aus anderen Textpartien der originalen Manuskripte.

193 Jannic Durand, La translation des reliques impériales de Constantinople à Paris, in: Le trésor (wie Anm. 74), 37-41, bes. 39.

194 Brook, La translation (wie Anm. 78), bes. 93 u. 101. 
Kapelle und ihrer Mosaiken sowie der Mosaizierung des Baptisteriums zu nennen. ${ }^{195}$ Demgegenüber ist bemerkenswert, dass es die Dogen im spätmittelalterlichen Venedig zu keiner Zeit als opportun erachteten, speziell für die Reliquien aus Konstantinopel eine Kapelle zu errichten. Nicht zuletzt das Fehlen eines solchen eigenen Kultortes ist symptomatisch dafür, dass man das Heiltum aus Byzanz nicht mit ausreichend Initiative und Konsequenz förderte.

195 Zu Andrea Dandolo als Auftraggeber jüngst Hans Belting, Dandolo's Dreams. Venetian State Art and Byzantium, in: Sarah Brooks (Hrsg.), Byzantium Faith and Power (1261-1557). Perspectives on Late Byzantine Art and Culture. New Haven u. a. 2006, 138-153. Zuvor auch Debra Pincus, Andrea Dandolo (1343-1354) and Visible History: the San Marco Projects, in: Charles M. Rosenberg (Hrsg.), Art and Politics in Late Medieval and Early Renaissance Italy: 1250-1500. Notre Dame/London 1990, 191-206. 